\title{
DIRETRIZES PARA REENGENHARIA DE SOFTWARE COM CARACTERÍSTICAS DE SOFTWARE LEGADO
}

\author{
Marcos Antonio Quinaia \\ Orientadora: Profa. Dra. Rosely Sanches
}

Dissertação apresentada ao Instituto de Ciências Matemáticas e de Computação da Universidade de São Paulo - ICMC-USP, como parte dos requisitos para a obtenção do titulo de Mestre em Ciências - Área de Ciências de Computação e Matemática Computacional. 
Este trabalho é dedicado à Sueli, minha esposa e ao Bruno César, meu filho. Meus amados. 


\section{Agradecimentos}

A Deus por ser tudo para mim.

À Profa . Dra. Rosely Sanches por ser mais que orientadora, por sua compreensäo, dedicação, paciéncia, carinho, apoio e amizade. Pelos valiosos ensinamentos, sugestōes, dicas, conselhos e profissionalismo dispensados.

A todos os professores do ICMC-USP que contribuiram com seus ensinamentos, tanto nas disciplinas, como nos esclarecimentos de dúvidas e em sugestōes.

A minha querida esposa Sueli, por compartilhar tudo comigo com muito amor, carinho e dedicação.

À Renata Ceneviva, pelo auxilio prestado no desenvolvimento do trabalho.

A todos os funcionários do ICMC-USP por serem sempre prestativos e dedicados.

A todos os colegas, pela amizade conquistada e ajuda em vários momentos.

A meus pais, minha irmá, sogros e cunhados, pelo apoio que deram quando da minha partida para a pós-graduação. 


\section{indice}

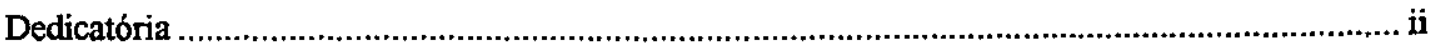

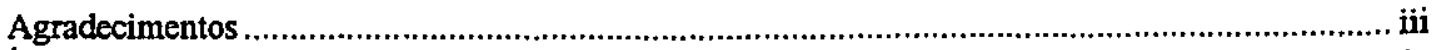

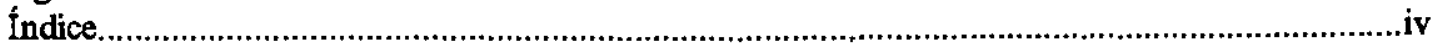

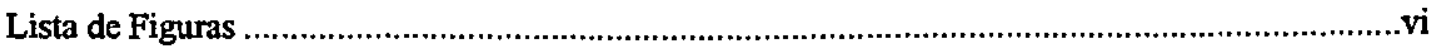

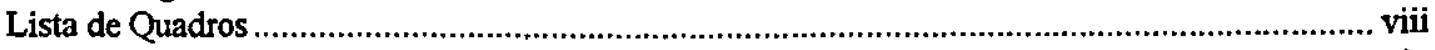

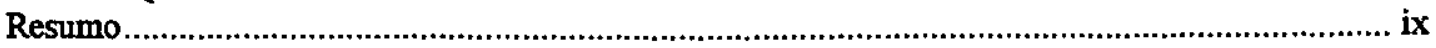

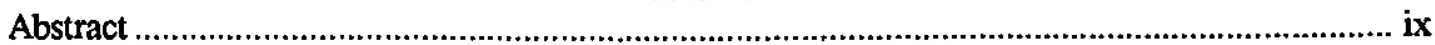

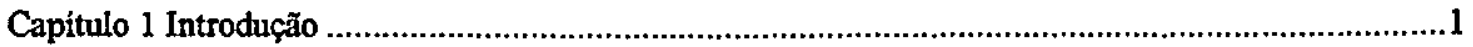

1.1 - Motivação para Reengenharia .......................................................................................

1.2 - Motivação Para Transformar Sistemas Orientados a Função Para S. Orientados a Objeto........4

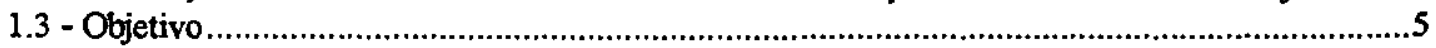

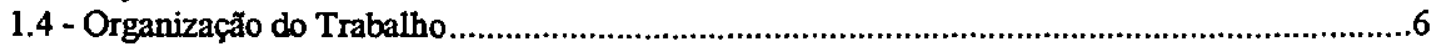

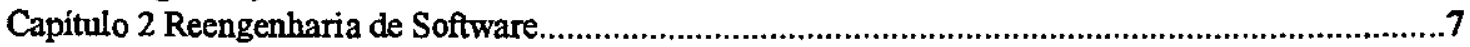

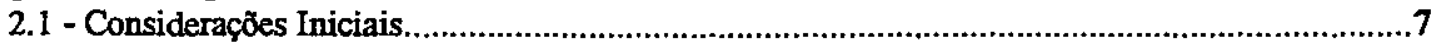

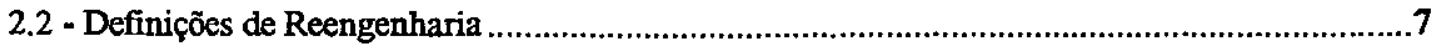

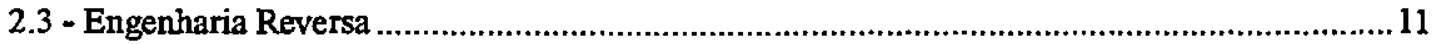

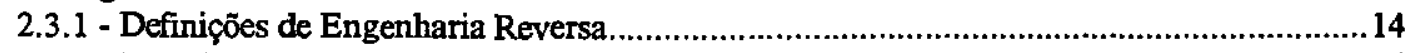

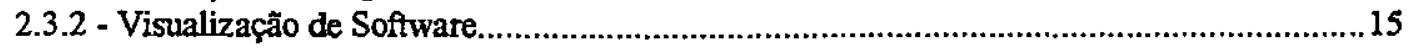

2.3.3 - Categorias de Engenharia Reversa............................................................................ 17

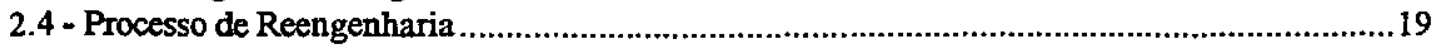

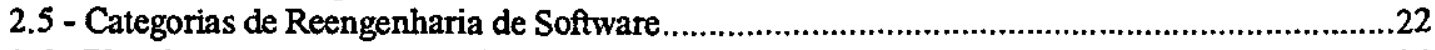

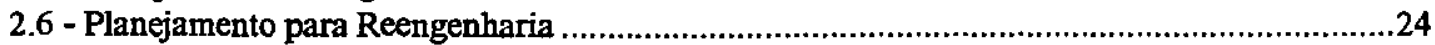

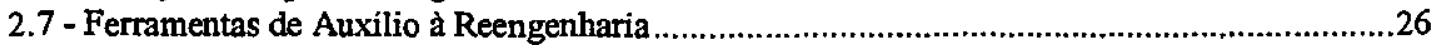

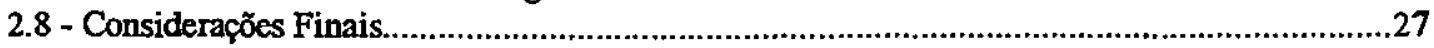

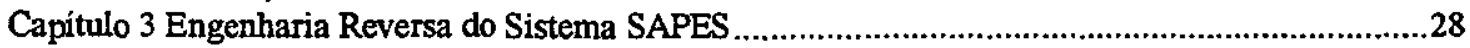

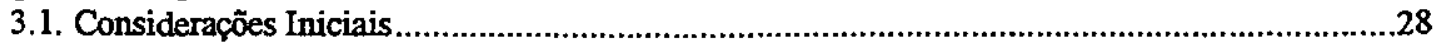

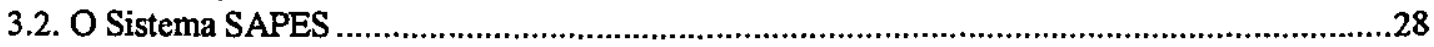

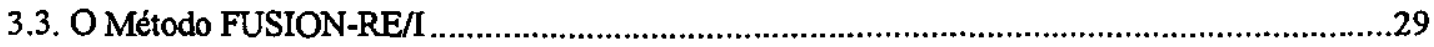

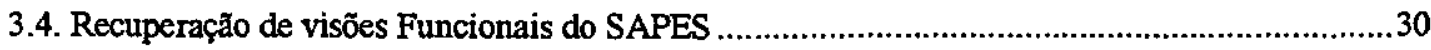

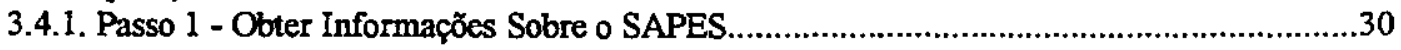

3.4.2. Passo 2 - Recuperação dos Modelos de Análise ............................................................... 31

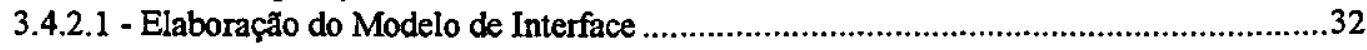

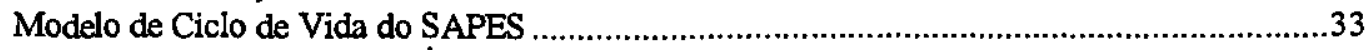

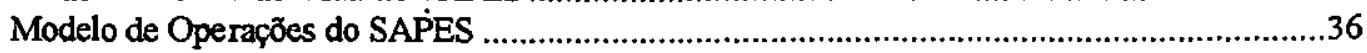

3.4.2.2 - Elaboração do Modelo de Objetos .................................................................40

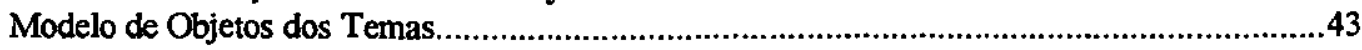

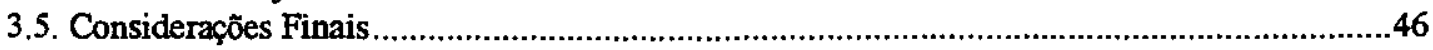

Capitulo 4 Engenharia Progressiva do Sistema SAPES ..........................................................47

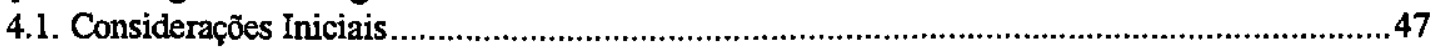

4.2. Análise Crítica aos Modelos de Objetos Produzidos pela Engenharia Reversa.........................47

4.3. Reconstrução do Modelo de Objetos do SAPES ..................................................................49

4.4. Reconstrução do SAPES Orientado a Objeto.......................................................................49

4.4.1. O Método Fusion e a Ferramenta FusionCASE ......................................................50

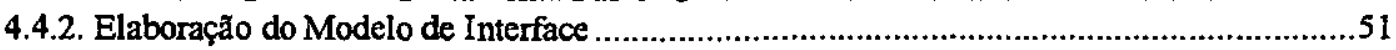

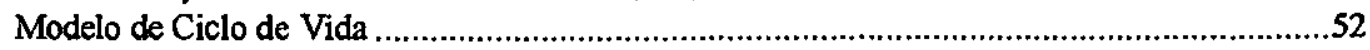

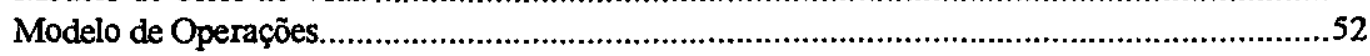

4.4.3. Elaboração dos Modelos de Projeto do Sistema SAPES ..................................................53

Grafos de Interação de Objetos ...............................................................................54

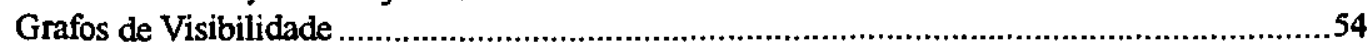

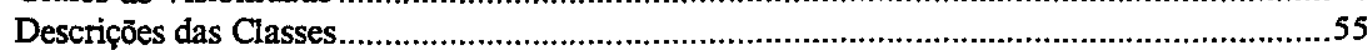

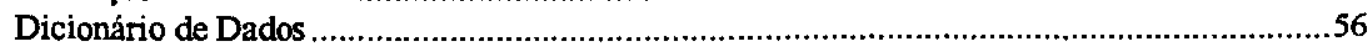

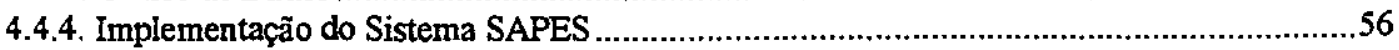


Exemplo de Classes do SAPES Implementadas em Delphi: .............................................57

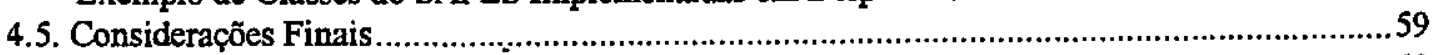

Capitulo 5 Diretrizes Para a Reengenharia de Software .............................................................60

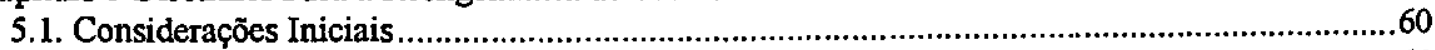

5.2 Diretrizes Para o Processo de Engenharia Reversa...............................................................61

5.2.1. Diretrizes Para o Passo 1 do FUSION-RE/I - Obter Informações Sobre o Sistema ...........61

5.2.2. Diretrizes Para o Passo 2 do FUSION-RE/I - Recuperar Modelos de Análise do Sistema 61

Diretrizes Para Elaboração do Modelo de Ciclo de Vida do Sistema......................................62

Diretrizes Para Elaboração do Modelo de Operações do Sistema ..............................................62

Diretrizes Para Elaboração do Modelo de Objetos do Sistema ..............................................64

5.3 Diretrizes Para o Processo de Engenharia Progressiva........................................................66

5.3.1. Diretrizes para a Análise Crítica e Reconstrução dos Modelos de Objetos Produzidos pela

Engenharia Reversa....................................................................................................67

5.3.2. Diretrizes para a Reconstrução do Modelo de Interface .................................................67

5.3.3. Diretrizes para a Elaboração dos Modelos de Projeto ....................................................69

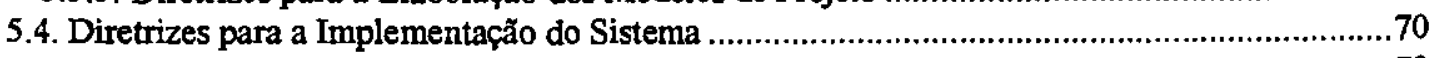

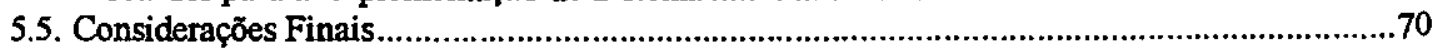

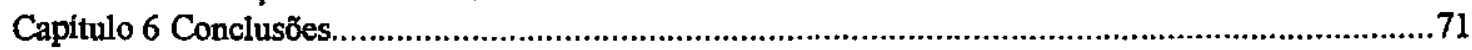

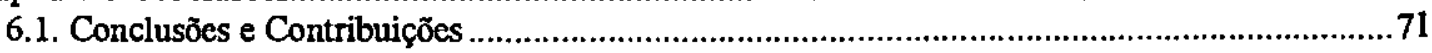

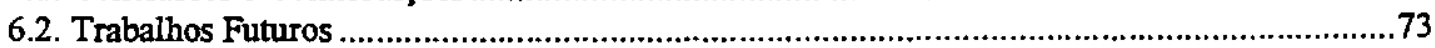

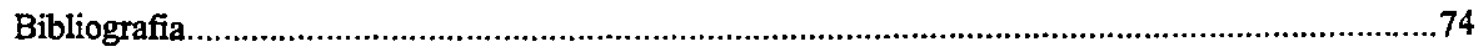

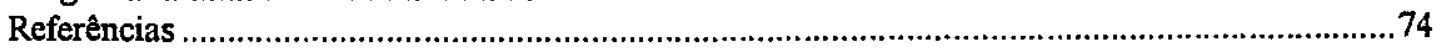

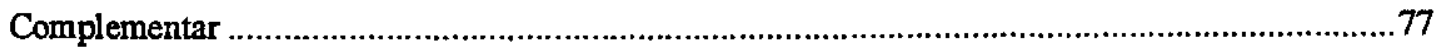

Apêndice A Modelo de Ciclo de Vida do SAPES Procedimental ....................................................80

Apêndice B Modelo de Operações do SAPES Procedimental ...........................................................86

Apêndice C Modelos do SAPES Produzidos Com Apoio da Ferramenta FusionCASE......................92

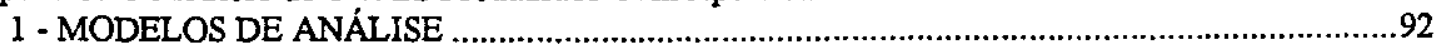

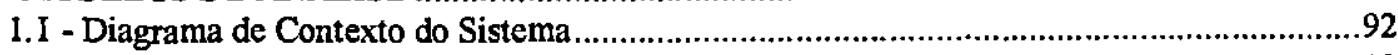

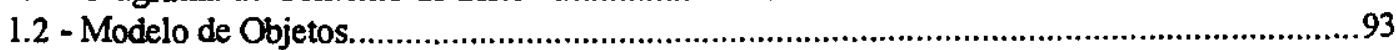

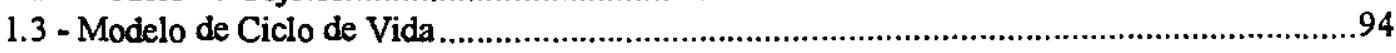

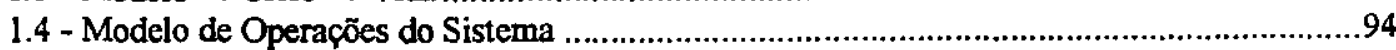

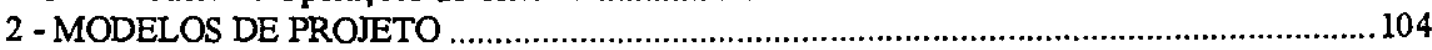

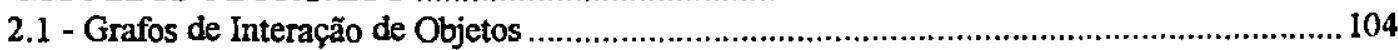

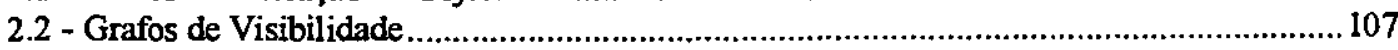

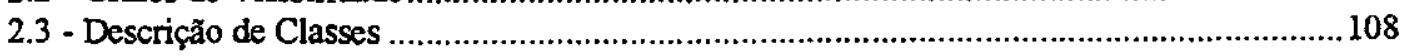




\section{Lista de Figuras}

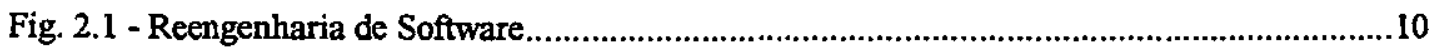

Fig. 2.2 - Relacionamentos no Ciclo de Desenvolvimento de Software.........................................10

Fig. 2.3 - Ciclo de Vida Genérico......................................................................................12

Fig. 2.4 - Nível e Grau de Abstração no Ciclo de Vida de Software ..........................................13

Fig. 2.5 - Engenharias Progressiva e Reversa no Ciclo de Vida de Software ................................13

Fig. 2.6 -Visualizações de Software no Ciclo de Desenvolvimento...............................................16

Fig. 2.7 - Visōes das Categorias de Engenharia Reversa ........................................................19

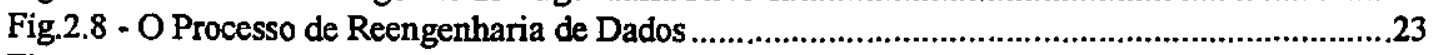

Fig. 2.9 - Matriz de Decisão Sobre o Destino de Software Legado ............................................25

Fig. 2.10 - Abordagens de Reengenharia .....................................................................25

Fig. 3.1 - Método de Engenharia Reversa FUSION-RE/ ......................................................30

Fig. 3.2 - Tela Correspondente ao Menu Principal .................................................................32

Fig. 3.3 (a) - Tela Correspondente ao Menu Principal ..............................................................33

Fig. 3.3 (b) - Tela Correspondente à Opção 1 do Menu Principal ...................................................33

Fig. 3.3 (c) - Tela Correspondente à Operação "Insere Novo Registro" da Fig. 3.3 (b) ..................33

Fig. 3.4 - Interface do Sistema SAPES e Expressão Principal do Modelo Ciclo de Vida Derivada 34

Fig. 3.5 - Expressão Principal e $2^{\circ}$ Nivel do Mod. Ciclo de Vida para a Opção Manut. B. Dados...34

Fig. 3.6 - Interface do SAPES e Modelo de Ciclo de Vida com Operaçöes e Eventos ......................35

Fig. 3.7 - Arquivo BIBGERAL.DBF Aberto Com a Ferramenta Browser ......................................38

Fig. 3.8 - Interface da Operaçåo INSERE e o Respectivo Modelo de Operaçäes...............................39

Fig. 3.9 - Modelo de Objetos Para o Tema Base de Dados ...........................................................44

Fig. 3.10 - Modelo de Objetos Para o Tema Bibliografia............................................................45

Fig. 3.11 - Modelo de Objetos Para o Tema Referência Bibliográfica............................................45

Fig. 3.12 - Modelo de Objetos Para o Tema Ficha Técnica ..........................................................46

Fig. 4.1 - Modelo de Objetos do Sistema SAPES Novo..............................................................49

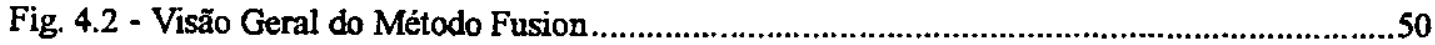

Fig. 4.3 - Menu de Entrada da Ferramenta FusionCASE .........................................................51

Fig. 4.4 - Menu Principal da FusionCASE ................................................................................

Fig. 4.5 - Edição do Modelo de Ciclo de Vida ..................................................................52

Fig. 4.6 - Edição do Modelo da Operação Consultar Título.........................................................53

Fig. 4.7 - Edição do Grafo de Interação de Objetos para a Operação Consultar Título.....................54

Fig. 4.8 - Edição do Grafo de Visibilidade Para a Classe Autor ......................................................55

Fig. 4.9 - Edição da Descrição da Classe Título .......................................................................55

Fig. 4.10 - Edição do Dicionário para Dados Para Classes do SAPES...........................................56

Fig. 4.11 - Ediçāo do Dicionário de Dados para Operações do SAPES..........................................56

Fig. 4.12 - Interface Principal, com Menu "pulldown" Para Arquivos .........................................58

Fig. 4.13 - Interface Principal, com Menu "pulldown" Para Arquivos e Submenu Imprimir ..........58

Fig. 4.14 - Interface Para Manutenç̃o de Autores ...................................................................59

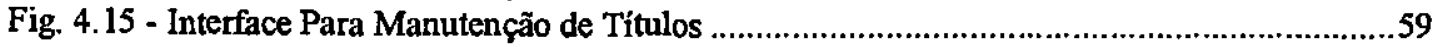

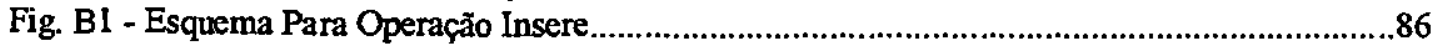

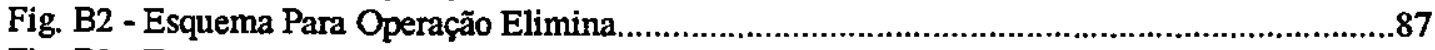

Fig. B3 - Esquema Para Operação Altera .......................................................................8 87

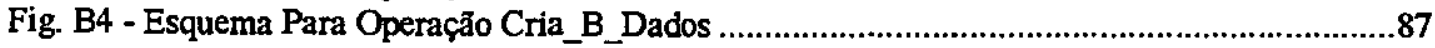

Fig. B5 - Esquema Para Operação Consulta ....................................................................8

Fig. B6 - Esquema Para Operação Formação_Biblio........................................................ 88

Fig. B7 - Esquema Para Operação Zerar-Arquivos ...............................................................88

Fig. B8 - Esquema Para Operação Geração-Ref_Bib...............................................................88

Fig. B9 - Esquema Para Operação Imp_B_Dados.............................................................89

Fig. B10 - Esquema Para Operação Imp__Biblio.................................................................89

Fig. B1 1 - Esquema Para Operação Imp_Ref_Inex............................................................89

Fig. B12 - Esquema Para Operação Imp_Ref_Bib ..............................................................90

Fig. B13 - Esquema Para Operação Criar_Ficha .................................................................90

Fig. B14 - Esquema Para Operação Imprimir_Ficha ........................................................90

Fig. B15 - Esquema Para Operação Alt_Ref_Bib................................................................ 91 
Fig. B16 - Esquema Para Operação Alt_Biblio .....................................................................91

Fig. B17 - Esquema Para Operação Ins_Ref_Bib...........................................................91 


\section{Lista de Quadros}

Quadro 2.1 - Escopo das informações utilizadas por cada ferramenta de reengenharia, e as respectivas

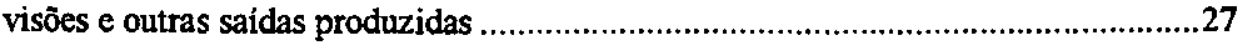

Quadro 3.1 - Informações Existentes Sobre o Sistema SAPES ........................................................ 31

Quadro 3.2 - Operaçðes e aspectos do domínio do problema do SAPES.........................................41

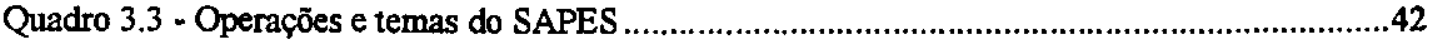

Quadro 5.1 - Operações e Aspectos do Domínio do Sistema ..........................................................65

Quadro 5.2 - Operações e Temas Identificados e Confirmados.........................................................65 


\title{
Resumo
}

Este trabalho apresenta um conjunto de diretrizes que apóiam o processo de reengenharia de um sistema procedimental (escrito na linguagem Clipper) para um sistema orientado a objeto (escrito na linguagem Delphi). As diretrizes foram baseadas na experiência adquirida com a realização da reengenharia no sistema SAPES (um sistema que apóia o uso de um banco de dados bibliográfico pessoal na escrita de documentos). As diretrizes envolvem o método FUSION-RE/l, no passo de engenharia reversa, e a ferramenta FusionCASE, no passo de reconstrução.

\begin{abstract}
This work presents a set of guidelines that support the reengineering process of a procedural system (implemented in the Clipper language) into an object-oriented system (implemented in the Delphi language). The guidelines are based on the experience acquired with the reengineering of the SAPES system (a system to support the use of a personal bibliographic database in task of writing documents). The guidelines involve the FUSION-RE/l method, in the reverse engineering step, and the FusionCASE tool, in the reconstruction step.
\end{abstract}




\section{Capítulo 1}

INTRODUÇÃO

\section{1 - Motivação para Reengenharia}

Todos os sistemas têm um tempo de vida limitado e cada alteraçăo efetuada no mesmo pode degenerar a sua estrutura, fazendo com que as manutençōes se tomem cada vez mais difíceis e dispendiosas. Isso ocorre principalmente em software legado [Jacobson \& Lindström, 1991].

Software legado pode ser informalmente definido como aquele que executa tarefas úteis para a organização, mas que foi desenvolvido utilizando-se técnicas atualmente consideradas obsoletas [Ward \& Bennett, 1995]. A quantidade de código em sistemas legados é imensa. Em 1990, estimava-se [Ulrich, 1993] que existia 120 bilhőes de linhas de código fonte de sistemas desse tipo. A maioria deles escrito em COBOL ou FORTRAN, linguagens com facilidades limitadas de estruturaçăo de programas e estruturas de dados. A migraçăo e / ou alteraçăo desse tipo de software gera desafios técnicos (por exemplo: verificar efeitos colaterais de uma alteração) e năotécnicos (por exemplo: estimar o custo de alteração) a todos os envolvidos com 
manutenção de software.

Existe um grande dilema na decisão sobre o futuro de software legado. Ao mesmo tempo em que ele traz incorporado o acúmulo de anos de experiência e refinamento, traz também todos os vícios e defeitos vigentes na época de seu desenvolvimento, mesmo que naquela época, o que hoje é chamado de vício e defeito fosse a melhor indicação para o desenvolvimento de software [Bennett, 1995]. Por exemplo, o tamanho do programa, que devido a limitação imposta pelo custo do hardware, tinha que ser reduzido. Atualmente, com o barateamento dos componentes de hardware, o fator tamanho de programa já não é crucial. Houve ainda a época em que se prezava a eficiência, em detrimento da clareza e estruturaçäo do programa. Adicione-se a isso as sucessivas manutençöes e conseqüentes degeneraçōes sofridas pelo software. Sabe-se hoje que todos esses fatores estão diretamente relacionados com a dificuldade de entendimento de qualquer software legado.

Muitos programas legados são críticos para os negócios das organizaçöes que os possuem. Eles têm embutidos informaçöes dos negócios e procedimentos, que podem não estar documentados. O risco de remover e reescrever tais programas é grande, pois muita informação teria que ser redescoberta por tentativa e erro. Consequentemente, as organizações, de um modo geral, näo "aposentam" seus sistemas legados, preferindo mantê-los em operação, com adaptações às novas necessidades. As dificuldades devem ser enfrentadas, pois qualquer software que não evoluir continuamente (portanto passar por manutençōes) tornar-se-á menos útil no mundo real [Lehman, 1980].

Segundo Bennett [1991], os maiores problemas em manter software legado são:

- Desestruturação e dificuldade de entendimento do código, muitas vezes porque o software foi desenvolvido antes da introdução dos métodos de programação estruturada.

- Programadores que não participaram do desenvolvimento de um produto de software seritem dificuldade em entender e mapear a funcionalidade para o código fonte.

- Documentação desatualizada, não auxiliando em nada a equipe de manutenção.

- Dificuldade de predizer as conseqüências de efeitos colaterais.

- Dificuldade de administrar múltiplas alteraçöes concorrentes.

A complexidade e tamanho dos programas legados têm influência direta no custo 
de manutenção dos mesmos [Ramamoorthy \& Tsai, 1996]. Pesquisas revelam que mais de $50 \%$ do custo de um produto de software está relacionado com as atividades de manutenção, havendo casos deste percentual chegar até a $85 \%$ [Layzell et al., 1995].

Em alguns negócios, estima-se que $80 \%$ de todos os gastos com software é consumido pelas manutenções e evoluções dos sistemas [Yourdon, 1990]. O número de sistemas que precisam ser modificados está aumentando gradualmente. Existe uma grande fila de espera para pedidos de manutenção. Isto significa que, algumas vezes, é impossivel para as organizaçöes investir em novos sistemas para melhorar a eficiência organizacional.

Uma pesquisa realizada em 100 grandes empresas norte americanas mostrou que, anualmente, estas empresas mantêm 35 milhões de linhas de código e, somente em atividades de manutenção, adicionam 3,5 milhões de linhas novas. Com isso deduziu-se que a quantidade de linhas de código de software dobra a cada 7 anos somente nessas 100 companhias. Estima-se ainda que o mercado de manutenção de software movimenta anualmente 30 bilhöes de dólares [Mackenzie \& Henshaw, 1994 apud Melymuka, 1991] e que somente no Reino Unido são gastos anualmente 1 bilhão de Libras em manutenção [Bennett, 1991].

O problema de manutençăo de sistemas legados é complexo porque, geralmente, esses sistemas não são simples programas, desenvolvidos e mantidos. Muitos deles são compostos de diferentes programas que, de alguma forma, compartilham dados. Também ocorre que estes programas foram desenvolvidos por diferentes pessoas ao longo dos anos, os quais não estão mais na organização. Muitas vezes eles usam um sistema de administração de bases de dados que pode estar obsoleto, ou dependem de arquivos armazenados separadamente. No caso de arquivos separados, cada um tem seu próprio formato e freqüentemente as mesmas informaçöes são duplicadas e representadas em diferentes formas e em diferentes arquivos. Esta duplicação usualmente acontece porque as informaçōes são fortemente integradas com as estruturas de dados dos programas.

Com o objetivo de minimizar os problemas gerados por manutençōes dificeis e algumas vezes degenerativas da estrutura do sistema, muitas organizações estăo optando por refazer seus sistemas. A idéia básica dessa reconstrução ou reengenharia é que as informaçōes de projeto e especificação sejam extraídas do código fonte, reformuladas e reconstruídas, resultando em um software mais fácil de ser mantido [Bennett, 1991]. 
Reengenharia de software consiste na reimplementação de um sistema em uma forma mais fácil de ser mantido. Com isso, o sistema pode ser redocumentado ou reestruturado, os programas podem ser traduzidos para.uma linguagem de programação mais moderna e implementados em uma plataforma distribuida, bem como seus dados podem ser migrados para uma base de dados diferente. A reengenharia de software objetiva fazer sistemas flexiveis, fáceis de modificar, frente as constantes mudanças das necessidades dos usuários.

- campo da reengenharia está crescendo rapidamente em resposta à necessidade crítica que existe na indústria de software por tecnologia que suporte a manutenção de sistemas legados e o desenvolvimento evolutivo de novos sistemas. Existe uma firme e crescente demanda para migrar programas legados de mainframes monoprocessados, para estações de computadores, multiprocessadas, distribuídas e ligadas em rede, visando acompanhar os avanços das técnicas de programação tais como: interfaces gráficas para o usuário, comunicação interprogramas, desenvolvimento orientado a objeto, reusabilidade, etc. [Rugaber, 1996; Sneed, 1995]. Também o desenvolvimento de novos projetos de software deverão se deparar, cada vez mais, com processos de reengenharia, visto que desenvolvimentos de software, que não envolvam códigos antigos, são raros na prática atual [Coleman et al., 1994].

\section{2 - Motivação Para Transformar Sistemas Orientados a Função Para Sistemas Orientados a Objeto}

Atualmente a nova fase de transição que a comunidade de informática está enfrentando para migrar software das plataformas centralizadas (mainframes) para ambientes de processamento distribuído em arquitetura cliente/servidor, mostra a importância da reengenharia e implica, muitas vezes, mover de uma arquitetura orientada a ação (paradigma procedimental) para uma arquitetura orientada a objeto (paradigma de orientação a objeto). [Sneed, 1992; Mittra, 1995].

Para Newcomb [1995], a programação orientada a objeto tem muitas vantagens sobre programação procedimental: possibilita construir sistemas altamente flexiveis, adaptáveis e extensiveis; possui uma coleção rica de mecanismos composicionais para formação de classes, instanciação de objetos, propriedades de herança, polimorfismo e ocultamento de informaçōes, que estão presentes em linguagens de programação orientadas a objeto, as quais provêm apoio para criar sistemas que exibem um alto grau 
de reuso e facilidade de manutenção.

Gall e Klosch [1995], citam vánios motivos para migraçăo do paradigma procedimental para o paradigma de orientação a objeto:

- Em programas procedimentais é muito dificil prever efeitos colaterais, pois freqüentemente os relacionamentos não são visiveis.

- Manutenções sucessivas requerem um conhecimento detalhado dos componentes do sistema, como foram criados e modificados e seus interrelacionamentos;

- A reusabilidade de software também é seriamente afetada pela estrutura própria dos programas procedimentais;

- A orientação a objeto oferece algumas caracteristicas úteis, tais como meios de abstração bem definidos, conceito de encapsulamento e comportamentos que efetivamente apóiam o processo de manutenção de software;

- A identificação de objetos nos programas procedimentais, exibindo explicitamente suas dependéncias, ajuda a entender o projeto do sistema, evita a degradação do projeto original durante as manutençőes e facilita o processo de reuso.

\section{3 - Objetivo}

A reengenharia ou reconstrução de um sistema é indicada quando o software possui alta utilidade, porém é de difícil manutenção. A reengenharia envolve primeiramente um processo de engenhana reversa para a recuperaçāo de informaçōes importantes sobre o sistema e, posteriormente, a reconstrução do mesmo (engenharia progressiva), utilizando-se métodos que proporcionam maior qualidade ao sistema. Atualmente, os métodos orientados a objeto mostram ser a melhor perspectiva, tanto para o desenvolvimento quanto para a manutenção de software.

O objetivo deste trabalho é propor um conjunto de diretrizes para o processo de reengenharia que transforme um sistema legado para um sistema orientado a objeto. Aliado a essa tendência, no processo de reconstrução, utiliza-se também a programação para ambiente Windows, o que permite que os sistemas possuam interface de melhor usabilidade e, portanto maior facilidade de alteração.

O conjunto de diretrizes para reengenharia, foi desenvolvido a partir da experiência de reconstrução (reengenharia) do sistema SAPES - Sistema de Apoio a 
Pesquisa. Apesar de não ser muito antigo (foi desenvolvido a cerca de 10 anos), esse sistema possui diversas caracteristicas de sistemas legados: foi escrito em Clipper, possui cerca de 5000 linhas de código e uma documentação que não condiz com os programas que estão implementados. Por outro lado é um software que traz embutidos valores que não podem ser desprezados.

$\mathrm{Na}$ etapa de engenharia reversa foi utilizado o método FUSION-RE/ (desenvolvido pelo grupo de Engenharia de Software do $(C M C)$, que possibilita a transformaçäo de sistemas procedimentais em sistemas orientados a objeto. Na etapa de engenharia progressiva, a ferramenta FusionCASE foi utilizada para apoiar o desenvolvimento de software orientado a objeto. Os programas foram implementados utilizando a' linguagem Delphi, pela facilidade de implementaçăo e elaboração de janelas que essa linguagem proporciona.

\section{4 - Organização do Trabalho}

Este trabalho está organizado em 6 capitulos. Neste capítulo foi exposto a motivação e os objetivos que se pretende atingir com o trabalho.

O capitulo 2 compreende a revisão bibliográfica e nele são apresentadas as principais características, os conceitos e definiçōes de reengenharia, engenharia reversa e engenharia progressiva, aplicados ao software.

No capitulo 3 é descrita a aplicação do método de engenhania reversa FUSIONRE/l no sistema SAPES.

A fase de engenharia progressiva do sistema SAPES, efetuada a partir dos modelos obtidos no capitulo 3, é apresentada no capítulo 4 .

No capítulo 5 são descritas as diretrizes do processo de reengenharia de software orientado a função, para software orientado a objeto.

No capitulo 6, as conclusões sobre o presente trabalho e as propostas de trabalhos futuros são apresentados. 


\section{1 - Considerações Iniciais}

A reengenharia de software envolve basicamente duas etapas: engenharia reversa e engenharia progressiva. Para melhor compreensão dos conceitos e propósitos da reengenharia, faz-se necessário o entendimento dos conceitos de engenhana reversa, categorias de reengenharia, o seu processo, definiçöes e aplicações.

\section{2 - Definições de Reengenharia}

O tema reengenharia está relacionado com a reconstrução de algo do mundo real, $e$ independentemente da aplicação da reengenharia, o seu principal propósito é a busca por melhorias que permitam produzir algo de qualidade melhor ou pelo menos de qualidade comparável ao produto inicial.

Sage [1995], indica diversas categorias de melhorias relacionadas à reengenharia, 
entre elas: melhorias de sistemas administrativos, melhorias de processos e melhorias de produtos.

A reengenharia de processos administrativos é direcionada para alteraçōes potenciais em todos os negócios ou processos organizacionais. Esta definição de reengenharia de processos administrativos é a mesma dada por Hammer e Champy [1993]: "reengenharia é o repensar fundamental e o reprojeto radical dos processos de uma organização, para realizar uma dramática melhoria em termos de performance, custo, qualidade e serviços".

A reengenharia de processos produtivos consiste de modificações em qualquer ciclo de processos padrão, que esteja em uso em uma dada organização, para melhor acomodar as tecnologias novas e emergentes ou requisitos dos clientes para um produto ou sistema. Indiretamente, melhoria nos processos de produção resulta em aumento de eficácia do produto pelo mesmo custo, ou na redução do custo pela mesma eficácia, ou ambos.

A reengenharia de sistemas de software ou produtos é o exame, estudo, captura e modificação de mecanismos intemos ou funcionalidade de um sistema existente ou produto, visando reconstituí-lo em uma nova forma e com novas características, freqüentemente para tomar vantagem das novas e emergentes tecnologias, mas sem grandes alterações na funcionalidade e propósito inerentes do sistema.

Quando se efetua a reengenharia de processos administrativos provavelmente será necessário efetuar reengenharia de software, visto que existe uma dependência implícita entre os processos administrativos e o software [Sommerville, 1995].

Neste trabalho, é dado enfoque à reengenharia de sistemas de software a qual também é definida por outros autores:

- Para Chikofsky e Cross [1990], IEEE CS-TCSE [1997] e GT-REG [1998], a reengenharia, conhecida também como renovação ou reconstrução, é o exame e alteração de um sistema de software, para reconstitui-lo em uma nova forma, e a subsequäente implementação dessa nova forma. Um processo de reengenharia geralmente inclui alguma forma de engenharia reversa, seguida por uma forma de engenharia progressiva ou reestruturação.

- Para Warden [1992], a reengenharia tem como principal objetivo melhorar um sistema de alguma maneira; através de alterações significantes que proporcionem melhoria, porém, sem alterar suas funções. A extração 
automática da descrição de uma aplicação e sua implementação em outra linguagem não é considerada, segundo o autor, reengenharia e sim tradução de código. Do mesmo modo que Chikofsky, Warden considera que a reengenharia pode ser dividida em duas fases principais: a Engenharia Reversa e a Engenharia Progressiva; e cada uma destas fases pode ser dividida em uma série de atividades.

- O padrão IEEE P1219/D14 [apud Sage, 1995], para manutenção de software define a reengenharia como um subconjunto da engenharia de software, composta por engenharia reversa e engenharia progressiva.

- Premerlani e Blaha [1994] citam que o objetivo da reengenharia é reutilizar automaticamente os esforços de desenvolvimento passados, objetivando reduzir custos de manutenção e melhoria na flexibilidade do software.

- Segundo Pressman [1995], a reengenharia, também chamada de recuperação ou renovação, recupera informaçōes de projeto de um software existente e usa essas informaçōes para alterar ou reconstituir o sistema, preservando as funçöes existentes, ao mesmo tempo em que adiciona novas funçōes ao software, num esforço para melhorar sua qualidade global.

- Para Sommerville [1995], a reengenharia de software é descrita como a reorganização e modificação de sistemas de software existentes, parcial ou totalmente, para tomá-los mais manuteniveis.

Dessas definições percebe-se que existe clara distinção entre o desenvolvimento de um novo software e reengenharia de software. A distinção está relacionada ao ponto de partida de cada um dos processos. O desenvolvimento de um novo software (definido como engenharia progressiva por Chikofsky e Cross [1990]) inicia-se com uma especificação escrita do software que será construído, enquanto que a reengenharia inicia-se tomando como base um sistema já desenvolvido.

Das definições nota-se também que existe distinção entre os objetivos da reengenharia e os da engenharia reversa. O objetivo da engenharia reversa é derivar o projeto ou especificação de um sistema, partindo-se de seu código fonte [Sommenville, 1995]. O objetivo da reengenharia é produzir um sistema novo e mais manutenivel e a engenharia reversa é usada como parte do processo de reengenharia, para o entendimento do sistema a ser reconstruído. Estas distinçōes estão ilustradas na figura 2.1. 


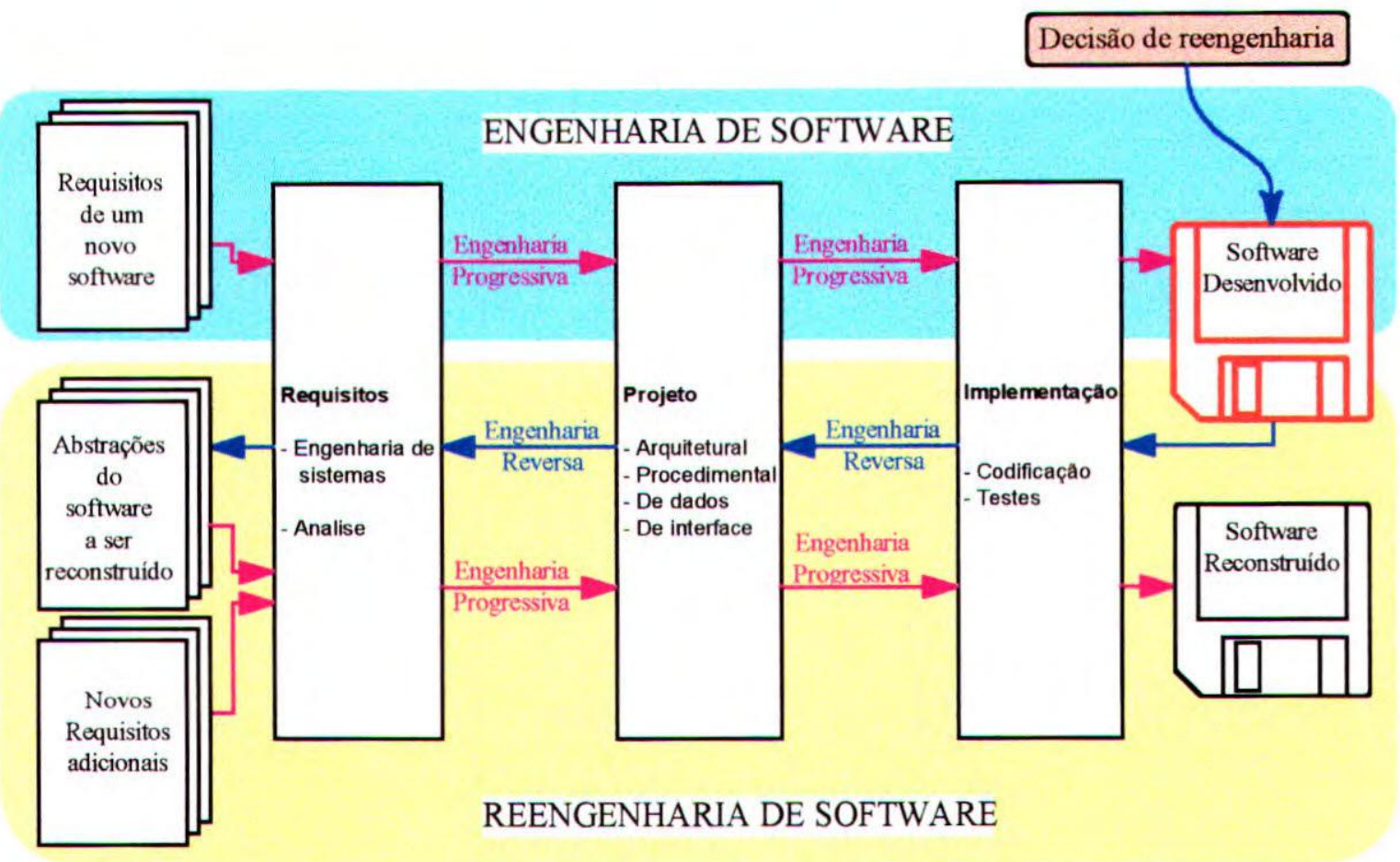

FIG. 2.1 - REENGENHARIA DE SOFTWARE

Outros conceitos relacionados à reengenharia são: redocumentação, reestruturação, recuperação de projeto e engenharia reversa (figura 2.2) [Chikofsky \& Cross, 1990].

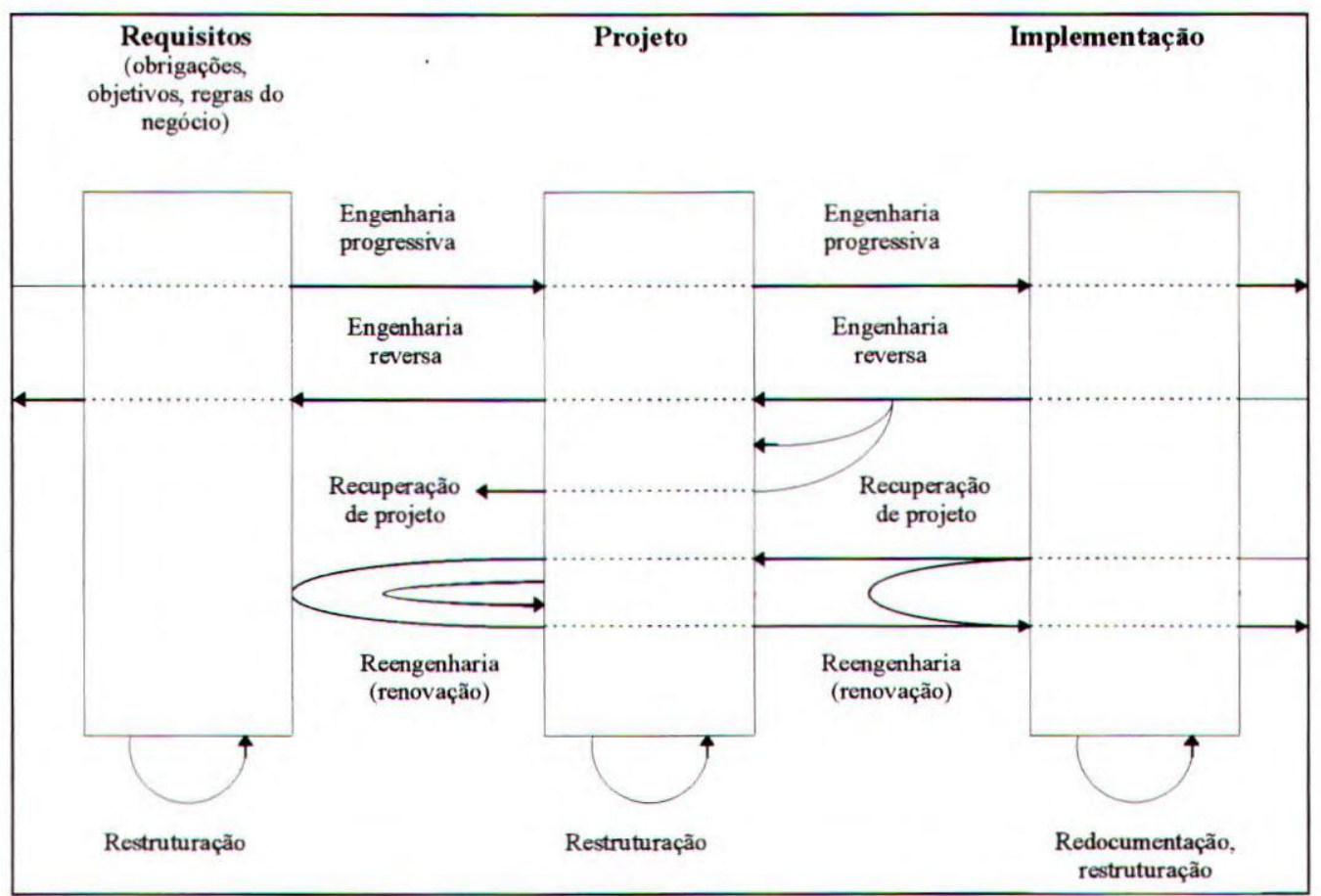

Fig. 2.2 - Relacionamentos no Ciclo de Desenvolvimento de Software [Chikofsky \& Cross, 1990] 
- Redocumentação. Como uma subárea da engenharia reversa, a redocumentação é a criação ou revisão de uma representação semanticamente equivalente, dentro do mesmo nivel relativo de abstraçäo, sendo que as formas resultantes de representação são consideradas como visões alternativas, utilizadas para uma melhor compreensão humana do sistema analisado.

- Recuperação de projeto. É uma subárea da engenharia reversa na qual o conhecimento do domínio da aplicação, informaçōes externas, e dedução săo adicionadas às observaçōes referentes ao programa, para se extrair abstraçōes significativas de mais alto nível, além daquelas obtidas através da observação direta do sistema.

- Reestruturação. É a transformação de uma forma de representação, para outra no mesmo nível de abstração relativo, preservando o comportamento externo do sistema (funcionalidade e semântica). Geralmente usada como uma forma de manutenção preventiva, a reestruturação aplica-se em sistemas que tenham sido desenvolvidos de forma desestruturada, resultando em uma representação que preserva as características do sistema, porém de forma mais bem estruturada.

\section{3 - Engenharia Reversa}

O ciclo de vida de software refere-se às etapas (ou estágios) da existência do software. Existem diversos modelos de ciclo de vida: o modelo em cascata [Royce, 1970], o evolutivo, a quarta geração e o espiral [Boehm, 1988], entre outros.

Independentemente do modelo de ciclo de vida adotado, o processo de desenvolvimento de software começa pela especificaçāo dos requisitos, passa pelo projeto e termina em implementação do software (figura 2.3).

No desenvolvimento de software, quando se parte dos requisitos, para a implementação, tem-se um aumento do nível de detalhes e, portanto uma diminuição na abstração. 


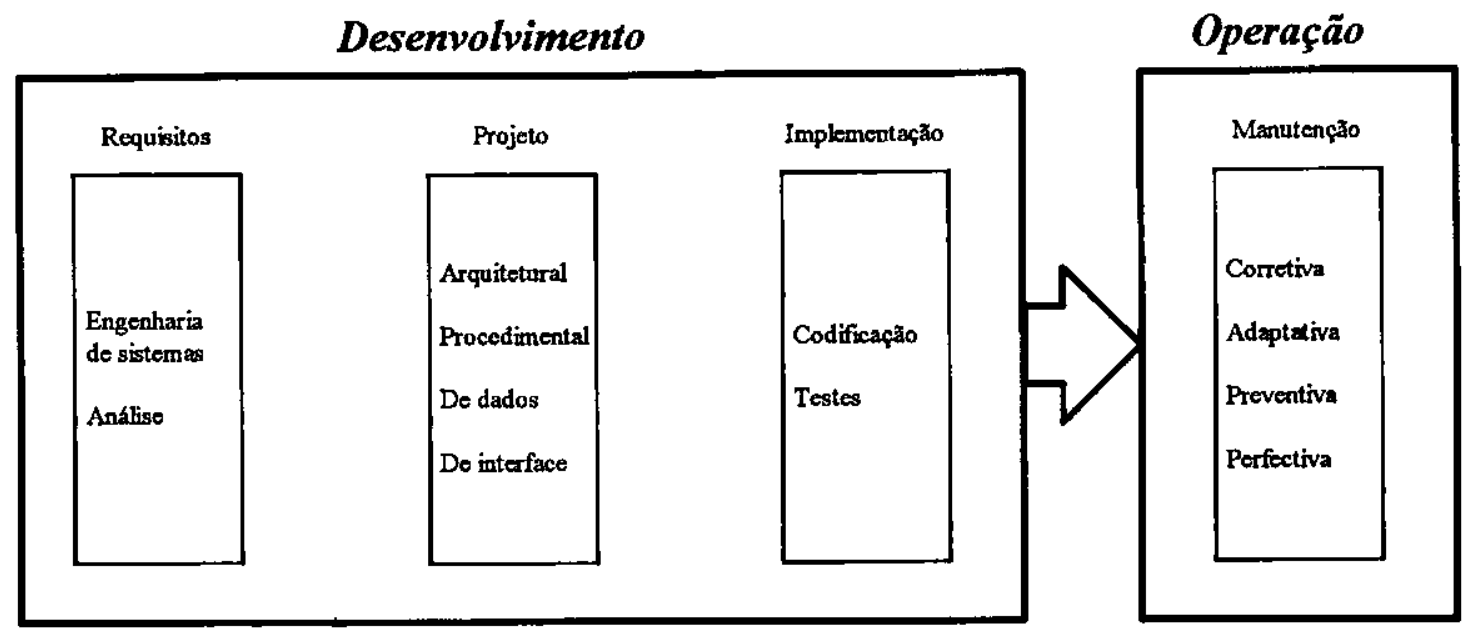

FIg. 2.3 - CicLo DE VIDA GENÉRICO

Abstração é definida como a habilidade de se ignorar os aspectos de assuntos não relevantes para o propósito em questão, tornando possível uma concentração maior nos assuntos principais [Oxford, 1986]. Dois conceitos relacionam abstração com as atividades do ciclo de vida:

Nivel de abstração: quanto mais próximo o projeto estiver do nível de implementação em máquina, menor será o nivel de abstração do projeto. Por outro lado, quanto mais próximo o projeto estiver da fase de especificação dos requisitos do sistema, maior será o nível de abstração do mesmo. Geralmente no desenvolvimento de software, parte-se de informaçōes em alto nível de abstração, e à medida que o projeto for caminhando através das etapas do ciclo de vida, o nivel de abstração vai diminuindo [Chikofsky \& Cross, 1990].

Grau de abstração: dentro de uma mesma etapa (ou fase) do ciclo de vida, se as informações forem pouco detalhadas, diz-se que é alto o grau de abstração, já se as informaçōes forem muito detalhadas, diz-se que é baixo o grau de abstração [Chikofsky \& Cross, 1990].

Resumindo, o grau de abstração é interno a cada fase do ciclo de vida, e o nível de abstração acontece entre as fases do ciclo de vida (figura 2.4). 


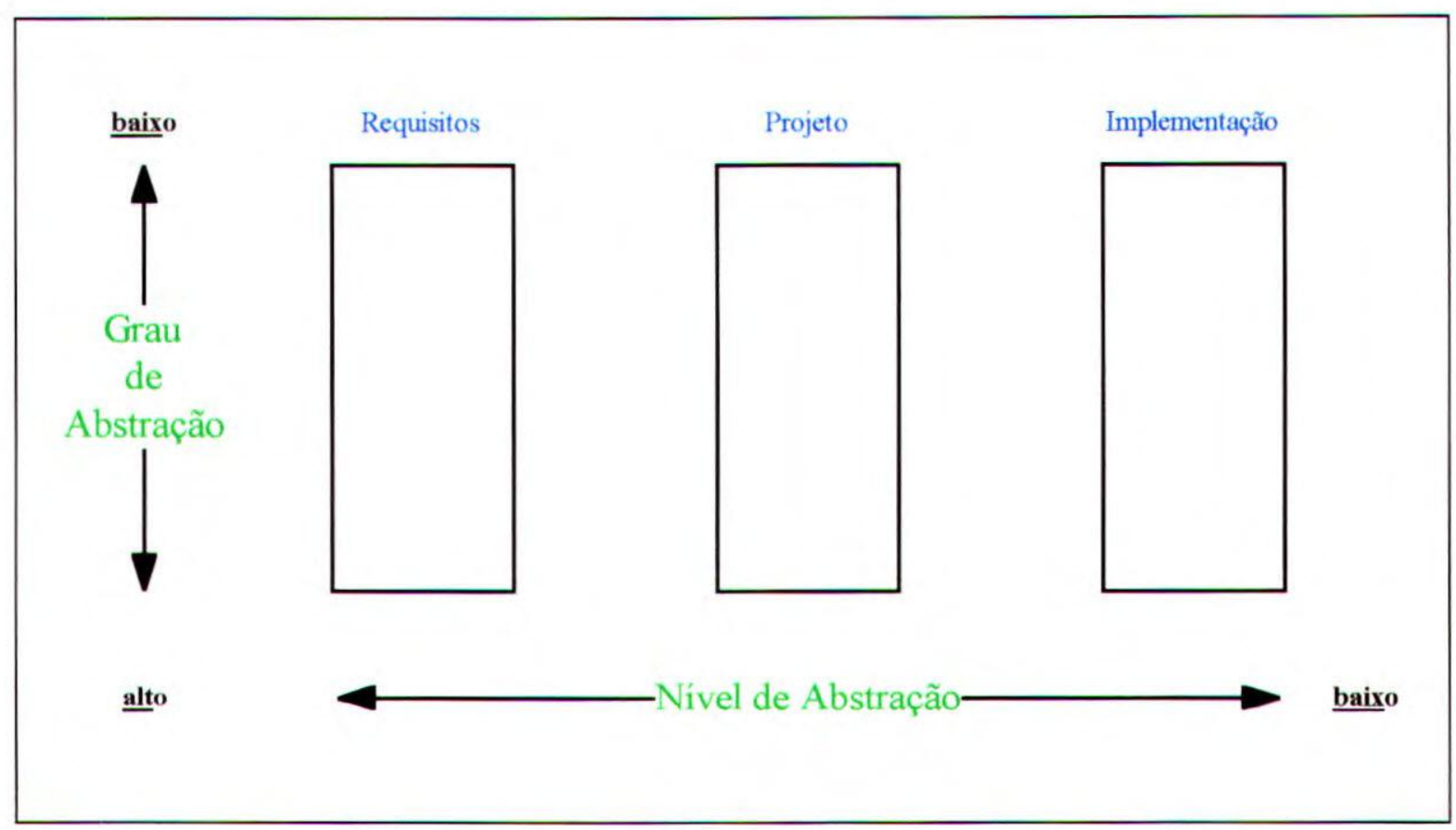

Fig. 2.4 - Nível E GRau de ABSTRaÇÃo no Ciclo de Vida de Software [Costa, 1997]

O processo tradicional de engenharia de software, caracterizado pelas atividades progressivas do ciclo de vida, que partem de um alto nível de abstração, para um baixo nivel de abstração, é conhecido como engenharia progressiva. Já o processo inverso à engenharia progressiva, caracterizado pelas atividades retroativas do ciclo de vida, que partem de um baixo nível de abstração para um alto nível de abstração, é conhecido como engenharia reversa (figura 2.5) [Chikofsky \& Cross, 1990].

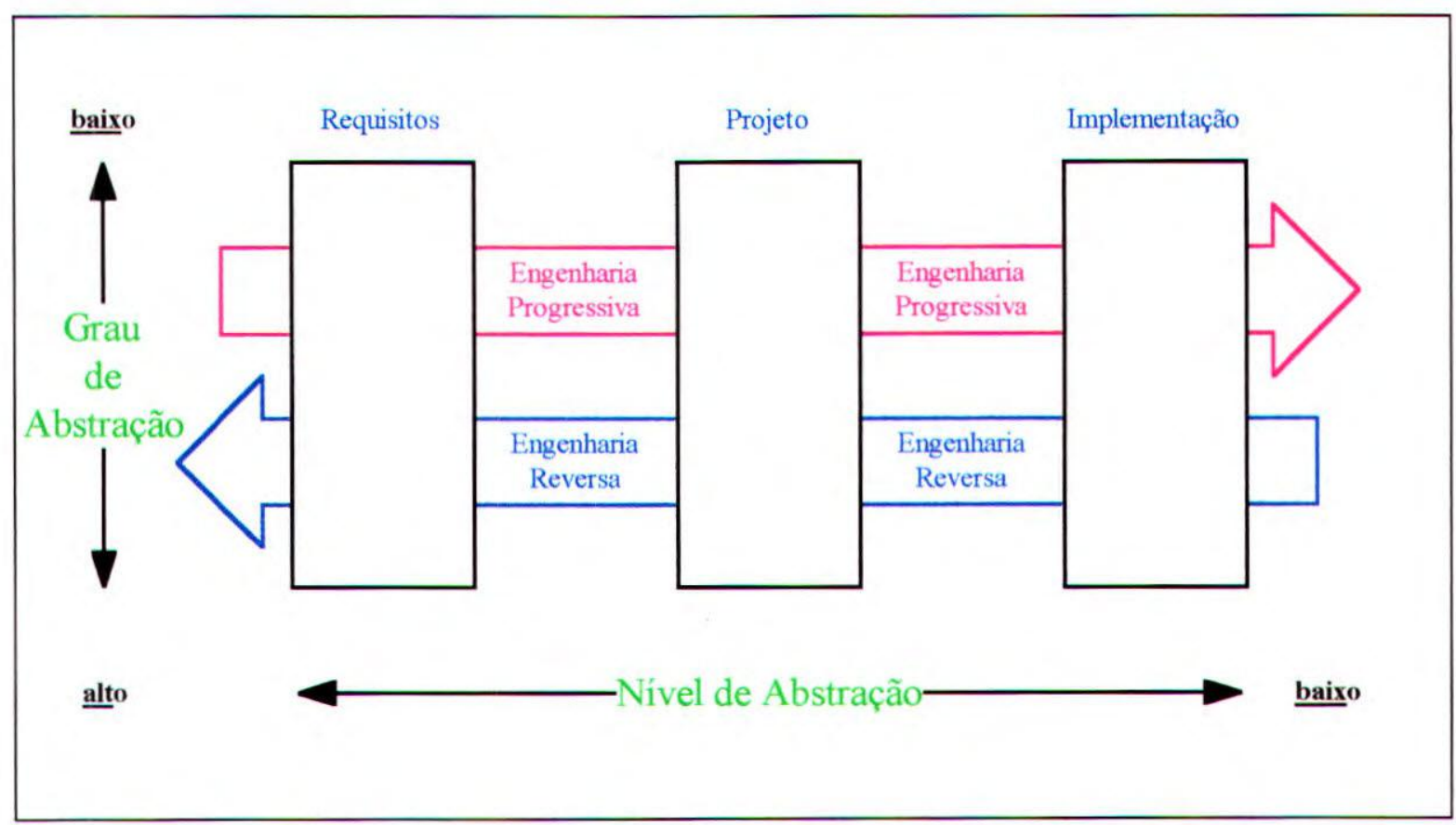

Fig. 2.5 - Engenharias Progressiva e Reversa no Ciclo de Vida de Software [Costa, 1997] 


\subsection{1 - Definiçōes de Engenharia Reversa}

O termo engenharia reversa originou-se na engenharia de hardware, onde o mesmo é considerado como o processo de desenvolvimento de especificações para um sistema de hardware complexo, através de exame minucioso de exemplares do sistema de hardware em estudo [Rekoff, 1985].

O conceito de Engenharia Reversa de Software é similar. Porém, tradicionalmente o objetivo da engenharia reversa de hardware é duplicar o sistema, enquanto o objetivo da engenharia de software freqüentemente é obter um entendimento do sistema em um nivel de abstração mais alto.

Para Pressman, a engenharia reversa de software é um processo de recuperação de projeto, consistindo em analisar um programa, na tentativa de criar uma representação do mesmo, em um nivel de abstração mais alto que o código-fonte [Pressman, 1995].

Para Gannod e Cheng, [1996], engenharia reversa de um programa é o processo de construir uma abstração de alto nivel objetivando facilitar o entendimento de um sistema legado ou geriátrico.

Segundo Benedusi, pode-se definir engenharia reversa como uma coleçăo de teorias, metodologias, e técnicas capazes de suportar a extração e abstraçăo de informações de um software existente, produzindo documentos consistentes, quer seja a partir somente do código fonte, ou através da adição de conhecimento e experiência que não podem ser automaticamente reconstruídos a partir do código [Benedusi et al., 1992 apud Ramamoorthy et al., 1986; Chikofsky \& Cross, 1990].

Para Samuelson, engenharia reversa é geralmente entendida como a ação de criar um conjunto de especificações funcionais para um sistema, por alguém que não foi - projetista original, baseado na análise de um sistema existente e suas partes componentes [Samuelson, 1990 apud Rekoff, 1985].

Segundo Waters e Chikofsky, o processo de análise de um sistema para identificar os componentes de um software e seus inter-relacionamentos, e para criar uma representação do software em outra forma, provavelmente num nivel mais alto de abstração que o codigo fonte, é engenharia reversa [Waters \& Chikofsky, 1994]. 
Stephen chama de engenharia reversa, entender, analisar, e abstrair o sistema para uma nova forma, num alto nível de abstração [Stephen \& Lynn, 1995].

A partir da engenharia reversa e com base nos diferentes níveis e graus de abstração o software pode ser visualizado de diferentes maneiras.

\subsection{2 - Visualização de Software}

As visöes que se obtêm do software podem ser classificadas em 4 categorias: visão em nivel-implementacional, visão em nível-estrutural, visäo em nível-funcional, visão em nível-de-domínio [Harandi \& Ning, 1990].

Visão em nível-implementacional. Abstrai características da linguagem de programação e características específicas da implementação. Exemplos de visöes em nivel implementacional são informações a respeito da sintaxe e da semántica da linguagem e informações da implementação.

Visão em nivel-estrutural. Abstrai detalhes da linguagem de programação para revelar sua estrutura a partir de diferentes perspectivas. O resultado é uma representação explícita das dependências entre os componentes do sistema. Exemplos de visöes em nivel estrutural são grafos de fluxo de dados, grafos de fluxo de controle [Cleveland, 1989], o projeto procedimental expresso através de uma linguagem de projeto de programação [Caine \& Gordon, 1975; Harband, 1990], o projeto arquitetural expresso através de gráficos de estruturas [Cross, 1990], ou através de uma linguagem de interconexão modular, como NuMIL [Choi \& Scacchi, 1990].

Visão em nível-funcional. Abstraj a função de um componente, isto é, o que o componente faz. Essa visão relaciona partes do programa às suas funçöes procurando revelar as relações lógicas entre elas (diferentemente das relações sintáticas ou das estruturais). Exemplos de visöes em nível funcional podem ser descriçöes da função do sistema expressos de maneira formal, usando linguagens tais como VDM [Jones, 1990], $\mathrm{Z}$ e Z ${ }^{++}$[Spivey, 1988; Bennet, 1991]; diagramas de fluxo de dados, que apresentam os processos e o fluxo de Hados entre eles [DeMarco \& Sarson, 1979]; diagramas de fluxo de controle [Hatley \& Pirphai, 1987], que apresentam os processos e o fluxo de controle entre eles e diagramas de entidade-relacionamento [Ross, 1988], que mostram os dados e seus relacionamentos. 
Visão em nível-de-domínio. Abstrai o contexto em que o sistema está operando, ou seja, o porquê do sistema a ser desenvolvido.

Na realidade poucas representações são restritas somente a uma fase do ciclo de vida ou consideradas como pertencentes a uma categoria de visualização. Uma linguagem de projeto de programa [Caine \& Gordon, 1975] pode ser usada para representar as funções na fase de requisitos ou o projeto procedimental na fase de projeto. Um diagrama de fluxo de dados [DeMarco \& Sarson, 1979], pode ser usado para descrever o que o sistema faz ou como o processo interage. Assim, se uma representação extraída é uma representação de requisitos ou uma representação de projeto depende principalmente do contexto em que a representação será usada.

É relevante ressaltar que uma forma de representação extraída do código pode diferir de uma representação similar que foi desenvolvida no processo de engenharia progressiva. A forma extraída irá refletir a idiossincrasia da representação do código muito mais do que a representação original, que reflete a compreensão do problema pelo analista ou projetista.

A figura 2.6 mostra a correspondência entre as categorias de visualização do software e as diferentes atividades do ciclo de desenvolvimento de software.

Engenharia Progressiva

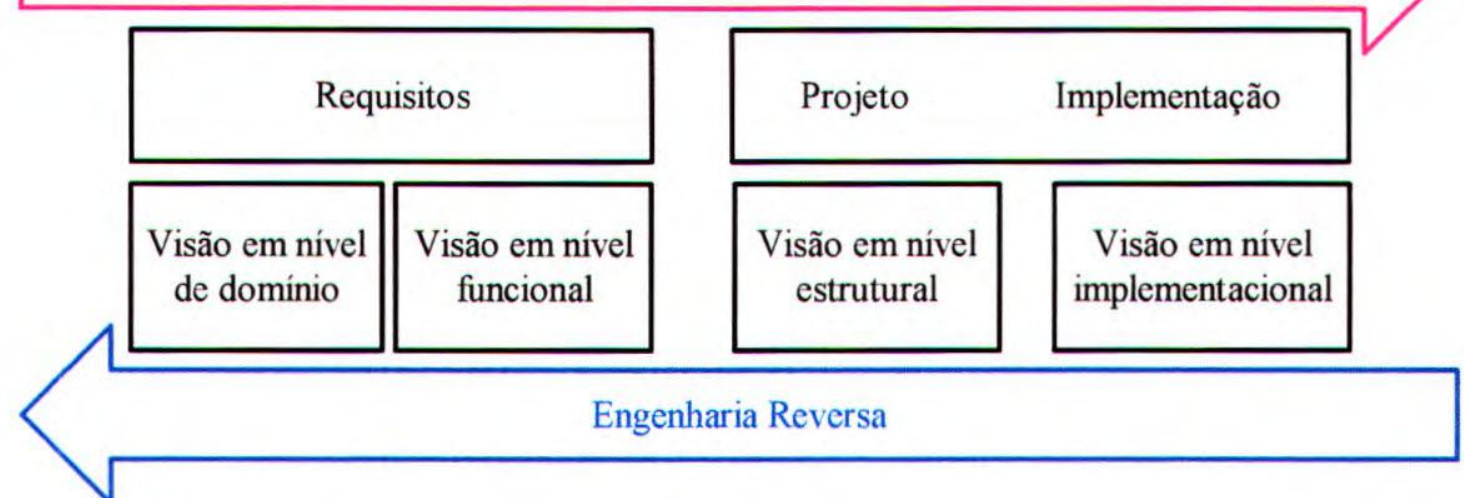

Fig. 2.6 -Visualizações de SOFTWARE no Ciclo de Desenvolvimento [Costa, 1997]

Muitas vezes é necessário acrescentar às informações contidas no código outras informações provenientes de conhecimentos e experiências humanas, para se obter 
"visōes" diferenciadas do software. Conforme o escopo das informaçöes usadas que resultarão em um nivel de entendimento obtido do sistema, pode-se formular uma categorização dos métodos de engenharia reversa.

\subsection{3 - Categorias de Engenharia Reversa}

De acordo com o nível de entendimento obtido do sistema e o escopo das informações usadas, duas categonias de engenharia reversa săo definidas: visualização de código [Oman, 1990] e entendimento de programa [Chikofsky \& Cross, 1990].

Visuallzação de código: Também denominada redocumentação. É a criação ou revisāo de representaçöes semanticamente equivalentes num mesmo nível de abstração [Chikofsky \& Cross, 1990]. O processo de visualização de código cria as representações a partir de informaçōes obtidas apenas da análise do código fonte, embora a apresentação dessas informaçōes possa se diversificar. As formas das representações são consideradas visōes alternativas, cujo objetivo é melhorar a compreensibilidade do sistema global.

A forma mais simples e mais antiga de engenharia reversa é a visualização de código. A intenção é recuperar a documentação que já existiu, ou que deveria ter existido, sobre o sistema. A ênfase, de fato, é a criação de visões adicionais, especialmente visões gráficas, que não foram criadas durante o processo original de engenharia progressiva.

A visualização de código não transcende a visão em nivel-estrutural e não atribui significados ao sistema analisado. Recuperaçōes mais ambiciosas tais como a função, os propósitos ou a essência do sistema exigem um nível de entendimento maior e são definidas como entendimento de programa.

Entendimento de programa: Nesta categoria de engenharia reversa, também denominada recuperação de projeto, o conhecimento do domínio das informaçoes extemas e as deduções são adicionadas às observações feitas sobre o sistema através do exame do mesmo, de modo a obter informações com nível mais alto de abstração [Chikofsky \& Cross, 1990].

Segundo Biggerstaff [1989], entendimento de programa recria abstrações do 
projeto a partir de uma combinação de código, documentação existente do projeto (se disponivel), experiencias pessoais, e conhecimentos gerais sobre o problema e 0 domínio de aplicação. Sintetizando, entendimento de programa deve produzir todas as informações necessánas para se entender completamente o que, como, e por que 0 sistema faz.

Até o momento pesquisas [Ramamoorthy \& Tsai, 1996], revelam que os métodos de engenharia reversa não recuperam de modo automático todas as visões do software. Isto acontece basicamente porque a fase de implementação - caracterizada principalmente por programas fonte e descrição de arquivos - não contém todas as informações essenciais para o processo de engenharia reversa, as quais são providas pela fase de análise, sendo necessária a intervençăo humana para extrair boas representações de projetos de software, principalmente em niveis mais altos de abstração [Tangorra \& Chiarolla, 1995]. Segundo Pressman [1995], as ferramentas baseadas em engenharia reversa estão ainda "engatinhando" e as pesquisas nesta área de entendimento de código são muito importantes e muitas outras ainda acontecerão.

Entendimento de programa distingue-se de visualização de código porque objetiva entender o sistema, em vez de simplesmente fornecer visões alternativas para auxiliar 0 usuário a entender o sistema. Esse entendimento vai além do conhecimento em nivel implementacional e estrutural, buscando obter o conhecimento em nivel-funcional e até mesmo em nivel-de-domínio (ambiente de operação do sistema).

Um completo entendimento de programa busca reconstruir não somente a função do sistema, mas também o processo pelo qual o sistema foi desenvolvido. Rugaber et al. [1990] enfatizam a importância da recuperação de decisões de projeto tomadas durante o desenvolvimento original para uma completa estrutura de entendimento.

Entendimento de programa é a forma mais critica de engenharia reversa porque tenta aproximar-se do raciocínio humano na busca do entendimento.

A figura 2.7 apresenta a amplitude de alcance das categorias de engenharia reversa, relacionadas com o escopo das informaçóes utilizadas (código fonte ou base de conhecimento) e o nivel de visualização pretendida (implementacional, estrutural, funcional e de dominio). 


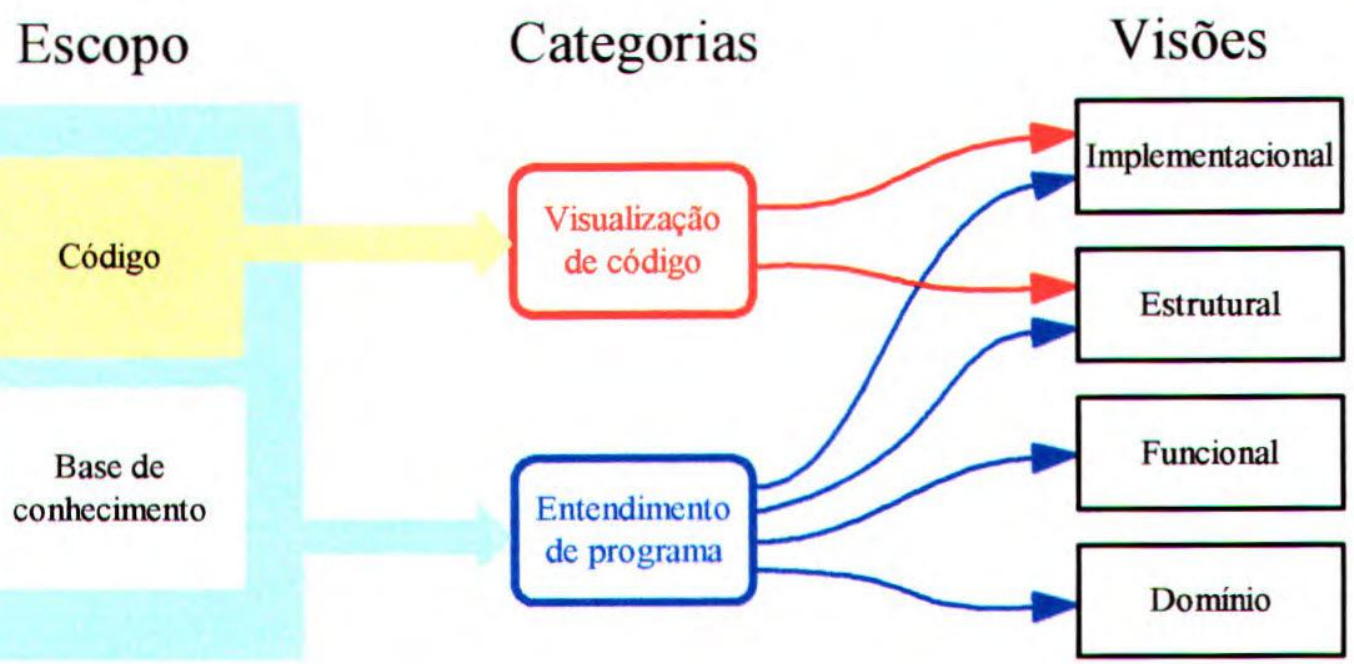

FIG. 2.7 - VISÕES DAS CATEGORIAS DE ENGENHARIA REVERSA

\section{4 - Processo de Reengenharia}

O processo de reengenharia de software é constituído de duas fases distintas, a primeira "desmonta" o software objeto de reconstrução, para seu entendimento e a segunda o constrói novamente, em uma nova forma desejada, a partir do produto da primeira fase juntamente com os ajustes que se fizerem necessários.

O processo de Reengenharia pode ser traduzido como [Jacobson \& Lindström 1991]:

Reengenharia $=$ Engenharia Reversa $+\Delta+$ Engenharia Progressiva

Onde $\Delta$ pode ser de dois tipos:

1. Alterações de funcionalidade (Alteram o objetivo principal do sistema): Ocorrem devido a mudanças nos negócios, ou necessidade do usuário.

2. Alterações de implementação (Alteram a forma de implementação do sistema): ocorrem devido a alterações no ambiente de operação do software e ou linguagem de implementação (protocolos, sistema operacional, portabilidade, linguagens, etc.).

Existem alguns pontos que devem ser considerados para um processo de reengenharia [Warden, 1992]:

- Reengenharia deve ser executada somente se existir um argumento aceitável de custo/benefício. 
- Reengenharia implica melhoria através de reprojeto.

- Reengenharia deve remover projetos ruins, mas reconhecer e manter projetos bons e simples, mesmo se ele for desestruturado.

- Engenharia Reversa é dirigida por tipos de problemas, os quais necessitam ser identificados.

- Problemas são identificados e expressos como violaçöes às técricas de projeto estruturado e regras de programação, ou outras que o usuário pode definir.

- Ferramentas dever ser adequadas aos processos de reengenharia, e não os processos adequados às ferramentas.

Jacobson e Lindström [1991] declaram que para executar um processo de reengenharia de um sistema é necessário:

1. Engenharia reversa: Identificar como os componentes do sistema se relacionam uns aos outros e então criar uma descrição mais abstrata do sistema. Um exemplo de identificação de relacionamentos entre componentes pode ser a identificação de dependências entre os arquivos $\theta$ as funçōes, entre as funçōes e as descrições da base de dados, etc.. Um exemplo da criação de uma descrição mais abstrata do sistema pode ser um diagrama de fluxo de dados para as funçōes e o modelo entidade-relacionamento para as descriçōes da base de dados. Com esse primeiro passo obtém-se um modelo abstrato o qual mostra a funcionalidade do sistema (propósito para o qual o sistema foi construido) e um número de mapeamentos entre os diferentes níveis de abstração. Os mapeamentos compreendem as decisర̄es de projeto que ocorrem quando se transforma uma representação abstrata em uma representação concreta.

2. Decidir sobre alterações na funcionalidade: as alterações de funcionalidade são as alteraçరes nos requisitos que o usuário determina que sejam implementadas no sistema. Esse passo é executado utilizando-se as abstraçōes de mais alto nível, obtidas no passo anterior. Sem o modelo abstrato é necessário decidir questóes de alto nivel, utilizando-se comandos de baixo nivel, por exemplo, um comando de alto nivel tal como "Altere a associação entre as entidades $X$ e $Y$ " deveria ser traduzido para um outro de baixo nível tal como "Adicione uma tabela que contenha as referencias entre $X$ e $Y^{\prime \prime}$.

3. Reprojetar o sistema: reprojeta-se o sistema partindo-se das abstraçōes de alto nivel, obtidas nos passos anteriores, para uma representação mais concreta, ou 
seja, executa-se a engenharia progressiva reimplementando o sistema. Neste processo, deve-se levar em consideração as alterações de técnicas de implementação. Se apenas parte do sistema for alterado, deve-se considerar questöes sobre a integração/comunicação entre as partes velhas e novas do sistema.

Gall e Klosch [1995], relatam um processo para encontrar objetos em programas procedimentais. Esse processo de identificação de objetos é baseado nas informações derivadas do código fonte, integradas com conhecimento especifico do sistema e do domínio da aplicação, os quais resultam em representaçöes das semânticas das aplicações em objetos. A identificaçăo de objetos inicia-se com a geraçăo de documentos de projeto de baixo nivel, como diagramas estruturados, e diagramas de fluxo de dados, sendo estes a base para o processo de identificação dos objetos.

Sneed e Nyáry [1995], relatam uma abordagem para extrair automaticamente documentação de projeto orientada a objeto a partir de programas escritos em $\mathrm{COBOL}$ para mainframe; mapas ou painéis para comunicação com o usuário; bases de dados armazenados e cartões de controle de execução do programa.

Yeh et al. [1995], abordam a recuperação de representaçỏes arquiteturais de software, partindo do código fonte. A experiência inclui desenvolvimento, implementação e teste de uma abordagem interativa para recuperação de tipos abstratos de dados (TADs) e instâncias de objetos extraidos de programas escritos em linguagens convencionais como $\mathrm{C}$.

Newcomb e Kotik [1995], descrevem uma ferramenta de reengenharia para transformar automaticamente um sistema procedimental em sistema orientado a objeto sem alteração de funcionalidade $O$ processo de transformação em forma orientada a objeto localiza dados e procedimentos redundantes, duplicados $\theta$ similares $\theta$ abstrai-os em classes e métodos.

Lewis e McConnell [1996], descrevem um processo geral de reengenharia de software usado em experimentos com software de missil. $O$ experimento envolve reimplementaçăo partindo-se de monoprocessamento, para multiprocessamento escalável e distribuído. O processo tem os seguintes passos: 1) configuração da engenharia reversa e reengenharia; 2) tradução para ADA95; 3) validação e correção; 4) reestruturação; 5) transformação arquitetural e ligação do novo código e 6) reimplementação para processadores distribuídos. 


\section{5 - Categorias de Reengenharia de Software}

Jacobson e Lindström [1991], categorizam a reengenharia segundo alguns cenários, onde ocorre a transformação de sistemas orientados à função para sistemas orientados a objeto:

a) Reengenharia completa da técnica de implementação, sem alteração de funcionalidade: este cenário raramente ocorre em um grande sistema, porque demanda uma mudança radical de paradigma, devido às alterações efetuadas em todo o sistema. Os principais passos do processo de reengenharia para este cenário são:

- Preparar um modelo de análise, com base no sistema a ser reconstruido;

- Mapear cada objeto de análise para a implementação do sistema velho;

- Reprojetar o sistema usando uma técrica orientada a objeto para deserivolvimento de sistemas de software.

b) Reengenharia parcial sem alteração de funcionalidade: Neste cenário o sistema antigo é alterado parcialmente. O objetivo é fazer a aplicação orientada a objeto "acreditar" que o sistema inteiro consiste de objetos. Este cenário requer alguns passos discriminados a seguir:

- Identificar as partes do sistema que serão reimplementadas usando técrica orientada a objeto;

- Preparar um modelo de análise da parte a ser remodelada e seu ambiente;

- Mapear cada objeto da implementação antiga do sistema;

- Iterar os passos anteriores até a interface entre as parte velhas e novas do sistema ser aceitável;

- Executar em paralelo:

$\diamond$ Projetar o novo subsistema e sua interface com o resto do sistema antigo;

$\diamond$ Modificar o antigo sistema e adicionar uma interface para o novo subsistema.

- Integrar e testar as partes novas e antigas do sistema.

c) Reengenharia com alteração de funcionalidade: Este cenário é um processo normal de engenharia progressiva, onde se adiciona as novas funcionalidades que se quer no sistema e o implementa usando-se uma técnica orientada a objeto. Os principais passos deste cenário são:

- Alterar o modelo de análise de acordo com os novos requisitos para o sistema.

- Reprojetar o sistema.

A categorização de reengenharia, segundo Sommerville [1995] está relacionada à 
profundidade (grau) com que será feita a reengenharia do software:

a) Conversão de programas fonte: É a mais simples das formas de reengenharia, onde $\mathrm{o}$ código fonte escrito em uma linguagem de programação é traduzido para código fonte em outra linguagem. A linguagem destino pode ser uma versão mais nova da mesma linguagem, ou uma linguagem completamente diferente. Este tipo de reengenharia pode ser útil quando, por exemplo, houver alteração da plataforma de hardware, falta de experiência do pessoal de manutenção na linguagem, ou alteraçōes nos padröes da organização.

b) Reestruturação de programas: aplicável quando a estrutura do sistema está corrompida, dificultando o seu entendimento, como por exemplo: existência de funçöes ou procedimentos nunca chamados ou dupllcados, existência de desvios gotos, existência de estruturas condicionais complexas, etc. Esta categoria se subdivide em:

- Reestruturação automática de programas

- Reestruturação automática de programa com alterações manuais

- Reestruturação de programas e dados.

c) Reengenharia de dados: Envolve a análise e reorganização de estruturas de dados em um programa. A reengenharia de dados pode também envolver, além da reorganização das estruturas de dados, a conversão dos valores dos dados. Para o processo de reengenharia de dados é necessária a criação de programas especiais para proceder a conversão dos dados. A reengenharia de dados é geralmente executada quando se procede a transformaçăo de um software para utilizar um sistema de administração de bases de dados, ou migrar de uma base de dados para outra. A fig. 2.8 mostra o processo de reengenharia de dados, incluindo a conversão de dados.

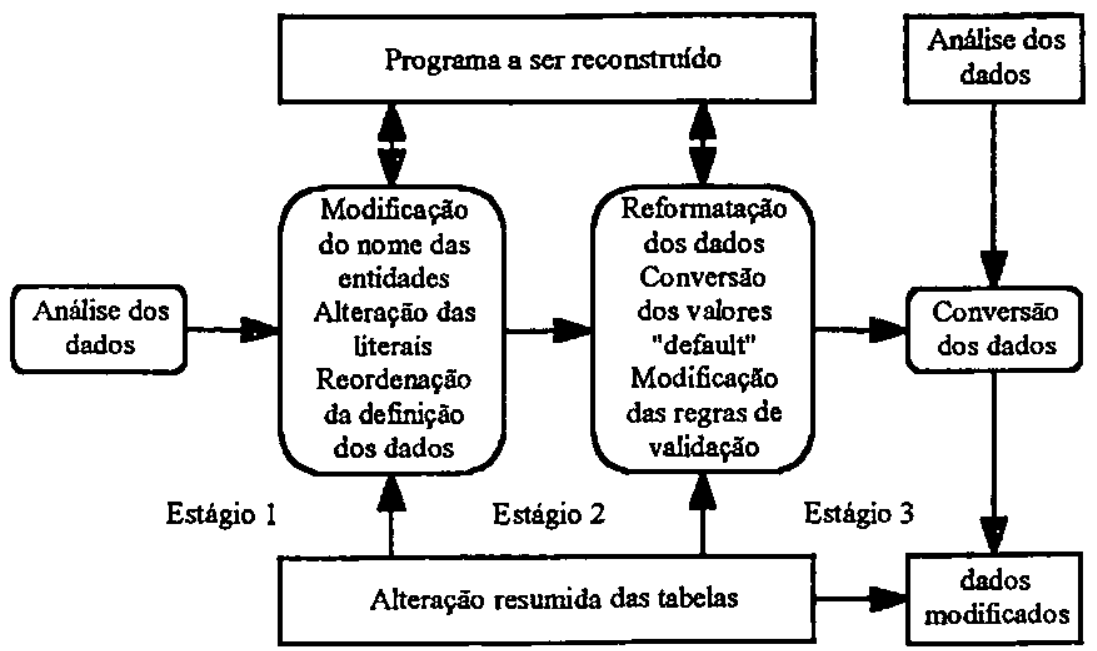




\section{6 - Planejamento para Reengenharia}

O planejamento para a reengenharia configura uma atividade que busca estabelecer os passos para o sucesso de um empreendimento de reengenharia.

Em vista da complexidade encontrada em se gerenciar um processo de reengenharia, dado o fato de que é difícil migrar ou atualizar programas e dados, Sneed [1995] apresenta um processo de planejamento de projetos de reengenharia em cinco passos:

1. Justificativa do projeto. Proceder um minucioso estudo sobre os sistemas da orgarização: seu processo de manutenção e sua importância, visando justificar o empreendimento do processo de reengenharia. Esta justificativa deve projetar retomo do investimento em reengenharia, enfatizando o aumento da qualidade do software, a melhoria no processo de manutenção e o conseqüente aumento do valor do software para a organização.

2. Análise do portifólio. Estabelecer critérios para a escolha das aplicações que são candidatas a reengenharia de acordo com sua qualidade técnica e valor para a organização. Essa análise pode ser feita utilizando-se a figurar 2.9 para a determinação das aplicaçōes de software candidatas a reengenharia.

3. Estimativa de custo. Estimar o custo de um projeto de reengenharia, pela identificação avaliação-ponderação de todos os componentes de software a serem reconstruídos. Estes componentes podem incluir. reengenharia do software, teste e reengenharia de dados.

4. Análise de custo-beneficio. Com base nos custos estimados no passo anterior, proceder uma comparaçăo do custo de fazer reengenharia com o custo esperado de manutenção. Se os custos de reengenharia forem altos, deve-se procurar outras altemativas como compra de software pronto, ou redeserivolvimento.

5. Contrato extemo. Existem basicamente dois tipos de contratos que podem ser usados em processos de reengenharia: contrato por tempo e material e contrato por resultados. Os contratos visam alcançar um nivel máximo de distribuição de projetos para evitar gargalos.

Para a tomada de decisão sobre reengenharia de software é importante fazer-se uma análise de custo-benefício. A matriz da figura 2.9 [Jacobson \& Lindström, 1991] mostra como analisar a viabilidade entre substituir, manter, melhorar ou efetuar a reengenharia de um sistema de software legado. 


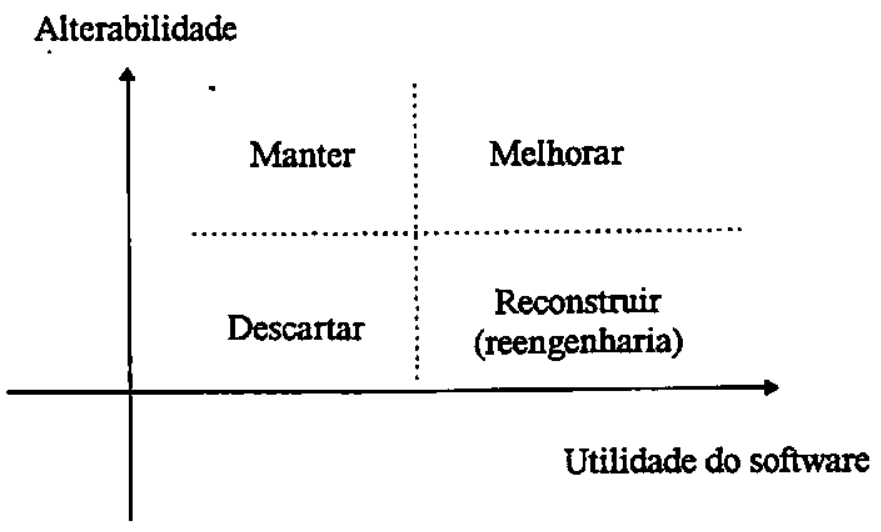

Fig. 2.9 - MATRIZ DE Decisão Sobre o Destino de SofTWARE LEGado

Pode-se visualizar na figura 2.9 que sistemas fáceis de alterar, porém com pouca utilidade para a empresa, devem ser mantidos sob manutenção. Os difíceis de alterar $e$ com menos utilidade, são indicados a serem descartados ou substituídos por outros. Por outro lado, os sistemas que tiverem um bom índice de alterabilidade, e forem de grande utilidade, devem continuar evoluindo. Somente os que forem de baixa alterabilidade e de alta utilidade para a empresa devem ser reconstruídos.

Os custos de um processo de reengenharia têm uma relação direta com a categoria (tipo) de reengenharia. A profundidade e extensão com que for executada a reengenharia, definirão os seus custos. Outros fatores que terão influência sobre os custos de reengenharia são: a qualidade do software a ser reconstruído; as ferramentas de suporte disponiveis para auxiliar a reengenharia; a extensão da conversão dos dados requerida; a disponibilidade de pessoal qualificado para reengenharia.

A figura 2.10 [Sommerville, 1995], mostra as categorias de reengenharia de software e a relação do seu custo com a profundidade com que é executada.

$\begin{array}{cc}\text { Restruturação } & \text { Restruturação de } \\ \text { automática de programas } & \text { programas e dados }\end{array}$

\begin{tabular}{ccc}
\hline & Restruturação automática \\
$\begin{array}{c}\text { Conversão automática } \\
\text { de programas fonte }\end{array}$ & com alterações manuais & $\begin{array}{c}\text { Restruturação mais } \\
\text { alterações arquiteturais }\end{array}$ \\
\hline
\end{tabular}

Aumento de custo

FIG. 2.10 - ABORDAGENS DE REENGENHARIA [SOMMERVILLE, 1995] 
Se, em uma análise de custo/benefício, os custos de reengenharia de um sistema de software forem considerados maiores que o redesenvolvimento de sistemas usando técnicas modernas de engenharia de software; então essa alternativa à reengenharia deve ser considerada. No entanto, a reengenharia tem duas vantagens chaves sobre 0 redesenvolvimento de sistemas [Sommerville, 1995]:

- Risco reduzido - Quando um software é essencial para uma determinada empresa, seu redesenvolvimento é uma atividade de risco, se comparada com a reengenharia do mesmo.

- Custo Reduzido - O custo de reengenharia é significativamente menor que o custo de desenvolvimento, talvez da ordem de quatro vezes ou menos.

No âmbito comercial, existe uma variedade de motivos para a aplicação de reengenharia [Warden, 1992]:

- Necessidade de aumentar a vida econômica de um sistema;

- Necessidade de aumentar significativamente a manutenibilidade de um sistema, o qual está se tornando rapidamente não manutenivel.

- Necessidade de remover problemas complexos para permitir expansão ou integração para alguns sistemas especificos.

\section{7 - Ferramentas de Auxilio à Reengenharia}

Existem ferramentas com a finalidade de auxiliar a execução da reengenharia. A maioria das ferramentas são utilizadas na etapa de engenharia reversa do sistema a ser reconstruido.

Segundo Pressman [1995], as ferramentas baseadas em engenharia reversa estão ainda "engatinhando", ficando claro que as pesquisas na área de entendimento de código são muito importantes e muitas outras pesquisas ainda acontecerăo.

Ferramentas devem ser adequadas aos processos de reengenharia, e não os processos adequados às ferramentas. As ferramentas de suporte disponiveis para auxiliar a reengenharia têm influência sobre os custos de reengenhania.

Existem muitas ferramentas de reengenharia com aplicabilidade em sistemas de software. O quadro 2.1 apresenta várias dessas ferramentas, mostrando o escopo das informações que cada uma utiliza (código fonte, base de conhecimento), bem como as saídas que cada ferramenta produz (visões produzidas e outras saidas). 
Quadro 2.1 - Escopo das informaçōes utilizadas por cada ferramenta de reengenharia, e as respectivas visões e outras saidas produzidas

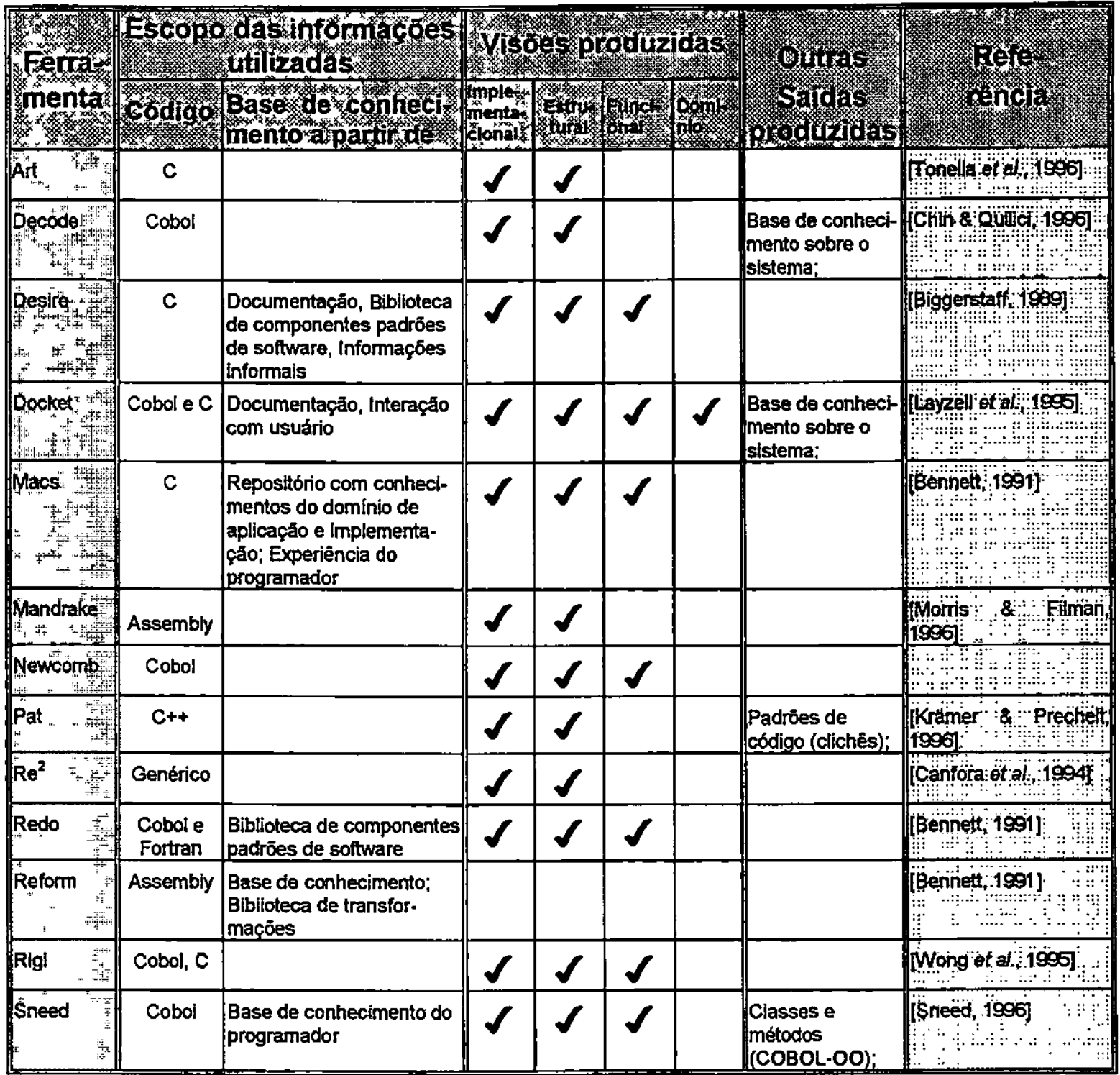

\section{8 - Considerações Finais}

Apresentou-se neste capítulo, definições sobre o processo de reengenharia de software, suas divisões, propósitos e conceitos relacionados. 


\section{CAPÍTULO 3}

\section{ENGENHARIA REVERSA DO SISTEMA SAPES}

\subsection{Considerações Iniclais}

Nesse capitulo, apresentam-se as etapas do processo de engenharia reversa efetuado no sistema SAPES. Nesse processo foi utilizado o método de engenharia reversa FUSION-RE/I [Costa, 1997].

\subsection{O Sistema SAPES}

Há alguns anos atrás (1987), foi projetado e desenvolvido pelos alunos de graduaçăo do curso de bacharelado em ciência de computação do Instituto de Ciências Matemáticas e de Computação da USP, um sistema denominado SAPES (Sistema de Apoio à Pesquisa), cujo objetivo é apoiar as atividades de pesquisa realizadas por docentes e pesquisadores. O sistema tem por objetivo auxiliar a organização e manipulação de informações bibliográficas quando da elaboração de materiais científicos como relatórios técnicos, artigos, notas didáticas, etc, tomando-a mais efetiva 
e eficiente.

Esse sistema envolve a manutenção de uma base de dados com informaçōes bibliográficas possibilitando o gerenciamento e controle dos dados como: inserção, eliminação, consultas e manutenção de informações bibliográficas, assim como a emissão de relatórios adequados ao apoio às atividades de pesquisa. Esses relatórios podem consistir de publicaçōes por autor, assunto, ano, entre outras combinações possíveis, ou outros relatórios pertinentes como a impressão de uma ou de um conjurito de fichas técnicas.

O sistema SAPES, escrito na linguagem Clipper, tem aproximadamente 5 mil linhas de código. Năo é um sistema muito antigo, porém possui diversas características tipicas de sistemas legados: foi desenvolvido há 10 anos, sua documentação não condiz com os programas que estăo implementados e existem erros de implementação. Entretanto é um software cujo valor não pode ser desprezado (para sua especificação diversas reuniōes foram realizadas, criando-se uma especificação de requisitos que atende prontamente as necessidades da comunidade de pesquisadores). Assim sendo, - SAPES constitui um excelente sistema para ser reconstruído, ou seja, ser submetido a um processo de reengenharia.

\subsection{O Método FUSION-RE/I}

O método de engenhana reversa, denominado FUSION-RE/ (FUSION - Reverse Engineering//nterface), cujos passos estão resumidos na figura 3.1 foi desenvolvido para auxiliar a atividade de manutenção de software. Ele é baseado nos conceitos e idéias do método FUSION-RE [Penteado, 1996] de engenharia reversa orientado a objeto.

O método FUSION-RE/l fornece mecanismos para abstrair Visões Funcionais (Modelos de Análise de Sistemas de acordo com o Método Fusion) e Visões Estruturais (Quadro de Operações-Procedimentos de Implementação) a partir de aspectos operacionais e de dados disponiveis via interface usuário-computador.

Neste trabalho, o método FUSION-RE/l é utilizado para realizar engenharia reversa do sistema SAPES. As visōes por ele geradas na primeira etapa (visōes mais abstratas), são as que serão utilizadas no processo de reengenharia. A seguir é descrito como essa primeira etapa foi aplicada sobre o sistema SAPES. 


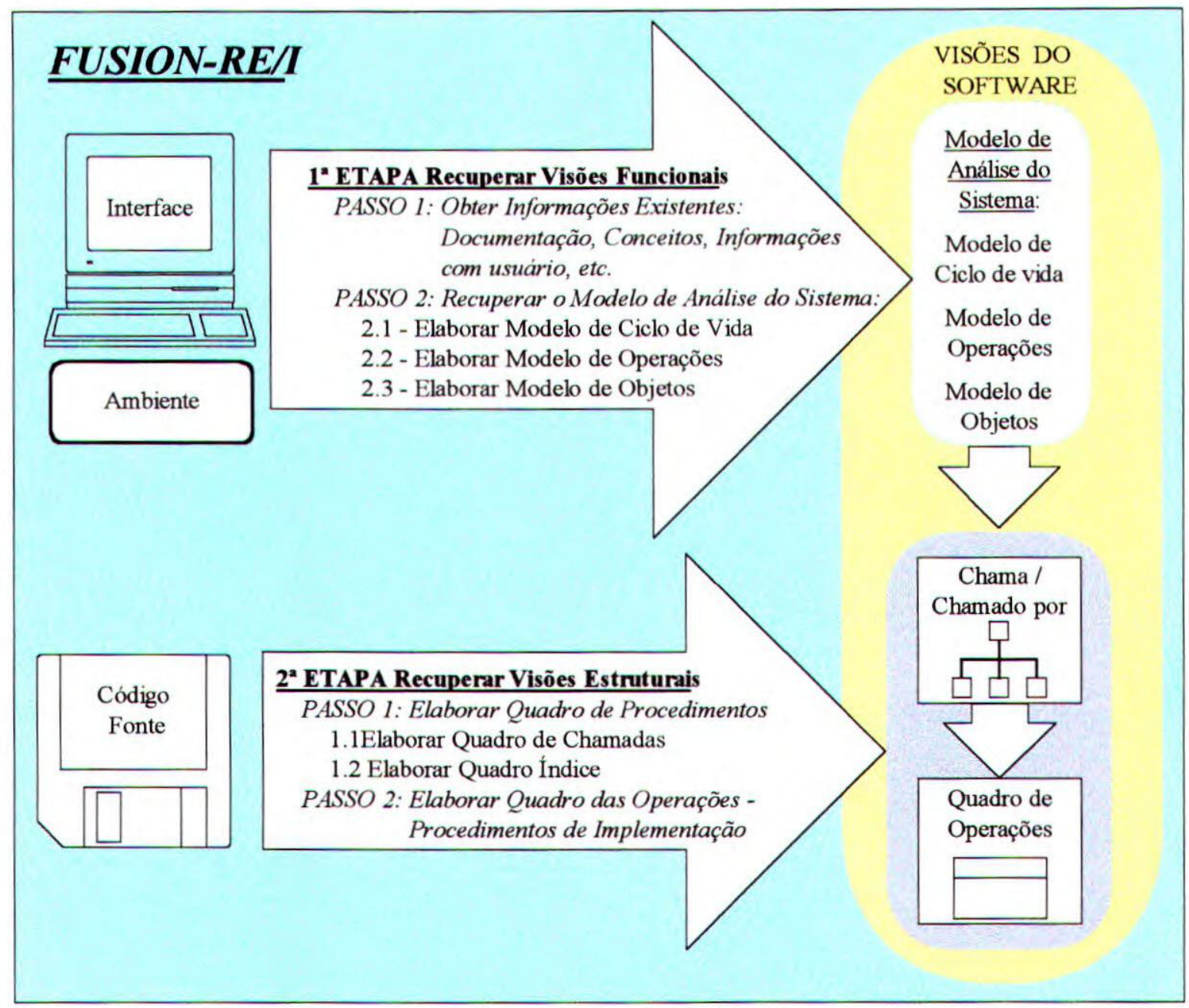

FIG. 3.1 - MÉTODO DE ENGENHARIA REVERSA FUSION-RE/I

\subsection{Recuperação de visões Funcionais do SAPES}

A primeira etapa do método FUSION-RE/l é constituída de 2 passos. No primeiro passo são recuperadas as informações existentes sobre o sistema. No segundo passo, é feita a abstração dos modelos de análise: modelo de ciclo de vida, modelo de operações e modelo de objetos. Estes modelos darão a visão da funcionalidade do sistema.

\subsubsection{Passo 1 - Obter Informações Sobre o SAPES}

As Informações existentes sobre o sistema são obtidas através da coleta de documentação e contatos com os idealizadores/projetistas do sistema. 
A documentação textual existente sobre o sistema é importante para auxiliar a recuperação de visões funcionais, no entanto, no caso do SAPES a documentação, por ser encontrada em diversas versões, não pôde ser considerada.

Os idealizadores, usuários, projetistas e desenvolvedores do sistema fornecem informaçōes complementares que são fundamentais para completar os modelos que representam as visões funcionais, $\Theta$ também podem auxiliar na validação dos modelos elaborados no decorrer do processo de engenharia reversa do sistema. No caso do SAPES, não foi ericontrado ninguém que tenha participado de sua implementação, porém, foram contatadas duas pessoas que participaram do projeto do sistema $e$ as informações fornecidas dizem respeito ao projeto do sistema.

As informaçōes obtidas sobre o deserivolvimento do sistema envolvem o projeto arquitetural, identificando os aspectos de modularização do sistema, a utilização e distribuição dos fontes $e$ dos dados em arquivos, a linguagem de implementação, como também o ambiente onde o sistema é executado. O quadro 3.1 apresenta o conjunto de informaçōes obtidas no passo 1 da primeira etapa do método FUSION-RE/.

\section{Quadro 3.1 - Informações Existentes Sobre o Sistema SAPES}

\begin{tabular}{|c|c|c|c|c|}
\hline \multicolumn{5}{|c|}{ INFORMAÇŌESDEANALISE PROJETO EIMPLEMENTAÇÄODOSAPES } \\
\hline Arquitetura: & \multicolumn{4}{|c|}{$\begin{array}{l}\text { Modular, orientada a função, distribuída em arquivos } \\
\text { fontes. }\end{array}$} \\
\hline Ambiente: & \multicolumn{4}{|c|}{ Sistema operacional DOS. } \\
\hline $\begin{array}{l}\text { Linguagem de } \\
\text { Implementação: }\end{array}$ & \multicolumn{4}{|c|}{$\begin{array}{l}\text { O sistema compõem-se de } 27 \text { programas fontes } \\
\text { desenvolvidos em Clipper, totalizando } 5092 \text { LOC's. }\end{array}$} \\
\hline $\begin{array}{l}\text { Arquivos de } \\
\text { programas fontes } \\
\text { do sistema, em } \\
\text { ordem alfabética: }\end{array}$ & $\begin{array}{l}\text { Alt.prg } \\
\text { Altbib.prg } \\
\text { Altera.prg } \\
\text { Altref.prg } \\
\text { Bibg.prg } \\
\text { Bliog.prg } \\
\text { Consulta.prg }\end{array}$ & $\begin{array}{l}\text { Cria.prg } \\
\text { Elimina.prg } \\
\text { Gerar.prg } \\
\text { Help1.prg } \\
\text { Help2.prg } \\
\text { Help3.prg } \\
\text { lbib.prg }\end{array}$ & $\begin{array}{l}\text { Ibliog.prg } \\
\text { Icpad.prg } \\
\text { Indexar.prg } \\
\text { Insere.prg } \\
\text { Irefbib.prg } \\
\text { Padrao.prg } \\
\text { Passos.prg }\end{array}$ & $\begin{array}{l}\text { Relato.prg } \\
\text { Sapes.prg } \\
\text { Tela.prg } \\
\text { Tratamen.prg } \\
\text { Tripla.prg } \\
\text { Zerar.prg }\end{array}$ \\
\hline $\begin{array}{l}\text { Arquivos de } \\
\text { dados do } \\
\text { sistema: }\end{array}$ & $\begin{array}{l}\text { Batr.dbf } \\
\text { Bibgeral.dbf } \\
\text { Bibliog.dbf }\end{array}$ & $\begin{array}{l}\text { Forr.dbf } \\
\text { Inex.dbf } \\
\text { Natr.dbf }\end{array}$ & $\begin{array}{l}\text { Outr.dbf } \\
\text { Padrao.dbf } \\
\text { Refbib.dbf }\end{array}$ & $\begin{array}{l}\text { Tipo.dbf } \\
\text { Tporario.dbf } \\
\text { Ultimo.dbf }\end{array}$ \\
\hline
\end{tabular}

\subsubsection{Passo 2 - Recuperação dos Modelos de Análise}

Após a obtenção das informações existentes sobre o sistema SAPES, o próximo passo é a recuperação do modelo de análise do sistema. Para representar as visóes obtidas na recuperação, o método FUSION-RE/l utiliza os modelos da fase de análise 
do método de desenvolvimento de software orientado a objeto Fusion [Coleman et al., 1994]: modelo de objetos e modelo de interface (composto por: modelo de ciclo de vida e modelo de operações).

O método de engenharia reversa FUSION-RE/l faz uma inversão na ordem de construção dos modelos proposta pelo método Fusion, elaborando primeiramente o modelo de interface e posteriormente o modelo de objetos. Essa inversão é feita porque o método FUSION-RE/l utiliza a interface do sistema como ponto de início do processo de engenharia reversa.

\subsubsection{1 - ELABORAÇÃO DO MODELO DE INTERFACE}

Interface é o meio que serve para a comunicação entre 0 ambiente $e \quad 0$ computador [Preece, 1994]. O modelo de interface é obtido através da análise de todas as interfaces que o sistema tem com o ambiente, observando o conjunto de operaçōes e eventos de saída gerados.

No caso do sistema SAPES, a interface com o ambiente é composta pelas telas de interação ser humano computador e os relatónios produzidos. Como as informaçōes apresentadas nos relatórios do sistema, são as mesmas apresentadas nas telas de consultas, o modelo de interface é elaborado através da análise dessas telas. As telas do SAPES são totalmente compostas de menus simples, com as opções sendo escolhidas através de números que as representam (exemplo: figura 3.2). O sistema possui grande quantidade de telas (aproximadamente cem telas) de menus para as opçōes de entrada e saída. Todas as telas são monocromáticas.

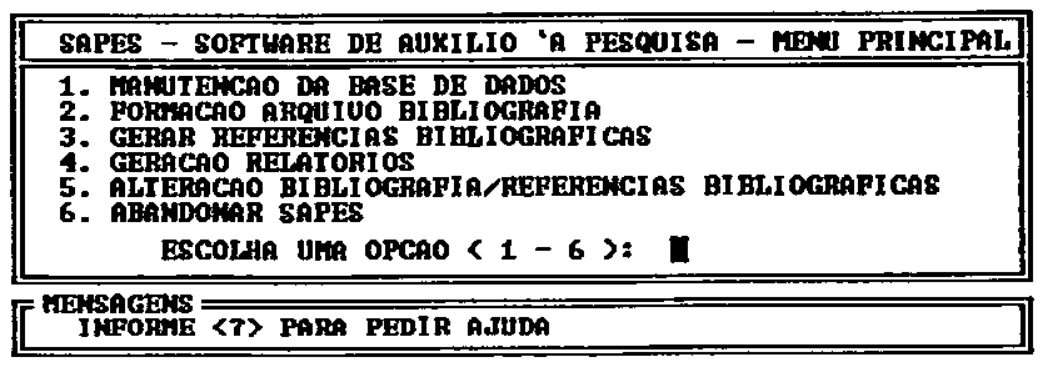

FIG. 3.2 - TELA CORRESPONDENTE AO MENU PRINCIPAL

No método Fusion, o modelo de interfaces modela o comportamento do sistema em termos de eventos e mudanças de estado por eles causados. O Modelo de 
Interfaces utiliza dois modelos para capturar aspectos diferentes do comportamento de um sistema: o Modelo de Ciclo de Vida, que caracteriza as seqüências permissiveis de operações e eventos do sistema, e o Modelo de Operaçőes, que caracteriza o efeito de cada operação individual do sistema em termos da mudança de estado por ela causada e os eventos de saida por ela enviados [Coleman et al., 1994].

Através da análise das telas do sistema SAPES, e do comportamento das operaçōes executadas, elaborou-se os dois modelos que compōem 0 modelo de interface Fusion: o modelo de operações e o modelo de ciclo de vida.

\section{- Modelo de Ciclo de Vida do SAPES}

O objetivo desse modelo é fomecer uma visão global do comportamento do sistema, mostrando como o sistema se comunica com seu ambiente, desde o momento da sua inicialização até o seu término, identificando as seqüências de interações permitidas com o ambiente, através de expressões regulares [Coleman et al., 1994].

O passo 1 do método FUSION-RE/l permitiu um conhecimento inicial do domínio da atividade inerente ao sistema; o conhecimento mais profundo foi possível após a instalação do sistema e diversas utilizaçōes do mesmo.

Do mesmo modo que no trabalho de Costa [Costa, 1997], também neste trabalho adotou-se uma nomenclatura para se referenciar as informaçōes da interface do sistema (figura 3.3).

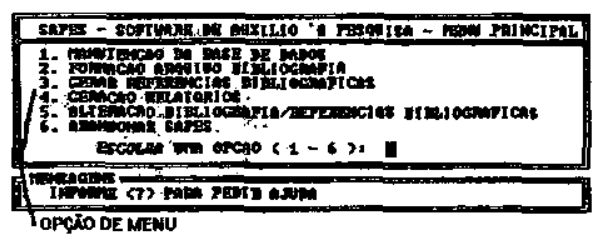

FIG. 3.3 (A) - TELA CORRESPONDENTE AO MENU PRINCIPAL

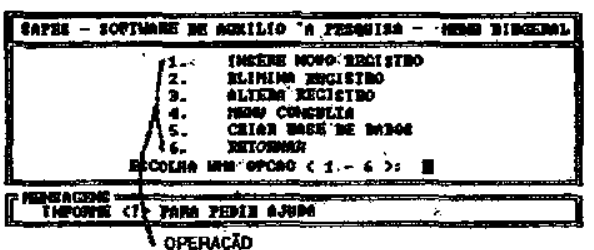

FIG. 3.3 (B) - TELA CORRESPONDENTE À OPÇÃo 1 DO MENU PRINCIPAL

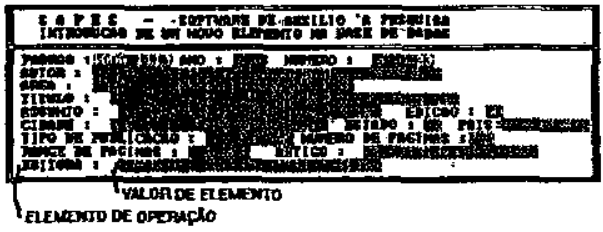

Fig. 3.3 (C) - TELA CORRESPONDENTE À OPERAÇĀo

"INSERE NOVO REGISTRO" DAFIG. 3.3 (B) 
Foram feitos testes variados, fornecendo-se informações corretas e incorretas, na tentativa de verificar o comportamento do sistema, em cada uma das opções de menu. A partir do uso do sistema foi possivel definir as seqüências de operações permitidas e os eventos aceitos (de entrada) e produzidos (de saída) pelo sistema, elaborando-se então o Modelo de Ciclo de Vida para o SAPES.

A expressão principal do modelo de ciclo de vida do sistema SAPES foi formada a partir das seqüências permitidas das opções do menu principal do sistema. A figura 3.4 apresenta o menu principal de opções e a respectiva expressão ciclo de vida elaborada.

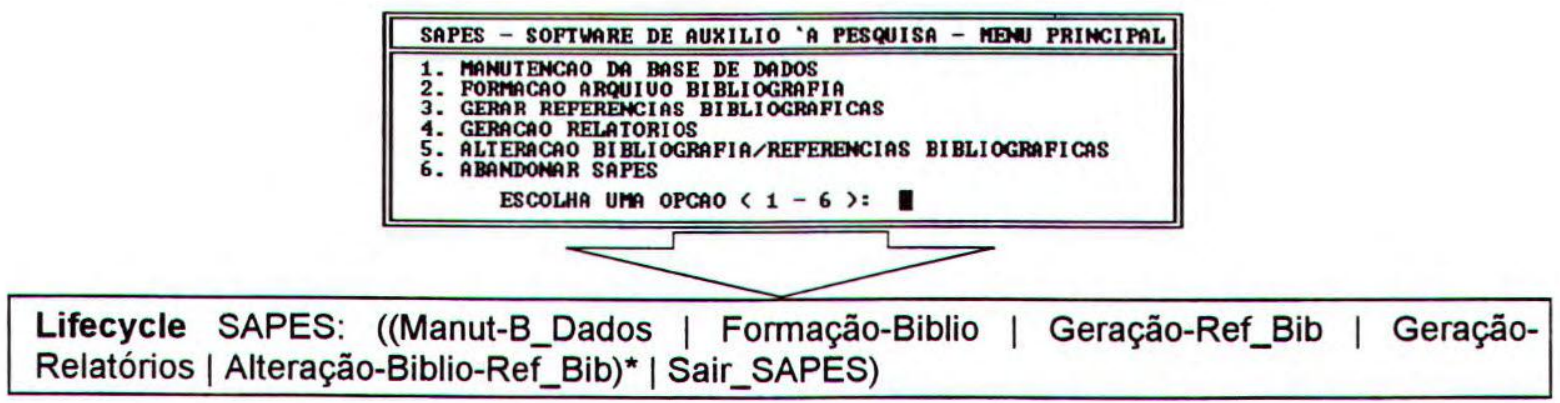

Fig. 3.4 - INTERFACE do Sistema SAPES E A EXPRESSÃo PRINCIPAL DO MODELO DE CICLO dE VIDA DERIVADA

Dando continuidade a elaboração do modelo de ciclo de vida, num nível mais baixo, para cada opção da interface foram identificadas as respectivas operações e então, elaborada a expressão ciclo de vida de segundo nível referente as seqüências permitidas dessas operações. A figura 3.5 apresenta a interface da opção1 (manutenção da base de dados) do menu principal, e o modelo de ciclo de vida elaborado com as expressões principal e de segundo nível para a opção Manutenção da Base de Dados.

Lifecycle SAPES: ((Manut-B_Dados | Formação-Biblio | Geração-Ref_Bib | Geração-Relatórios | Alteração-Biblio-Ref_Bib)* | Sair_SAPES)

Manut-B_Dados $=\left(\right.$ Cria-B_Dados $\mid(\text { Insere } \mid \text { Elimina } \mid \text { Consulta } \mid \text { Altera } \mid \text { Volta_Menu_Princ })^{\star}$

Fig. 3.5 - EXPRESS Ão PRINCIPAL E de SEGUNdo Nível do Modelo de Ciclo de Vida PARA a OpÇão MANUTENÇÃo DA BASE DE DADOS 
Continuando a elaboração do modelo de ciclo de vida, num nível ainda mais baixo, para cada operação identificada na expressão ciclo de vida de segundo nivel, foram identificados os elementos da operação (eventos de entrada) e as possíveis respostas do sistema (eventos de saída) a esses elementos. A partir disso, para cada operação foi elaborada a expressão ciclo de vida referente as seqüências permitidas dos elementos e respectivos eventos de saída.

A figura 3.6 apresenta a interface da operação 1 (insere novo registro), da opção1 (manutenção da base de dados) do menu principal, e o modelo de ciclo de vida elaborado com as expressões principal e de segundo nível para a opção Manutenção da Base de Dados, e de terceiro nivel para a operação Insere Novo Registro.

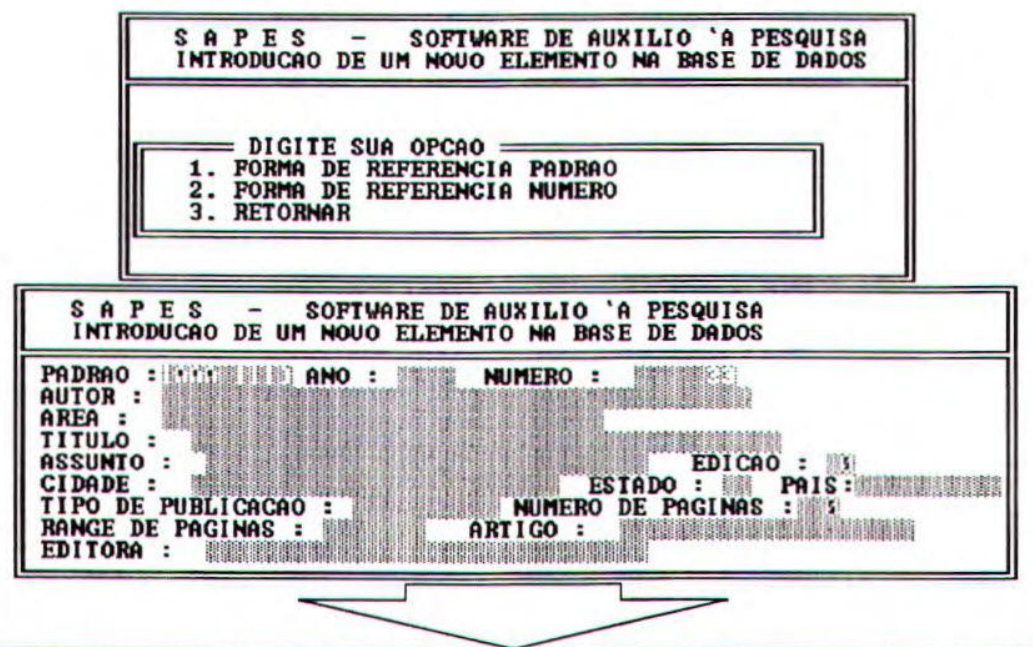

Lifecycle SAPES: ((Manut-B_Dados | Formação-Biblio | Geração-Ref_Bib | GeraçãoRelatórios | Alteração-Biblio-Ref_Bib)* | Sair_SAPES)

Manut-B_Dados $=($ Cria-B_Dados $\mid($ Insere $\mid$ Elimina $\mid$ Consulta $\mid$ Altera $\mid$ Volta_Menu_Princ)*

Insere $=(\text { Opc_Padrão } \mid \text { Opc_Número } \mid \text { Volta_Menu_Manut-B_Dados) })^{*}$

Opc_Padrão $=$ Padrão . (\#Mens_Padrão_Existente $\mid$ Padrão . Ano . Número .

Autor . Área. Subárea. Título. Ėdição. Ássunto . Cidade. Estado . País .

Tipo_Publicação. Número_Páginas . Range_Páginas . Artigo . Editora .

((Ins_Resumo) | Volta_Menu_Insere | Volta_Menu_Manut-B_Dados))

Opc_Número $=$ Número. (\#Mens_Número_Existente $\mid$ Padrão . Ano . Número .

Autor . Área . Subárea. Título. Edição. Assunto . Cidade. Estado . País .

Tipo_Publicação. Número_Páginas. Range_Páginas . Artigo . Editora .

((Ins_Resumo) | Volta_Menu_Insere | Volta_Menu_Manut-B_Dados))

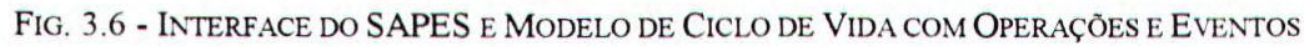

No Apêndice A é apresentado o Modelo completo de Ciclo de Vida do SAPES. 


\section{- Modelo de OPERAÇões do SAPES}

O objetivo do modelo de operaçōes, do método Fusion, é especificar, através de um gabarito textual, o comportamento das operaçōes do sistema, identificadas no modelo de ciclo de vida, definindo seus efeitos em termos de mudanças de estado e eventos gerados [Coleman et al., 1994].

O gabarito textual do modelo de operaçōes é constituido dos itens: Descrição, Lé, Altera, Envia, Assume, e Resulta, os quais especificam detalhadamente a operação.

Através de uma análise criteriosa da execução de cada operação, considerandose não apenas os eventos visíveis na tela, mas também os eventos não visíveis via interface, que são ativados pelas operaçōes do sistema, tais como arquivos modificados e arquivos temporários criados, as informações dos itens do gabarito do modelo de operações săo identificadas.

O modelo de ciclo de vida elaborado no passo anterior $\theta$ todas as informações obtidas no passo 1 (entrevistas com os usuánios e características implementacionais do sistema, programas fontes) são utilizadas na elaboração do modelo de operações.

As expressర̋es do modelo de ciclo de vida possibilitam identificar as operações do sistema e as seqüências permitidas para as mesmas. Essas operações são executadas e através da observação do comportamento do sistema completa-se os campos do gabarito textual do modelo de operaçōes.

A familiandade com o sistema foi enriquecida também com o conhecimento das funcionalidades requeridas do sistema, identificadas através das entrevistas com os usuánios.

As informaçōes dos itens Descrição e Lê são obtidas a partir da observação da interface, identificando-se o conteúdo referente a cada elemento acessado pela operação (eventos de entrada).

As informaçōes dos itens Altera e Envia são obtidas a partir da observação da interface, da observação da execução da operação, identificando-se o valor referente a cada elemento acessado e modificado pela operação. Através da observação dos arquivos de trabalho do sistema (identificados no passo 1 do método) é possivel identificar se determinada operação cria ou modifica arquivos.

As informaçōes do item Assume, são obtidas a partir da observação da interface, da observação dos valores antes e após a execução das operações, do conhecimento 
adquirido da funcionalidade do sistema, identificando-se as pré-condiçōes que a operação necessita para ser executada.

As informaçōes do item Resulta, foram obtidas a partir da observação da irterface, da observaçăo da execução da operação e do conhecimento da funcionalidade do sistema, identificando-se o relacionamento entre o estado iricial do sistema, antes da operação ser ativada, e o estado final, após a execução da operação.

Para o preenchimento dos itens Altera, Envia, Assume e Resulta, do modelo de operaçōes do sistema SAPES, utilizou-se uma ferramenta de visualização de arquivos de dados denominada Browser ${ }^{4}$, a qual permite, com facilidade, obter uma visão do comportamento dos arquivos de dados (poderia ter sido utilizada outra ferramerita qualquer, cujo propósito fosse o mesmo). Essas ferramentas permitem a abertura de um arquivo de dados tal como uma planilha, possibilitarido inclusive que se façam maripulações nos dados armazenados na base. Isso permitiu uma maior flexibilidade nas verificaçōes que foram efetuadas nas operaçōes. A seguir descreve-se 0 procedimento adotado na verificação do comportamento dos arquivos, quarıdo da execução das operações.

\section{PROCEDIMENTO:}

1. Visualizar o diretório que contém os arquivos de dados, através do comarido DIR, com as opções $/ O D$, que permitem ordenar os arquivos por data/hora de atualização. Este procedimento mostra o estado atual dos arquivos de dados:

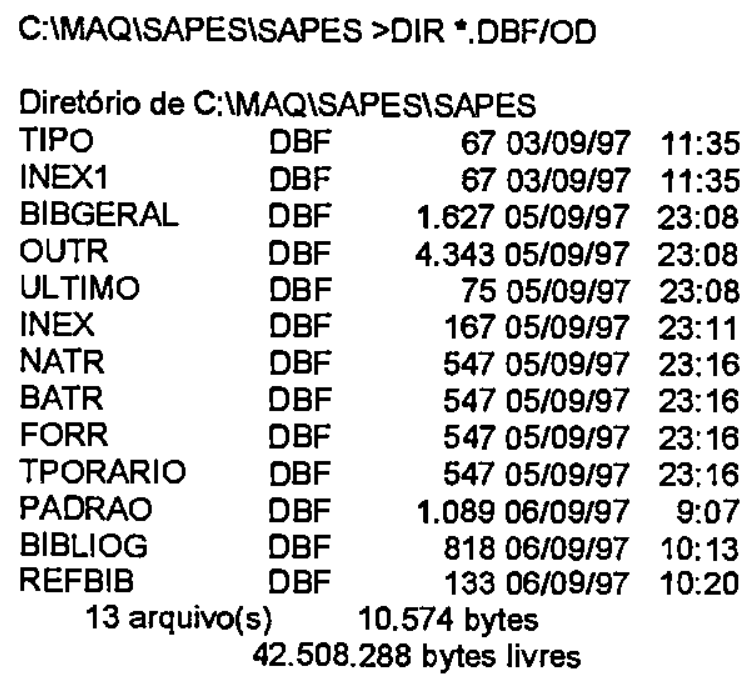

1. Proceder a execução da operação do sistema SAPES que se quer analisar. Como

${ }^{1}$ BroPlus Versão 2.41 - Escrito por Peter Voltz - Copyright C SmartCode Programming 1989-1993 
exemplo executamos uma operação de inserção de um novo item bibliográfico qualquer.

2. Executar o passo 1 novamente e comparar com o estado atual dos arquivos. Com isso pode-se visualizar os arquivos que foram modificados:

C:IMAQISAPESISAPES >DIR *.DBF/OD

Diretório de C:IMAQISAPESISAPES

\begin{tabular}{|c|c|c|c|}
\hline O & DBF & 67 03/09/97 & $11: 3$ \\
\hline INEX1 & DBF & 67 03/09/97 & $11: 35$ \\
\hline INEX & DBF & 167 05/09/97 & 23:11 \\
\hline NATR & DBF & 547 05/09/97 & 23: \\
\hline BATR & DBF & 547 05/09/97 & 23: \\
\hline FORR & DBF & 547 05/09/97 & $23:$ \\
\hline TPORARIO & DBF & 547 05/09/97 & 23: \\
\hline PADRAO & DBF & $1.08906 / 09 / 97$ & 9: \\
\hline BIBLIOG & $\mathrm{DBF}$ & 818 06/09/97 & 10: \\
\hline REFBIB & DBF & $13306 / 09 / 97$ & $10:$ \\
\hline BIBGERAL & DBF & $1.89710 / 04 / 98$ & 10: \\
\hline OUTR & DBF & $5.30810 / 04 / 98$ & $10:$ \\
\hline TIMO & DBF & 75 10/04/98 & 10: \\
\hline & & $\begin{array}{l}11.809 \text { bytes } \\
752 \text { bytes livr }\end{array}$ & \\
\hline
\end{tabular}

Comparando-se os arquivos descritos no passo 1, com os mesmos arquivos do passo 3, percebe-se, através da análise das datas e hora de atualização, que os arquivos BIBGERAL.DBF, OUTR.DBF e ULTIMO.DBF foram alterados. Percebe-se também que não houve a criação ou deleção de nenhum arquivo de dados (Os passos 1 e 3 contêm o mesmo número de arquivos).

3. Utilizar a ferramenta Browser para verificar os arquivos que foram alterados, identificados no passo anterior. A interface da figura 3.7 mostra o arquivo BIBGERAL.DBF aberto com a ferramenta Browser, descrita anteriormente. Pode-se confirmar então o efeito da operação de inserção, executado no passo 2.

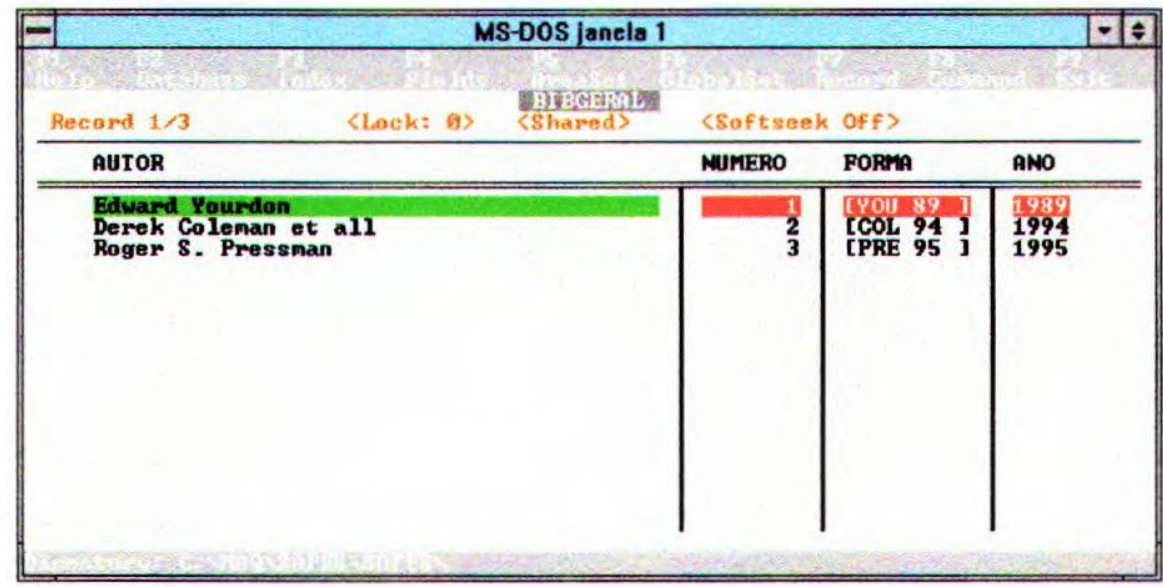

FIG. 3.7 - ARQUIVO BIBGERAL.DBF ABERTO COM A FERRAMENTA BROWSER 
Os passos descritos no procedimento acima foram executados várias vezes para as operações do SAPES, formando a base para o preenchimento dos gabaritos de cada operação do sistema.

A figura 3.8 apresenta a interface do sistema para a operação INSERE, da opção Manut-B_Dados, bem como o respectivo modelo de operações elaborado, seguindo os passos descritos acima.

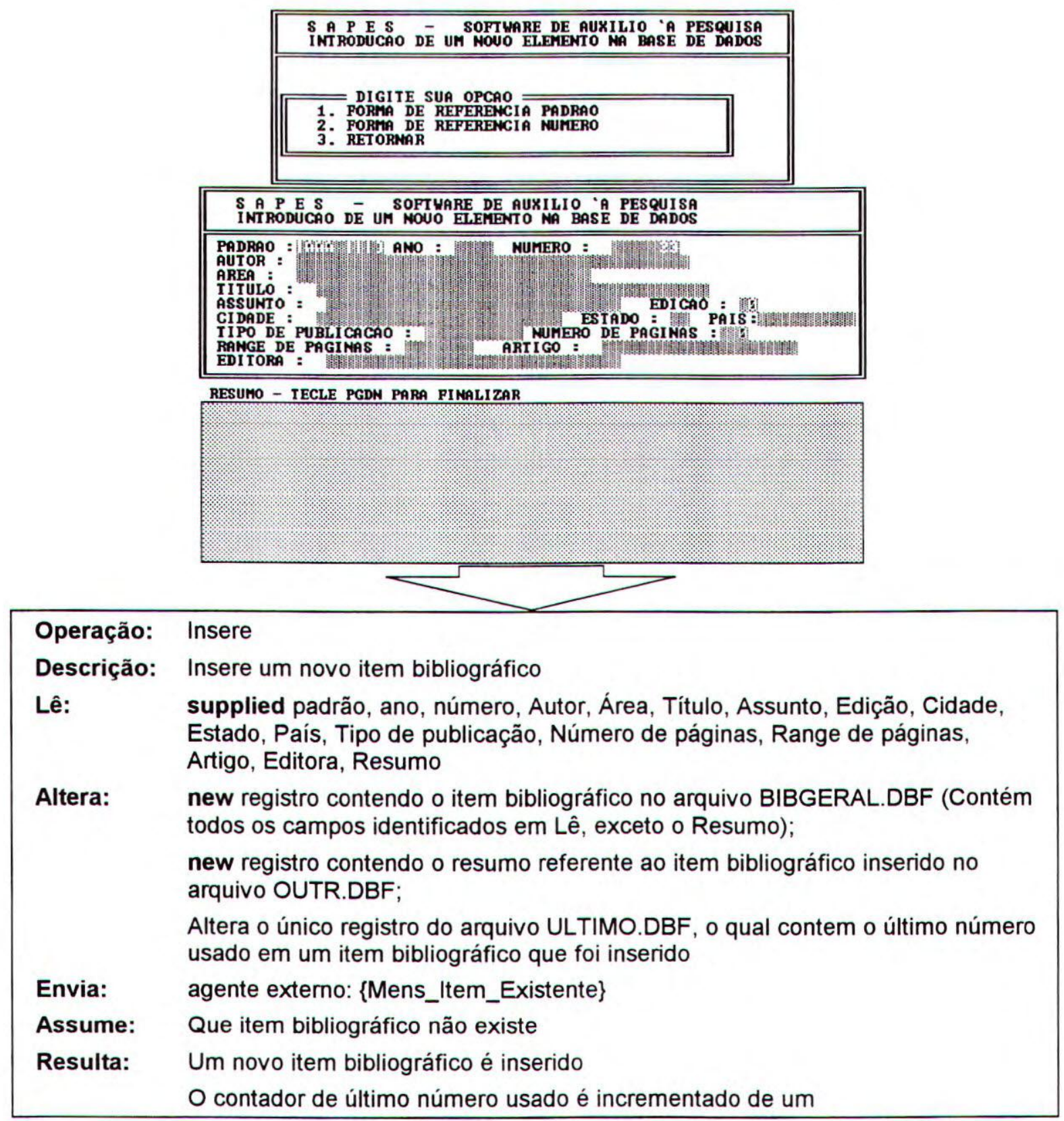

Fig. 3.8 - INTERFACE DA OPERAÇÃo INSERE E O RESPECTIVO MODELO DE OPERAÇÕES 
Durante a elaboração do modelo de operaçōes, verificou-se a existência de alguns equivocos nas seqüências das operaçōes estabelecidas durante a elaboração do modelo de ciclo de vida. Assim, durante a elaboração do modelo de operaçōes, foram efetuadas alteraçōes no modelo de ciclo de vida. Isto possibilitou um aperfeiçoamento dos modelos, através do cruzamento da verificação das operações, quando da execução das operaçōes do sistema SAPES.

No apêndice B é apresentado o modelo completo das operações do SAPES.

\subsubsection{2 - ELABORAÇÃo do MODELO DE OBJETOS}

O objetivo do modelo de objetos do método Fusion é representar os conceitos existentes no domínio do sistema e os relacionamentos entre eles, ou seja, representar a estrutura estática do sistema [Coleman et al., 1994].

Como o modelo de objetos é semelhante ao modelo entidade-relacionamento MER [Coleman et al., 1994] e como sistemas escritos em Clipper geralmente trabalham com tabelas mapeadas a partir do MER, houve a tentativa de se construir o modelo de objetos do sistema SAPES, a partir do modelo entidade-relacionamento. Tentou-se extrair o modelo a partir da observação das tabelas de dados encontradas, porém, como existiam muitas tabelas duplicadas, as quais formavam um subconjunto de uma única tabela (bibgeral.dbf); essa tentativa foi frustrada. Ao se considerar apenas a tabela bibgeral.dbf, a modelagem também ficou comprometida por não ser esta tabela normalizada.

Sendo assim, para a elaboração do modelo de objetos aplicou-se o que é sugerido no método FUSION-RE/l. Primeiramente é indicado, para a elaboração do modelo de objetos, que se defina, primeiramente, assuntos com os quais a funcionalidade do sistema se relaciona. $O$ objetivo da definição de assuntos é identificar diferentes niveis de abstração da funcionalidade do sistema e os possiveis agrupamentos de operaçōes de um mesmo assunto. Seguindo a nomenclatura do método FUSION-RE [Penteado, 1996], esses assuntos são denominados Temas.

Uma maneira de se identificar os temas relacionados ao SAPES, foi através da criação de uma tabela (quadro 3.2) contendo todas as operaçöes identificadas no modelo de ciclo de vida e especificadas no modelo de operaçöes do SAPES, procurando-se associar essas operações aos diferentes aspectos do domínio do problema. Esses aspectos, possiveis candidatos a temas, podem ser identificados 
primeiramente considerando-se os objetos envolvidos nas operações da expressão de primeiro nivel do modelo de ciclo de vida (figura 3.4 ).

Quadro 3.2 - Operações e aspectos do domínio do problema do SAPES

\begin{tabular}{|c|c|c|c|c|}
\hline \begin{tabular}{|rr} 
Operações (descrição) & Aspectos do domínio do \\
problema
\end{tabular} & $\begin{array}{l}\text { Base } \\
\text { Dados }\end{array}$ & $\begin{array}{l}\text { Biblio- } \\
\text { grafia }\end{array}$ & $\begin{array}{l}\text { Refer. } \\
\text { Bibliog. }\end{array}$ & $\begin{array}{l}\text { Rela- } \\
\text { tórios }\end{array}$ \\
\hline $\begin{array}{l}\text { - Insere um novo item bibliográfico na B.Dados } \\
\text { - Elimina um item bibliográfico existente na B.Dados } \\
\text { - Altera um item bibliográfico existente na B.D. } \\
\text { - Apaga todos os itens bibliográficos existentes na B. } \\
\text { Dados } \\
\text { - Consulta um item bibliográfico cadastrado na B. Dados }\end{array}$ & & & & \\
\hline $\begin{array}{l}\text { - Inclui item bibliográfico na Bibliografia } \\
\text { - Apaga todos os itens bibliográficos da Bibliografia } \\
\text { - Altera um item bibliográfico na Bibliografia }\end{array}$ & & & & \\
\hline $\begin{array}{l}\text { - Gera os arquivos de Referências Bibliográficas e } \\
\text { Referências Inexistentes } \\
\text { - Altera uma Referência Bibliográfica } \\
\text { - Insere Referência Bibliográfica } \\
\end{array}$ & & & & \\
\hline $\begin{array}{l}\text { - Imprime os itens bibliográficos existentes na B.Dados } \\
\text { - Imprime os itens bibliográficos da Bibliografia } \\
\text { - Imprime Referência Bibliográfica } \\
\text { - Imprime Referência Inexistente } \\
\text { - Cria Ficha Técnica para um item bibliográfico existente } \\
\text { na B. Dados } \\
\text { - Imprime a Ficha Técnica criada }\end{array}$ & & & & \\
\hline
\end{tabular}

Ao analisar-se os aspectos do dominio do problema juntamente com as operações verificou-se que os aspectos Base Dados, Bibliografia e Referência Bibliográfica poderiam constituir temas. Entretanto o aspecto do domínio do problema Relatório não deveria constituir um tema, pois todas as operações a ele associadas, exceto criação e impressão de ficha técnica, estavam relacionadas aos aspectos de domínio já identificados. Assim os temas definidos foram: Base Dados, Bibliografia, Referência Bibliográfica e Ficha Técnica. O quadro 3.3 mostra as operações do sistema, relacionadas com seus respectivos temas identificados. 
Quadro 3.3 - Operaçōes e temas do SAPES

\begin{tabular}{|c|c|c|c|c|}
\hline 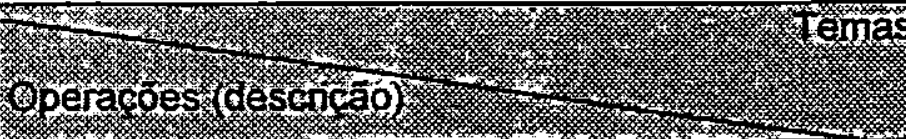 & Dad & Silong & Refer & Hencos \\
\hline $\begin{array}{l}\text { - Insere um novo item bibliográfico na B.Dados } \\
\text { - Elimina um item bibliográfico existente na B.Dados } \\
\text { - Altera um item bibliográfico existente na B.D. } \\
\text { - Apaga todos os itens bibliográficos existentes na B. } \\
\text { Dados } \\
\text { - Consulta um item bibliográfico cadastrado na B. } \\
\text { Dados } \\
\text { - Imprime os itens bibliográficos existentes na B.Dados }\end{array}$ & 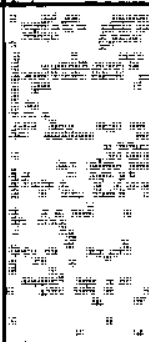 & & & \\
\hline $\begin{array}{l}\text { - Inclui item bibliográfico na Bibliografia } \\
\text { - Apaga todos os itens bibliográficos da Bibliografia } \\
\text { - Altera um item bibliográfico na Bibliografia } \\
\text { - Imprime os itens bibliográficos da Bibiiografia }\end{array}$ & & 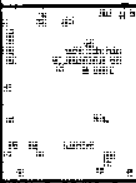 & & \\
\hline $\begin{array}{l}\text { - Gera os arquivos de Referências Bibilográficas e } \\
\text { - Referências Inexistentes } \\
\text { - Altera uma Referência Bibliográfica } \\
\text { - Insere Referência Bibliográfica } \\
\text { - Imprime Referência Bibilográfica } \\
\text { - Imprime Referência Inexistente } \\
\end{array}$ & & & 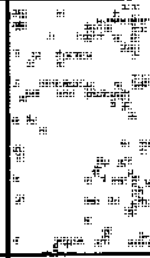 & \\
\hline $\begin{array}{l}\text { - Cria Ficha Técnica para um item bibliográfico } \\
\text { existente na B. Dados } \\
\text { - Imprime a Ficha Técnica criada }\end{array}$ & & & & \\
\hline
\end{tabular}

Definidos os temas, parte-se para a elaboração dos respectivos modelos de objetos.

Segundo o método FUSION-RE/l [Costa, 1997]:

- Para a elaboração do modelo de objetos, todas as operaçöes referentes aos temas devem ser novamente analisadas, agora com outro ponto de vista, buscando-se identificar componentes que constituem o modelo de objetos (para isso é necessário identificar classes, relacionamentos entre classes, atributos de classes e de relacionamentos e possíveis agregações, especializações e generalizações [Coleman et al., 1994]). A análise inicia-se em um alto nivel de abstração, sendo que os detalhes são inseridos somente depois que a estrutura geral for considerada satisfatória.

- Define-se como classe, cada elemento de cada operação que possui ideritificação única e os arquivos criados pela execução de uma operação (conforme identificado no modelo de operações).

- Para a definição de relacionamentos, busca-se identificar em cada operação, elementos que sejam associações ou correspondências entre as classes 
consideradas.

- Para a definição de atributos, de cada classe e de cada relacionamento, buscase identificar em cada operação, elementos que sejam valores dessas classes ou valores desses relacionamentos.

- Para a definição de agregação, busca-se identificar uma estrutura de composição entre as classes identificadas.

- Para a definição de generalização, busca-se identificar entre as classes definidas, as classes (supertipos) que sejam formadas pela fatoração de propriedades comuns de várias classes (subtipos). Para a definição de especialização, busca-se identificar entre as classes subtipos, as classes que sejam uma versão mais especializada das classes supertipos.

Para complementar a definição dos componentes dos modelos de objetos, além da identificação dos elementos de cada operação, constantes no modelo de operações, deve-se buscar também identificar componentes advindos da abstração e do entendimento da funcionalidade de cada elemento e de cada operação.

\section{- Modelo de Objetos dos Temas}

Para a criação do modelo de objetos do tema Base de Dados (quadro 3.3) examinou-se 0 gabarito textual das operaçס̋es (figuras B1 a B5 do Apêndice B) envolvidas com o tema.

Analisando-se os gabaritos foram identificados:

- Como Classes, os arquivos BIBGERAL.DBF, OUTR.DBF, ULTIMO.DBF, BATR.DBF, NATR.DBF e FORR.DBF. Foram considerados também como classe, o relatório produzido - REL_BASE_DADOS - e o USUÁRIO; este último participa como agente do ambiente do sistema.

- Visto que cada item bibliográfico, armazenado no arquivo BIBGERAL.DBF, contem um único resumo, armazenado no arquivo OUTR.DBF; O Relacionamento Coritem liga as classes BIBGERAL e OUTR. Há o relacionamento Mantém que liga o USUÁRIO à BASE_DADOS. Outro relacionamento denominado Possui, liga a BASE_DADOS ao ULTIMO. BIBGERAL também recria as três classes: BATR, NATR e FORR, através do relacionamento Recria. BATR, NATR, FORR, juntamente com OUTR geram o 
REL_BASE_DADOS, mostrado no relacionamento Geram.

- Os atributos de cada classe são os mesmos atributos (campos) dos respectivos arquivos. Tem-se então para as classes BIBGERAL, BATR, NATR e FORR os atributos: Padrão, Ano, Número, Autor, Área, Título, Assunto, Edição, Cidade, Estado, País, Tipo de publicação, Número de páginas, Range de páginas, Artigo e Editora; e para a classe OUTR, os atributos: Padrão, Número, Linha1, Linha2,..,Linha12.

- Como as classes BIBGERAL e OUTR compóem a base de dados, foi identificada como uma agregação, a qual denominou-se BASE_DADOS.

A figura 3.9 mostra o modelo de objetos elaborado para o tema Base de Dados. Para os demais temas, os modelos de objetos foram criados segundo as mesmas diretrizes, e esses modelos são mostrados nas figuras 3.10 a 3.12 .

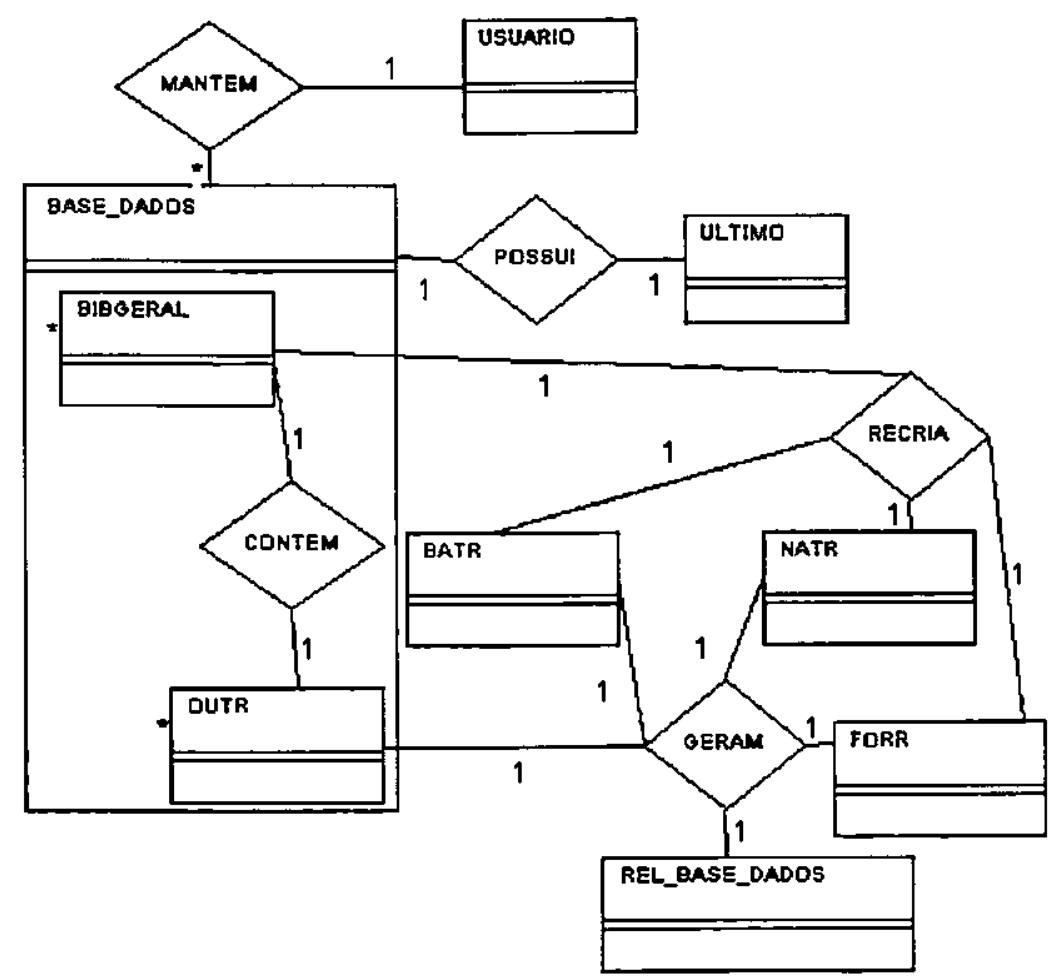

Fig. 3.9 - Modelo de ObJetos Para o Tema Base de Dados 


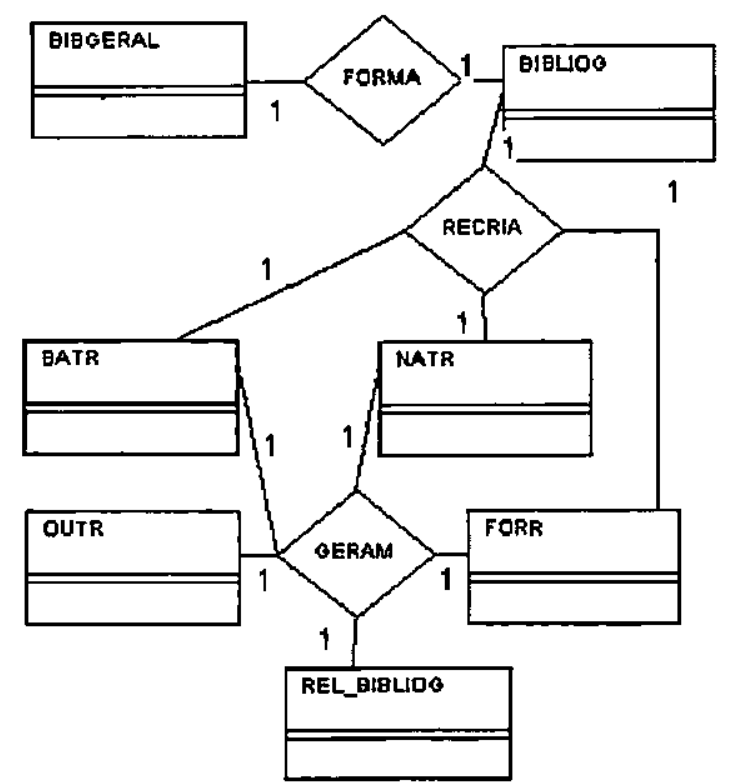

Fig. 3.10 - Modelo de ObJetos Para o Tema Bibliografia

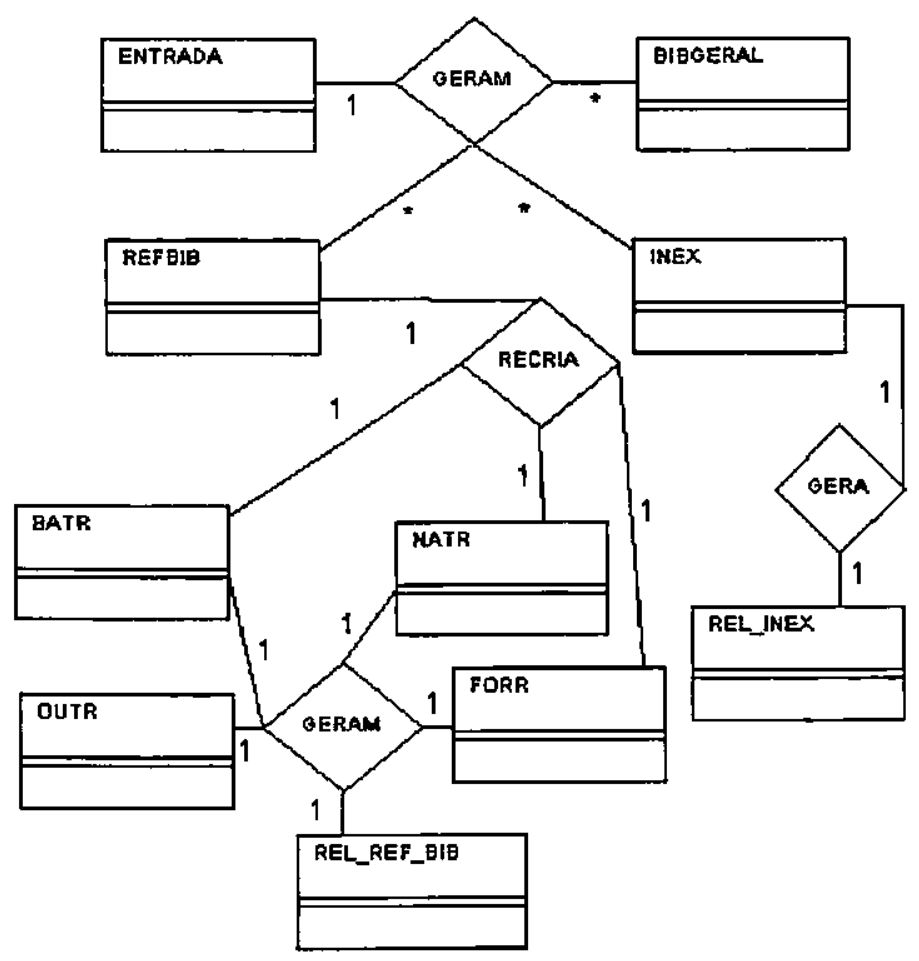

Fig. 3.11 - MOdELO de OBJetos PARA O TEMA REFERENCIA BIBLIOGRÁfICA 


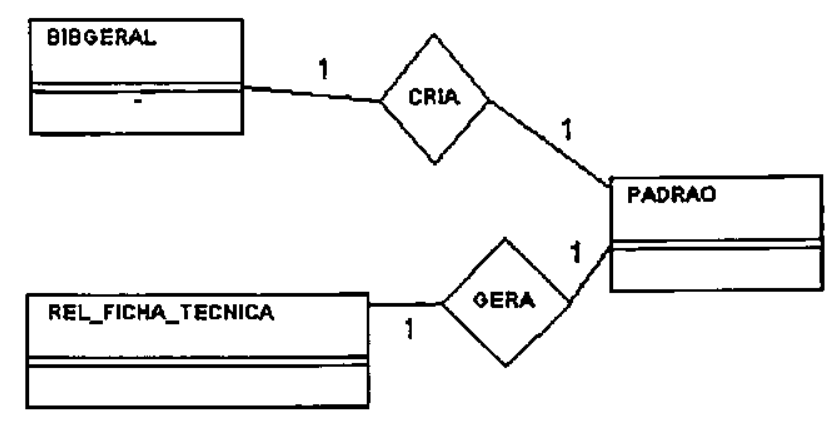

FIg. 3.12 - MOdelo de ObJetos PARA O TEMA FICHA TÉCNICA

\subsection{Consideraçóes Finais}

Apresentou-se neste capítulo a aplicação do método FUSION-REI de engenharia reversa efetuada no sistema SAPES, extraindo-se os modelos de ciclo de vida, de operações e de objetos, os quais serão utilizados na reconstrução do SAPES. 


\section{Capítulo 4}

\section{ENGENHARIA PROGRESSIVA do SISTEMA SAPES}

\subsection{Consideraçōes Iniciais}

Nesse capítulo, apresentam-se as etapas do processo de engenharia progressiva efetuado no sistema SAPES. O método Fusion [Coleman et al., 1994] e a ferramenta FusionCASE' foram usados nessa etapa da reconstrução sistema SAPES.

\subsection{Análise Crítica aos Modelos de Objetos Produzidos pela Engenharia Reversa}

- Críticas ao modelo de objetos do tema Base de Dados:

A classe ULTIMO é desnecessária, por guardar unicamente o último registro de item bibliográfico inserido. Isto pode ser implementado como uma operação que varre a

1 FusionCASE é uma ferramenta desenvolvida pela empresa SoftCASE Consulting Ltd. (www.softcase.com), especializada em ferramentas e desenvolvimento personalizado de soluções CASE para empresas. 
base de dados e descobre, rapidamente, quem é o último registro, não necessitando de um arquivo para guardar essa informaçăo. Além disso, o sistema de armazenagem é falho, pois quando se efetua deleçōes na base de dados, os "buracos" não são aproveitados, pois sempre é tomado o último registro armazenado.

As classes BATR, NATR E FORR são totalmente desnecessárias, visto que os objetivos de cada uma dessas classes é armazenar os dados da base de dados, temporariamente, respectivamente nas ordens de autor, número e forma padrăo. Tais ordenaçōes podem ser facilmente implementadas via comandos de linguagem que efetuam as ordenaçōes de maneira mais rápida e sem duplicar os dados armazenados.

Cada item bibliográfico armazenado na classe BIBGERAL tem um correspondente resumo, armazenado na classe OUTR. Assim, essa classe $e$, na verdade, um atributo da classe BIBGERAL, e deveria ser implementado como tal, diminuindo e facilitando a implementação das operaçöes do sistema.

- Críticas ao modelo de objetos do tema Bibliografia:

Do mesmo modo que o tema Base de Dados, o tema Bibliografia contém as classes BATR, NATR e FORR, totalmente desnecessánas, sendo que sua finalidade pode ser substituída por comandos da linguagem de implementaçäo, para efetuar as ordenações necessánas e produzir os relatónios nas ordens desejadas.

A classe BIBLIOG é totalmente desnecessária porque é apenas um subconjunto da base de dados, e, portanto não necessita estar em classe diferente. Pode ser obtida com operaçōes simples de seleção da base de dados.

- Críticas ao modelo de objetos do tema Referência Bibliográfica:

Assim como os temas Base de Dados e Bibliografia, o tema Referència Bibliográfica contém as classes BATR, NATR e FORR, totalmente desnecessánas, sendo que sua finalidade pode ser substituída por comandos da linguagem de implementação, para efetuar as ordenaçōes necessárias e produzir os relatónios nas ordens desejadas.

A forma de identificação de cada registro, para ambas as classes REFB|B e INEX são as mesmas, ou seja, pela forma como foram referenciadas no documento de pesquisa (classe ENTRADA). A única diferença é que a classe INEX só contém a referência, e a classe REFBIB contém, além da referência, todos os atributos da classe BIBGERAL. Assim as duas classes poderiam ser resumidas em uma só, diferenciadas apenas pela utilização dos atributos da classe. 
Percebeu-se nas abstrações orientadas a objeto produzidas pela etapa de engenharia reversa sobre o sistema antigo, orientado a funçäo, a geração de algumas classes e relacionamentos desnecessários, vistos da ótica da orientação a objeto. Portanto, o modelo reconstruido diferenciou-se em vários pontos do modelo anterior.

\subsection{Reconstruçăo do Modelo de Objetos do SAPES}

A partir da análise crítica feita sobre a modelagem abstraída do sistema, da análise do documento de especificaçăo de requisitos [Turine, 1996] proposto pelos idealizadores do sistema, e do conhecimento sobre o sistema SAPES adquinido durante a fase de Engenharia Reversa, relatada no capítulo anterior, foi possivel remodelar o SAPES, conferindo-Ihe uma forma orientada a objeto. A figura 4.1 mostra o novo modelo de objetos para o sistema SAPES.

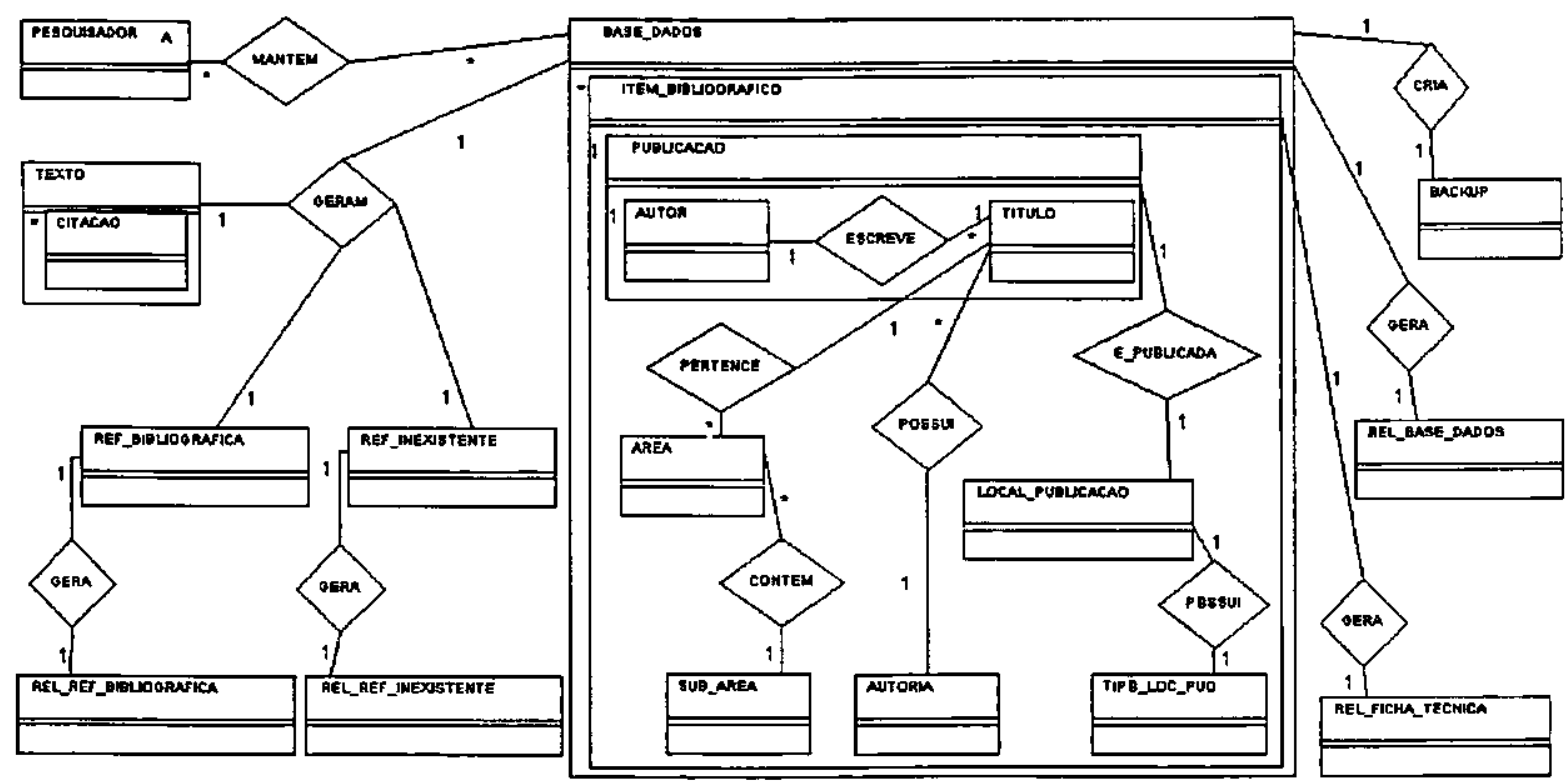

FIG. 4.1 - MODELO DE OBJETOS DO SISTEMA SAPES Novo

\subsection{Reconstrução do SAPES Orientado a Objeto}

Para a reconstrução do sistema SAPES utilizou-se o método de desenvolvimento orientado a objeto Fusion, aplicado sobre as informações obtidas com a execução da engenharia reversa sobre o SAPES orientado a função, elaborada no capítulo anterior. O método foi utilizado tendo como apoio a ferramenta FusionCASE, a qual suporta todas as fases do método Fusion. 


\subsubsection{O Método Fusion e a Ferramenta FusionCASE}

O método Fusion, desenvolvido por Coleman et al., apresenta uma abordagem sistemática para o processo de desenvolvimento de software orientado a objeto, abrangendo as fases de análise, projeto e implementação. O método é constituído de um conjunto de notações definidas para a captura das decisões de análise e de projeto. A fase de análise gera um conjunto de modelos os quais fomecem uma descrição declarativa sobre o comportamento esperado do sistema. Os modelos de análise estabelecem restriçōes de alto nivel, a partir das quais os modelos de projeto serão desenvolvidos. A fase de projeto gera um conjunto de modelos que representam o comportamento do sistema na forma de uma coleção de objetos que interagem entre si. A fase de implementação mostra como mapear os modelos do projeto em construçōes da linguagem de implementação.

A figura 4.2 mostra um mapa geral do método e apresenta as dependências entre os modelos produzidos.

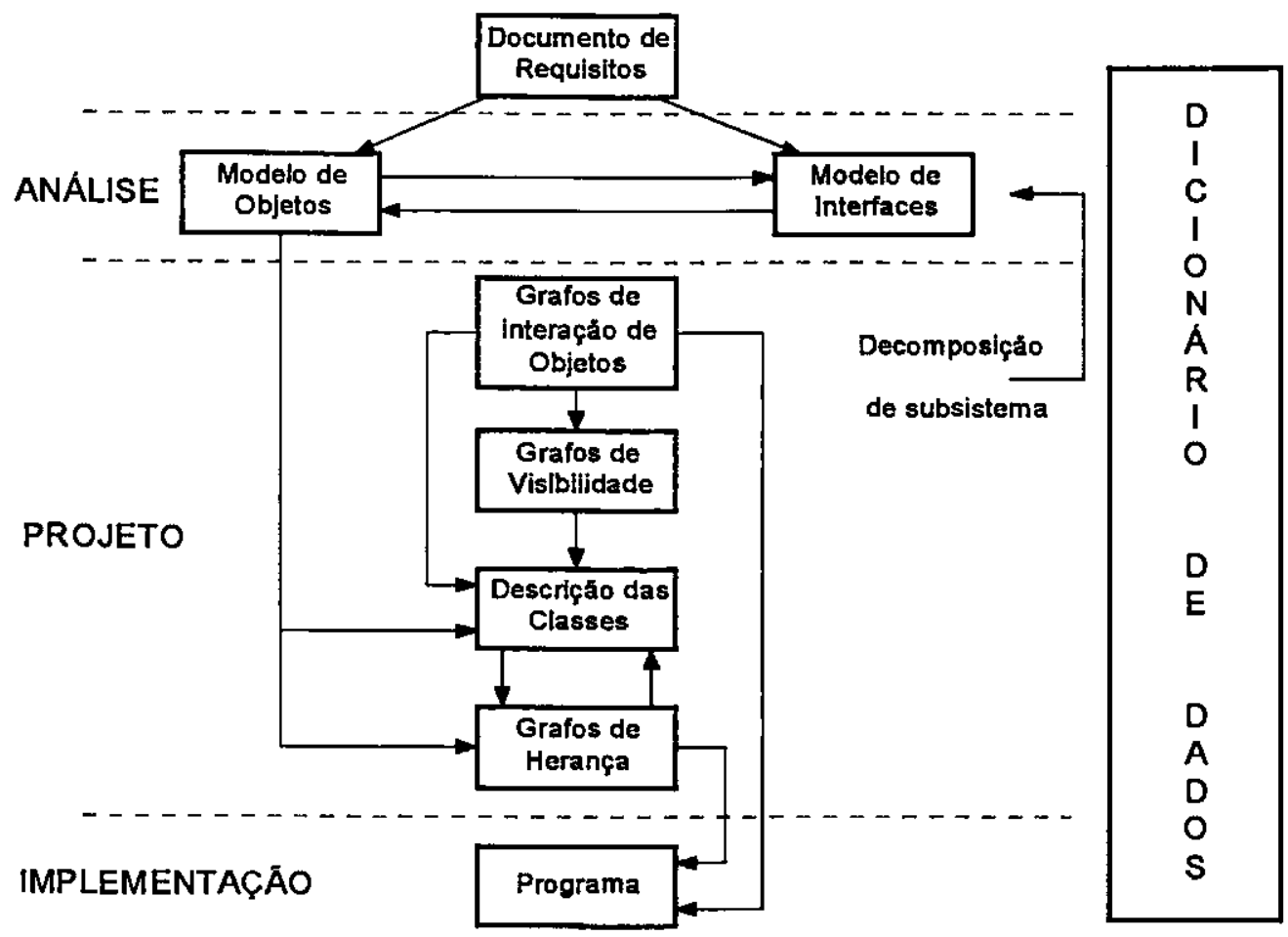

Fig. 4.2 - VISÃo GERAL do MÉTOdo FUSION [COLEMAN ET AL., 1994]

A ferramenta FusionCASE, versão 1.4, desenvolvida pela empresa SoftCASE Consulting Ltd., fornece suporte para todas as fases do método Fusion. Na fase de análise, possibilita a criação dos modelos: Modelos de Objetos, Modelo de Ciclo-deVida, Modelos de Operações-Análise e Diagrama de Contexto do Slstema. Na fase de 
projeto, é possivel criar, com a ferramenta, os modelos: Grafos de Interação de Objetos, Modelo de Operações-Projeto, Grafos de Visibilidade, Grafos de Herança e Descrição das Classes.

As figuras 4.3 e 4.4 mostram algumas telas de interação da ferramenta FusionCASE. O apêndice $C$ mostra alguns modelos do SAPES produzidos com o apoio da ferramenta FusionCASE.

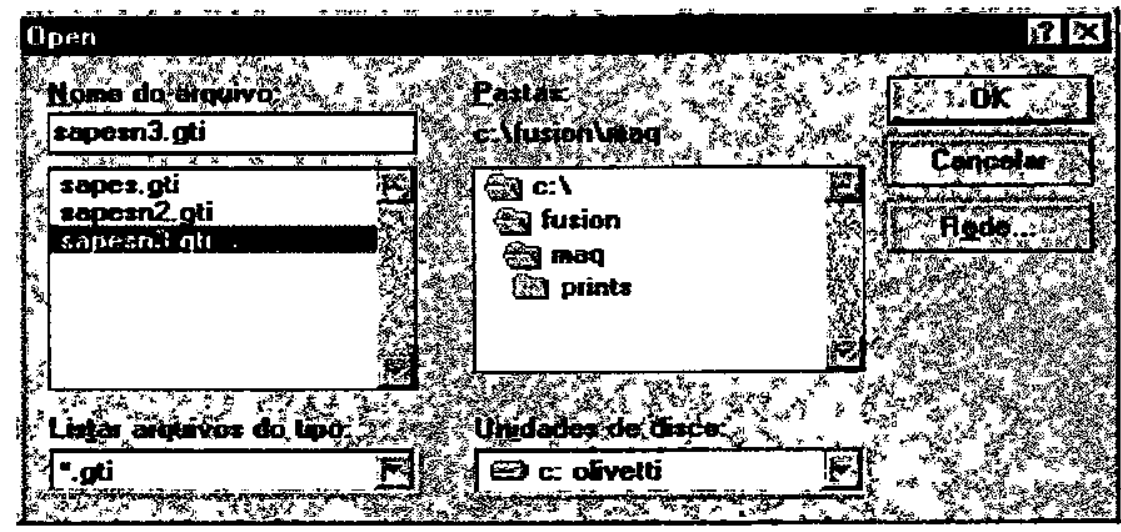

FIg. 4.3 - MENU DE ENTRADA DA FERRAMENTA FUSIONCASE

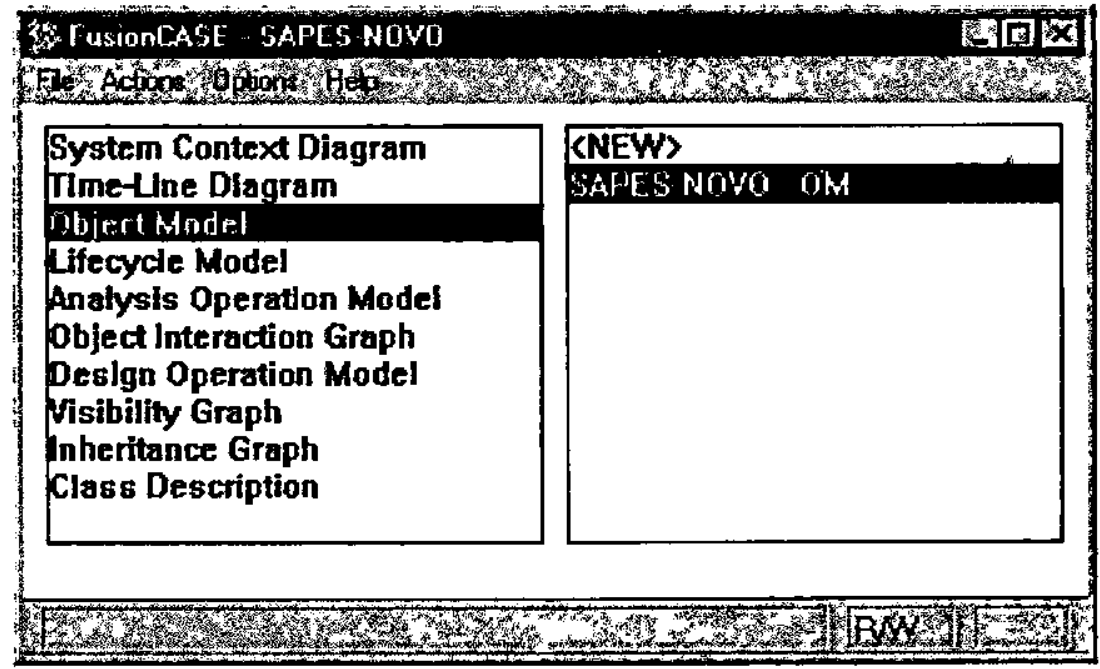

FIg. 4.4 - MENU PRINCIPAL dA FUSIONCASE

\subsubsection{Elaboração do Modelo de Interface}

O modelo de interface foi reconstruido, procurando-se mapear para as operaçōes individuais, a funcionalidade declarada no documento de especificação de requisitos [Turine, 1996]. Após uma análise crítica aos modelos de ciclo de vida e do modelo de 
operaçōes do SAPES oriertado a função (Apêndice $A$ e B), obtidos pela engenharia reversa, procurou-se reconstruir o novo modelo de interface do sistema, retirarido-se as discrepâncias contidas nos modelos obtido a partir do sistema orientado a função e ajustando-os para melhor refletirem a funcionalidade desejada do sistema novo. As alterações efetuadas no modelo de objetos, vistas na seção 4.3 , também se refletiram em ajustes no modelo de interface do novo sistema SAPES.

\section{MOdelo de CiClo de VidA}

O modelo de ciclo de vida obtido no processo de engenharia reversa foi estruturado de acordo com as operações constantes da interface, como também para a estrutura de arquivos que existia no SAPES onientado a função. Por exemplo, a expressão ciclo de vida Alteração-Biblio-Ref_Bib, deixou de existir por não ser mais necessária a sua inclusão no sistema. O modelo de ciclo de vida atual é baseado na funcionalidade requerida para o sistema refletindo as seqüências possíveis para as operações do sistema. A figura 4.5 mostra o modelo de ciclo de vida.

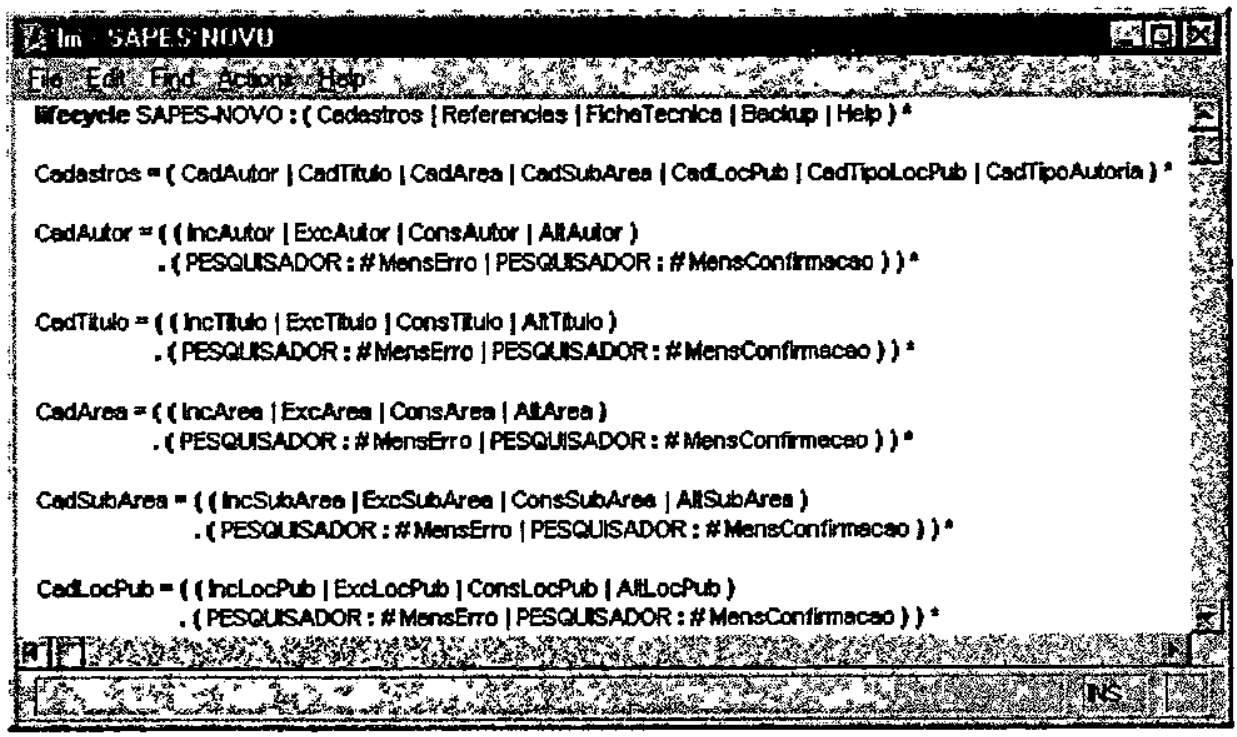

FIG. 4.5 - EDIÇÃo dO MODELO DE CICLO DE VIDA

\section{MOdELO DE OPERAÇÕES}

Da mesma forma que o modelo de ciclo de vida, o modelo de operações do novo SAPES reflete as operaçōes que são necessárias para implementar a furıcionalidade do sistema. As operaçōes que deixaram de ser necessánas, ou aquelas que realmente 
tiveram que ser incluídas, assim o foram, no novo modelo de operações do sistema. Cada operação do sistema orientado a função foram examinadas, por exemplo, a operação Insere do SAPES orientado a função foi abandonada porque foi elaborada para inserir um item bibliográfico que continha autor, título, área e local de publicação juntos. No sistema novo, as classes são individualizadas, portanto as operações foram separadas. A figura 4.6 mostra o modelo de operaçőes para a operação Consultar Título.

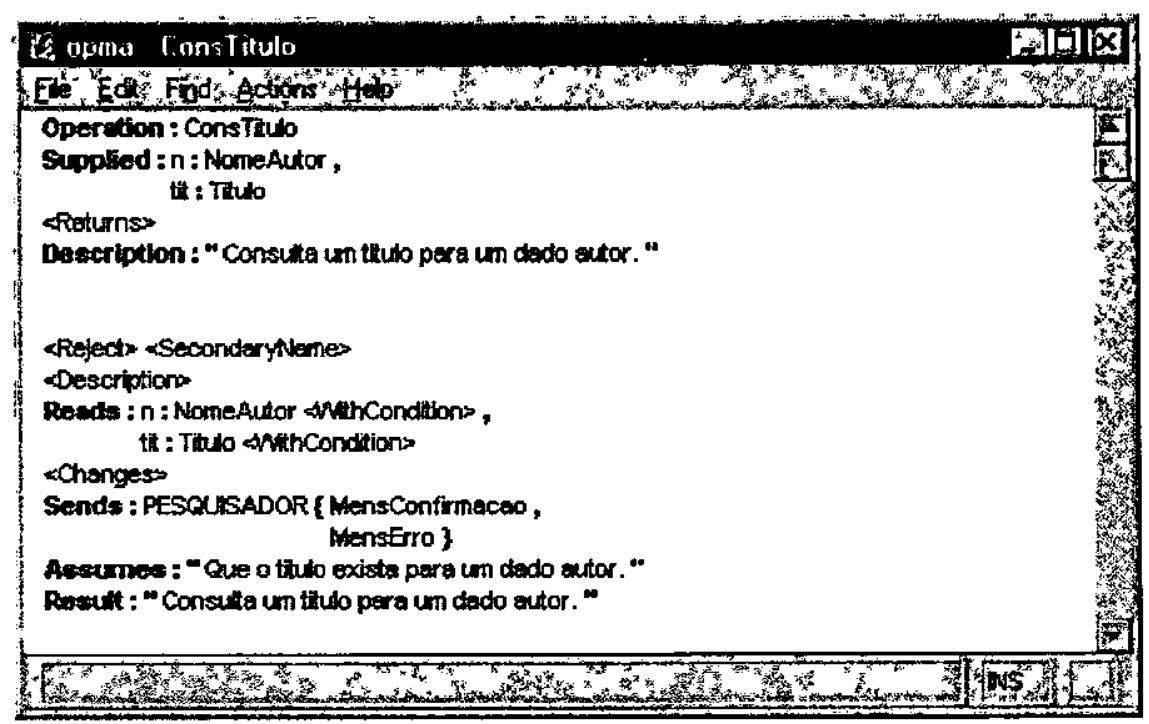

Fig. 4.6 - Ediçāo do Modelo da Operação Consultar Título

\subsubsection{Elaboração dos Modelos de Projeto do Sistema SAPES}

A fase de projeto, segundo o método Fusion, gera modelos que mostram como as operações do sistema, definidas de forma abstratas no modelo de operações da fase de análise, serão implementadas através de interações entre os objetos, e como as classes, definidas no modelo de objetos também da fase de análise, farão referências uma a outra. Os modelos de projeto do método Fusion utilizados foram: Grafos de Interação de Objetos, Grafos de Visibilidade e as Descrições das Classes. O método Fusion apóia a utilização de dicionários de dados para guardar todos as classes, relacionamentos, atributos, métodos, etc. pertencentes ao sistema; esses dicionários serão utilizados constantemente para dirimir dúvidas sobre os termos utilizados. 


\section{- GRAFos de INTERAÇÃo de OBJetos}

Os Grafos de Interação de Objetos fornecem uma representação visual para a estrutura dos algoritmos; são elaborados para cada operação definida para o sistema no modelo de operações da fase de análise. Cada grafo define a estrutura que viabiliza a troca de mensagens que ocorrem entre os objetos de um determinado grupo, quando realizam uma operação em particular, durante a execução do sistema, para que seja suportada a funcionalidade especificada no modelo de operações. A figura 4.7 mostra o grafo de interação de objetos para a operaçāo Consultar Título.

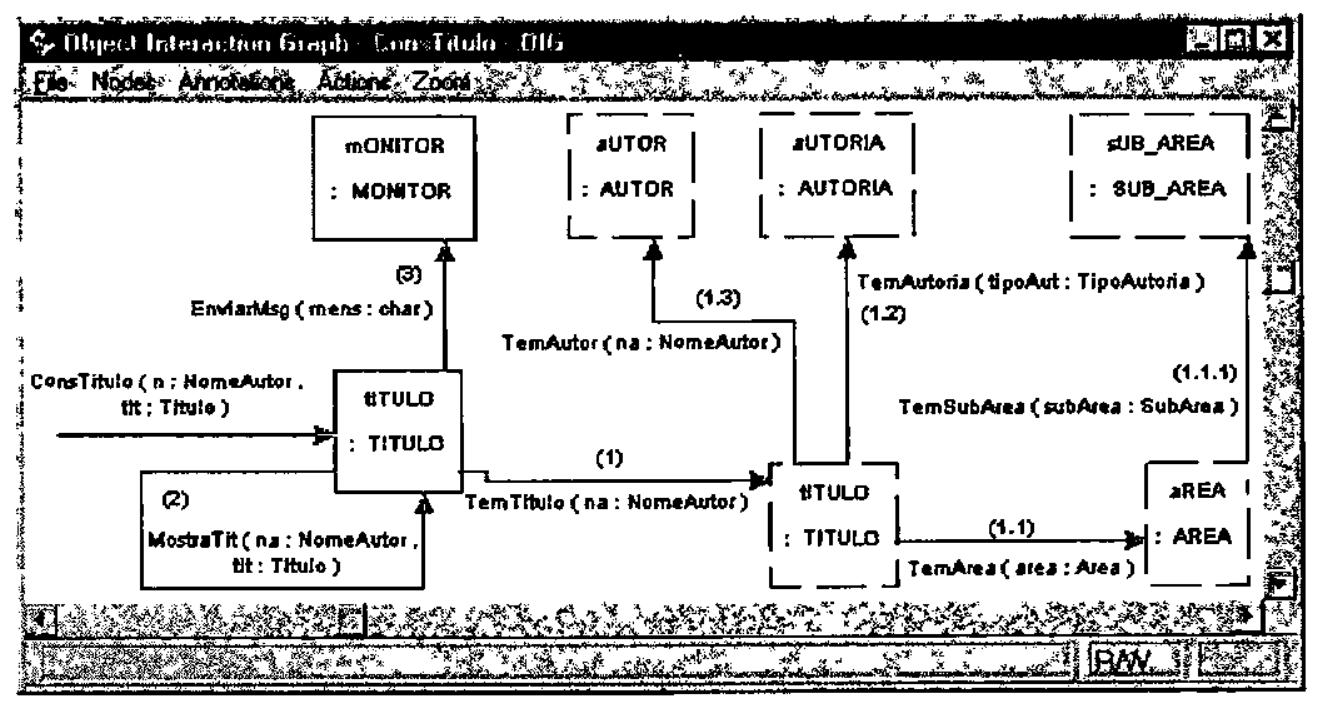

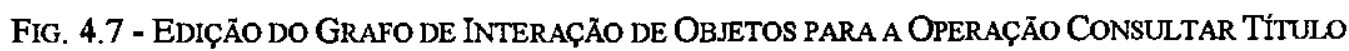

\section{- Grafos de VISIBILIDADE}

A segunda fase do processo de projeto será decidir como as classes se visualizam. Os Grafos de Visibilidade elaborados para cada classe, definida no modelo de objetos da fase de análise, descrevem as estruturas de referências existentes entre as classes do sistema. São identificados, nessa fase, os objetos para os quais as instâncias das classes fazem referências e o tipo apropriado de referência para esses objetos. A figura 4.8 mostra o grafo de visibilidade para a classe autor. 


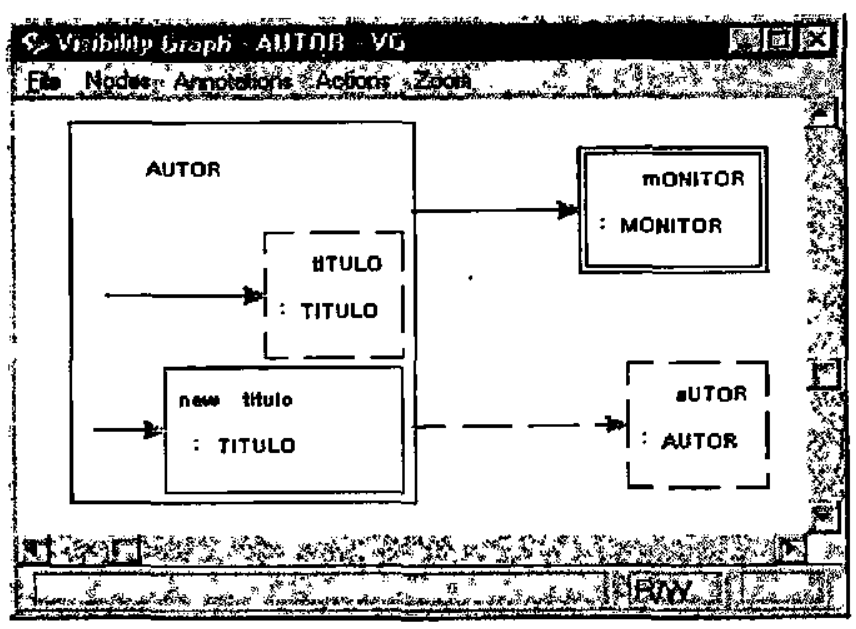

Fig. 4.8 Edição do Grafo de VisibILIdade Para A Classe Autor

\section{- Descriçóes das Classes}

O passo seguinte aos grafos de visibilidade é a descrição das classes do sistema. Essa descrição é elaborada a partir de informações do modelo de objetos, dos grafos de interação de objetos, e dos grafos de visibilidade. Săo estabelecidos, para cada classe, os métodos, e os atributos. As descrição das classes fornecem os fundamentos para a implernentação. A ferramenta FusionCASE fornece automaticamente, a partir dos modelos definidos anteriormente, a descriçăo de cada classe definida para o sistema. A figura 4.9 mostra a descrição da classe Titulo.

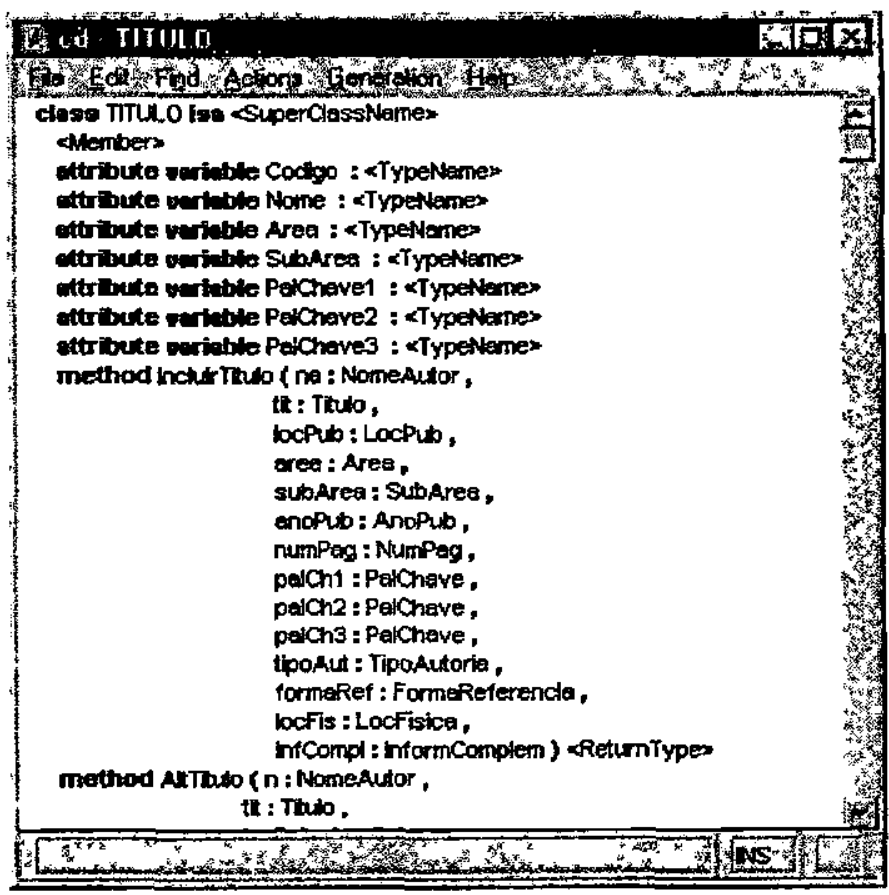

FIG. 4.9 - EdiçÃo dA DEscrição da Classe Título 


\section{- DICIONÁRIO dE DADOS}

O método Fusion orienta para a utilização de dicionário de dados (figura 4.2), como repositório único onde se encontra as definições para todos os itens descritos tanto na fase de análise como na fase de projeto, servindo esse dicionário como fonte para consulta em qualquer fase do processo. As figuras 4.10 e 4.11 mostram exemplos extraídos do dicionáno de dados para Classes e Operações, utilizados no sistema SAPES.

\begin{tabular}{|c|c|}
\hline Class Nams & Description \\
\hline AREA & Area a que pertence um determinado título. \\
\hline AUTOR & Autor ds tatulos. \\
\hline AUTORLA & Tipo de autoria para um tftulo. \\
\hline BACKUP & Segurança da bass de dados. \\
\hline BASE_DADOS & Base geral do sistsma. \\
\hline CITACAO & Uma citsçáo presente em um arquivo texto. \\
\hline TEM_B\&BUOGRAFICO & Agragaçáo de todos os dados que compöam a base ds dados. \\
\hline LOCAL_PUBLCACAO & Local onde uma publicą̧ấo foi faita. \\
\hline PESQUISADOR & Usuásio do sistema SAPES. \\
\hline
\end{tabular}

FIG. 4.10 - EDIÇĀo DO DICIONÁRIO PARA DADOS PARA CLASSES DO SAPES

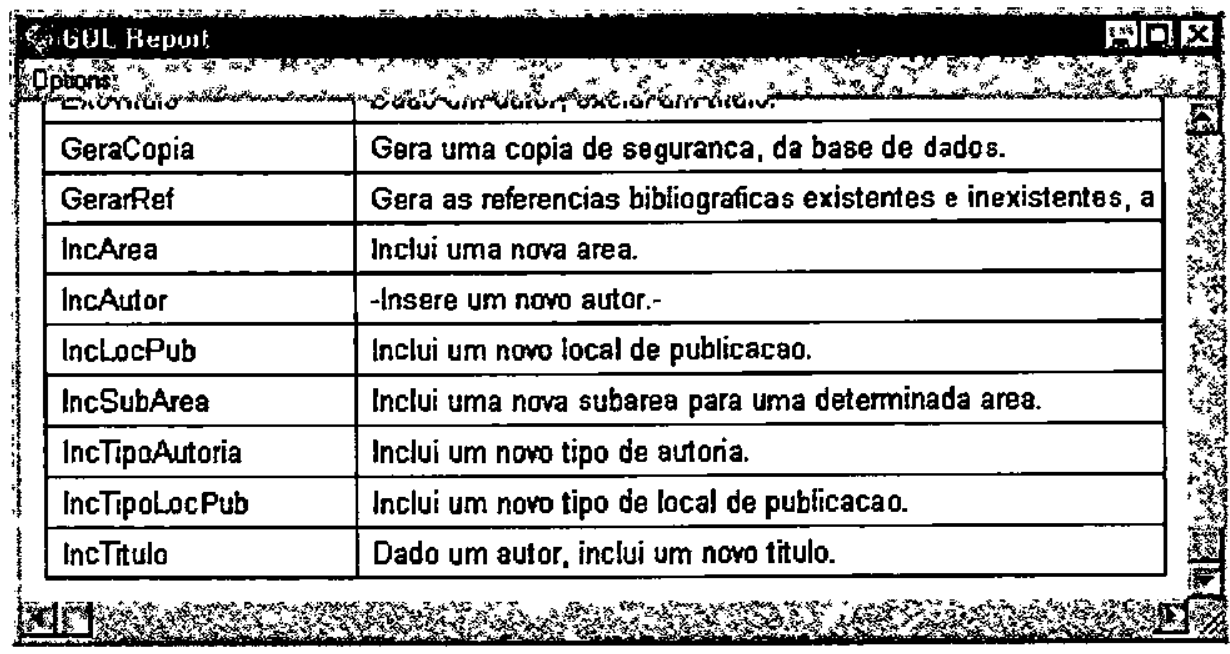

FIG. 4.11 - EdIÇÃo do DiCIONÁRIO dE DADOS PARA OPERAÇÕES do SAPES

\subsubsection{Implementação do Sistema SAPES}

A fase de implementação foi executada, em uma linguagem de programação que suporta a orientação a objeto. No caso do SAPES, foi utilizada a linguagem Delphi, 
versão 2.0. As descrições de classes, os grafos de interação de objetos e os dicionários de dados elaborados nas etapas de análise e projeto são agora utilizados para implementar o sistema. A seguir são descritas algumas classes, extraídas dos programas fontes em Delphi.

\section{- EXEMPLO de CLASSES do SAPES IMPLEMENTADAS EM DELPHI:}

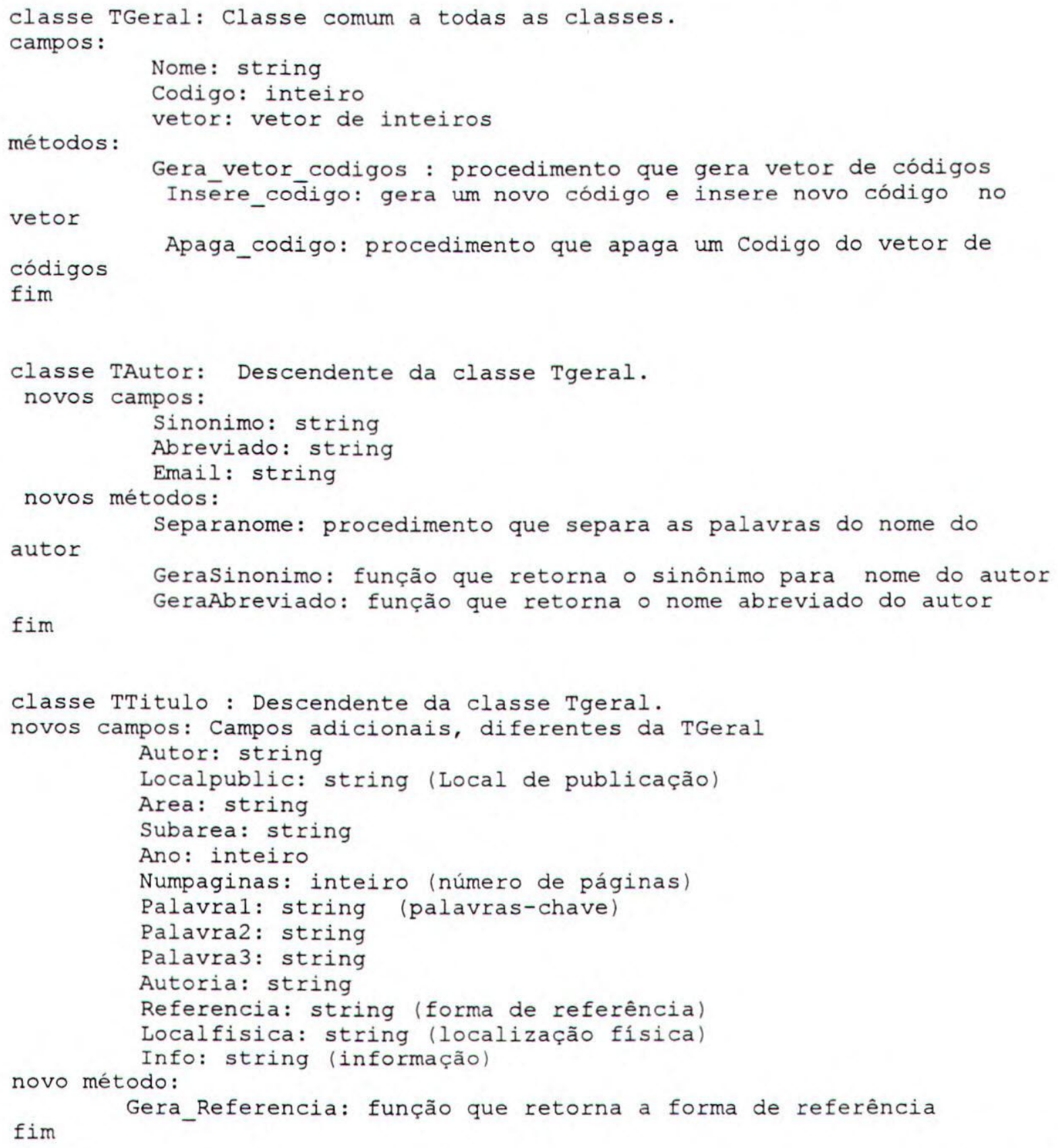

As figuras $4.12,4.13,4.14$ e 4.15 descrevem algumas partes da interface do sistema SAPES novo. 


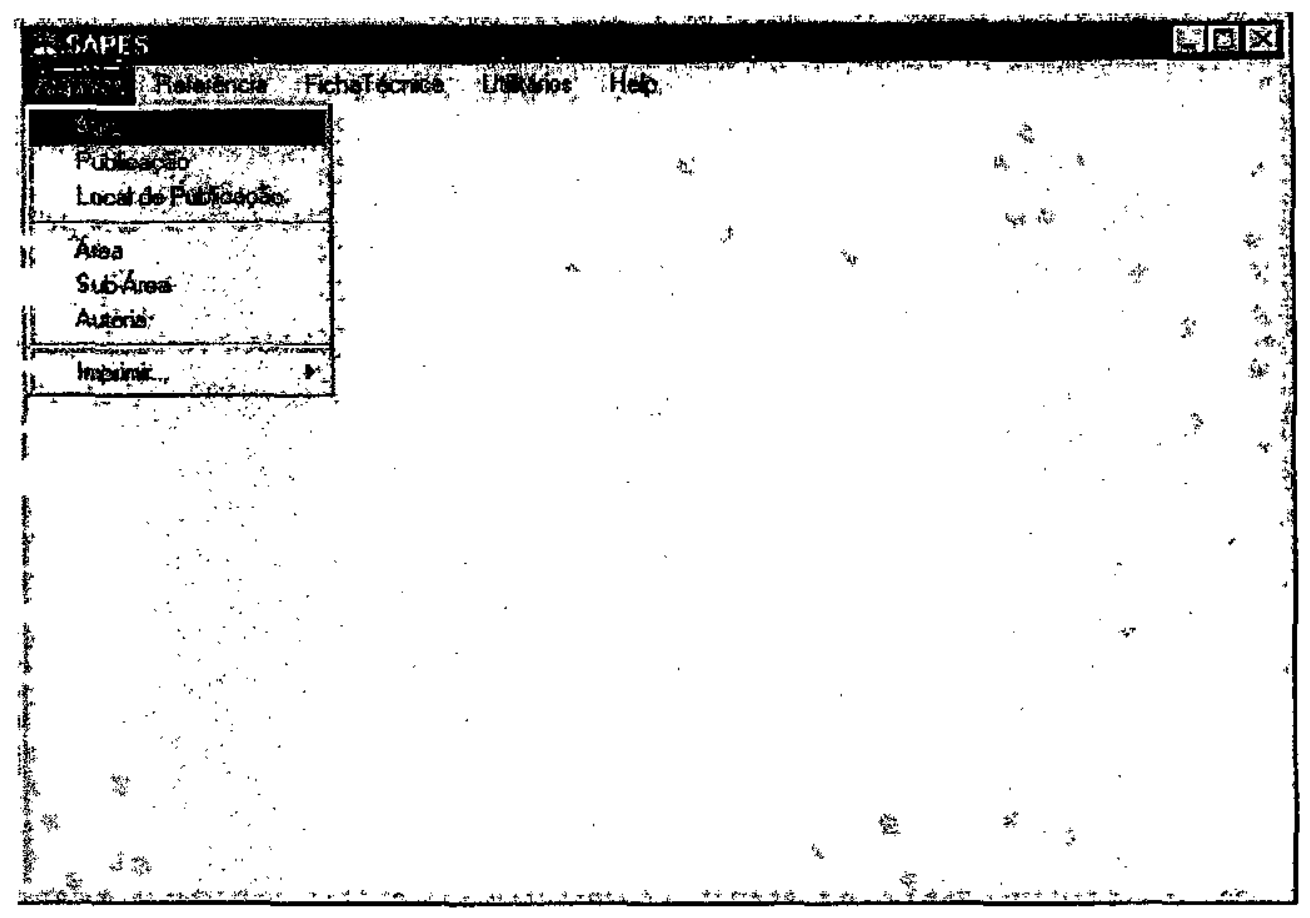

FIG. 4.12 - INTERfACE PRINCIPAL, COM MENU "PULLDOWN" PARA ARQUIVOS

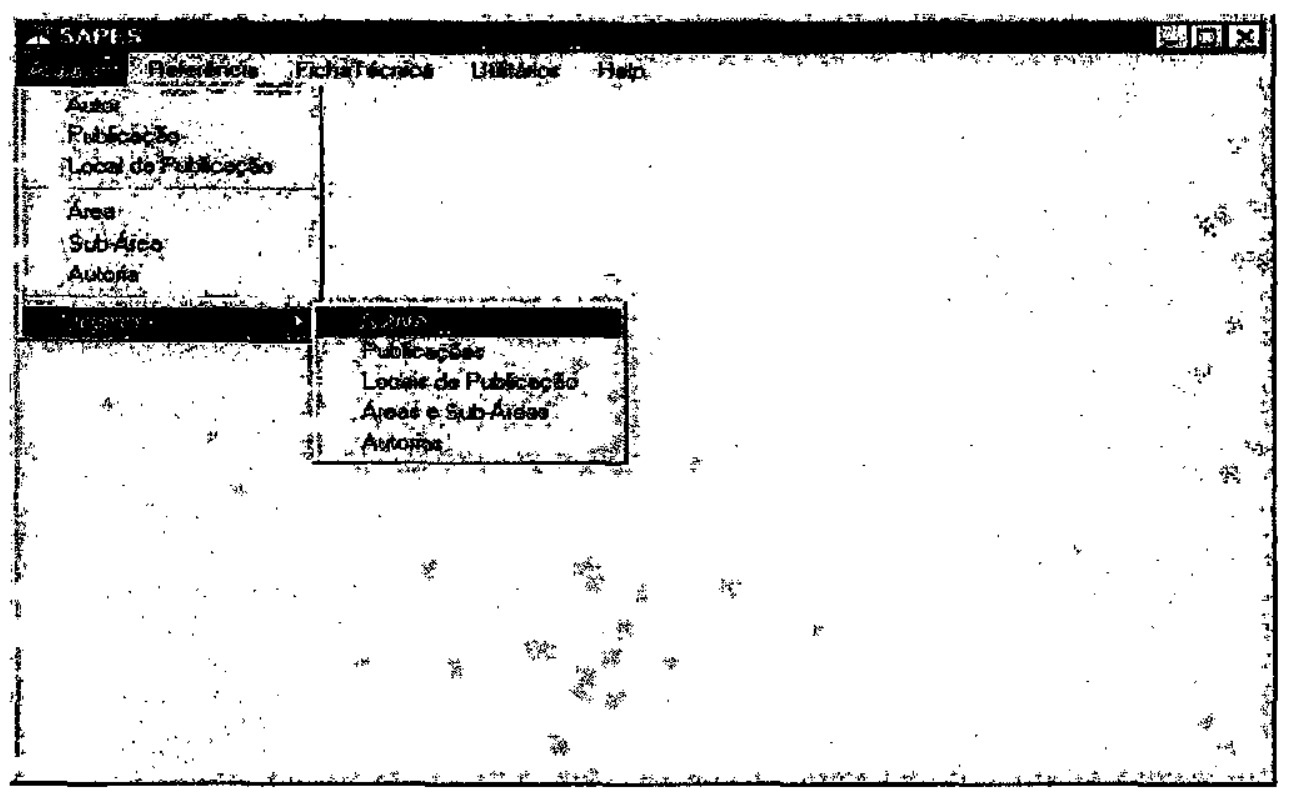

FIG. 4.13 - INTERFACE PRINCIPAL, COM MENU "PULLDOWN" PARA ARQUTVOS E SUBMENU IMPRIMIR 


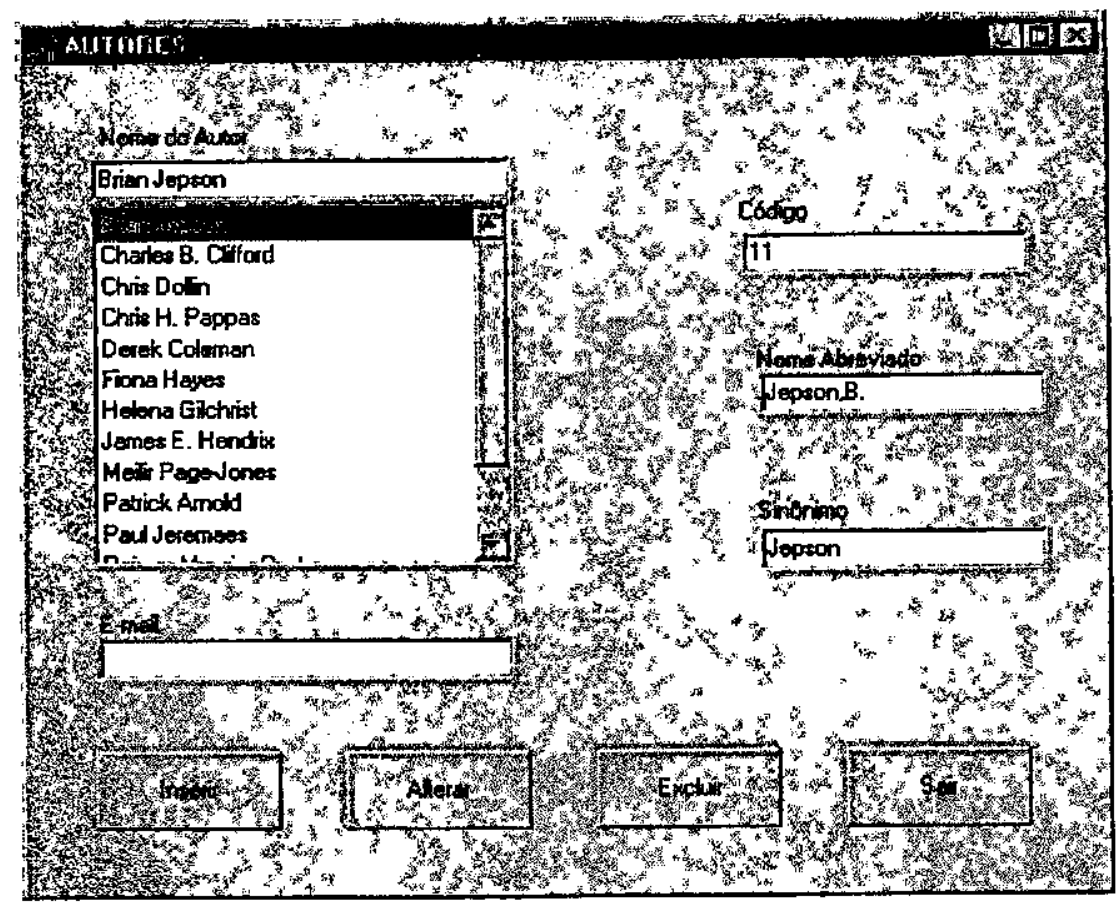

FIG. 4.14 - INTERFACE PARA MANUTENÇÃo DE AUTORES

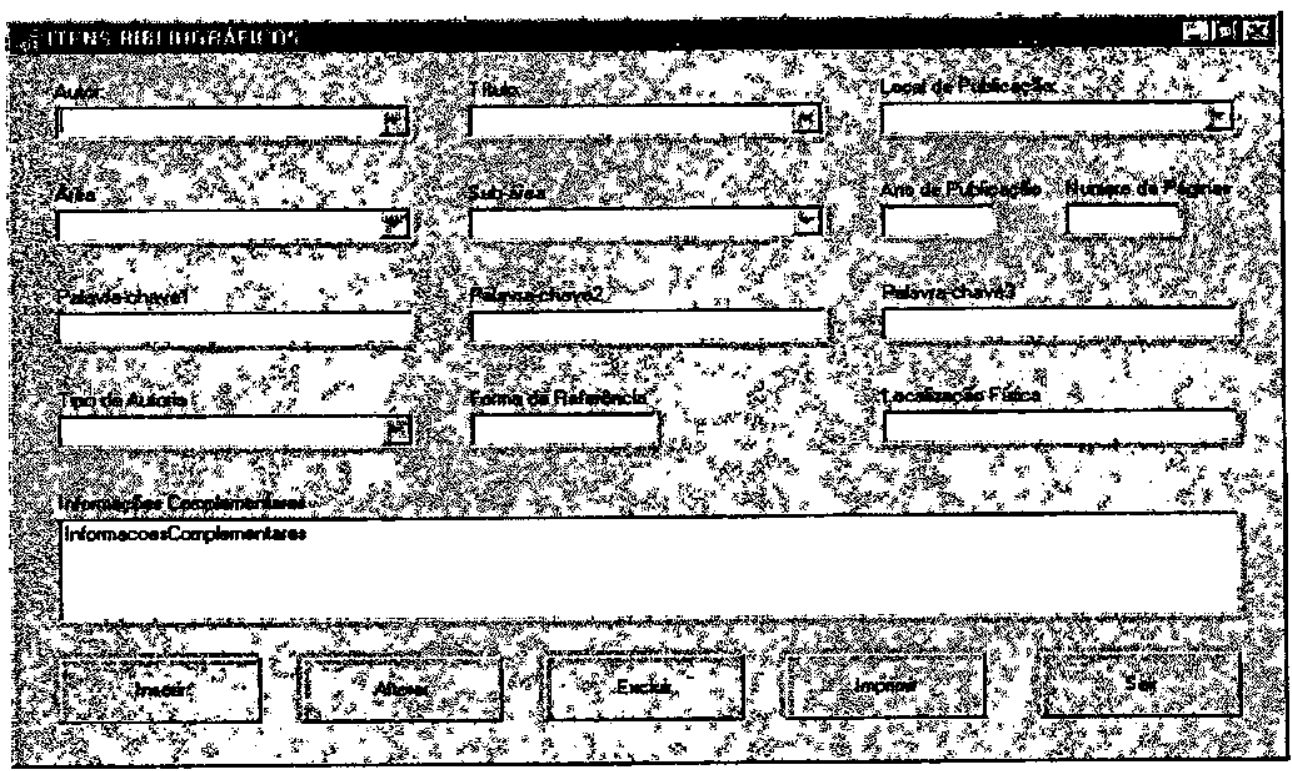

FIG. 4.15 - INIERFACE PARA MANUTENÇÃo DE TT́TULOS

\subsection{Considerações Finais}

Este capitulo apresentou a etapa de engenharia progressiva efetuada em partes do sistema SAPES, através da utilização do método Fusion, apoiado pela ferramenta FusionCASE e implementado em Delphi. 


\section{Capítulo 5}

\section{DIRETRIZES PARA A REENGENHARIA DE SOFTWARE}

\subsection{Considerações Iniciais}

Reengenharia é o processo de exame e alteração de um software visando sua reconstrução em uma nova forma. A reengenharia envolve um processo de engenharia reversa e posteriormente um processo de engenharia progressiva. Primeiramente são apresentadas as diretrizes para o processo de engenharia reversa, e em seguidas as diretrizes para o processo de engenharia progressiva. Para a compreensão $\Theta$ aplicação das diretrizes é necessário o conhecimento do método Fusion de desenvolvimento de sistemas orientado a objeto [Coleman et al., 1994]; o conhecimento do método FUSIONRE/ de engenharia reversa de software [Costa, 1997]; o domínio da ferramenta FusionCASE, que apoiará a reconstrução; o conhecimento da linguagem Delphi; e noçöes da linguagem Clipper. 


\subsection{Diretrizes Para o Processo de Engenharia Reversa}

As diretrizes foram elaboradas com base na experiência adquirida com a aplicação do método FUSION-RE/ de engenharia reversa sobre o sistema SAPES.

Como essas diretrizes são voltadas especificamente para o processo de engenharia reversa visando à reengenharia de sistemas de software, utiliza-se apenas a primeira etapa do método FUSION-REI (figura 3.1), na qual são recuperadas as informaçōes existentes sobre o sistema e são abstraídos os modelos de análise (modelo de ciclo de vida, modelo de operaçōes e modelo de objetos) que têm por objetivo mostrar a visão da funcionalidade do sistema.

Genericamente, o objetivo é direcionar essas diretrizes para o processo de engenharia reversa de qualquer sistema escrito em linguagem Clipper, o qual deseja-se reconstruir para a forma orientada a objeto.

\subsubsection{Diretrizes Para o Passo 1 do FUSION-RE/l - Obter Informaçóes Sobre o Sistema}

O primeiro passo para a recuperação das visōes funcionais é a obtenção de informaçōes pertinentes ao sistema objeto do processo de engenharia reversa. Não existem recomendaçōes especificas nesta fase, que sejam adicionais às já apresentadas por Costa [1997], pois se trata de uma fase subjetiva na qual quaisquer documentos textuais, pastas, software, programas fonte, ferramentas de software, manuais são obtidos. Contatos com os construtores/idealizadores do sistema, podem auxiliar a validar os modelos elaborados no decorrer do processo de engenharia reversa do sistema. Todas as informaçōes coletadas devem ser catalogadas e arquivadas, formando um banco de dados sobre o sistema a ser reconstruído.

\subsubsection{Diretrizes Para o Passo 2 do FUSION-RE/l - Recuperar os Modelos de Análise do Sistema}

Após a obtenção das informações existentes sobre o sistema a ser reconstruido e montado o banco de dados, parte-se para a recuperação dos modelos de análise do sistema. Para representar as visōes obtidas na recuperação, o método FUSION-RE/ utiliza os modelos da fase de análise do método Fusion, fazendo apenas uma inversão 
na ordem da utilização dos modelos. $A$ inversão se dá elaborando-se primeiramente o modelo de interfaces, e posteriormente o modelo de objetos.

O modelo de interfaces, segundo o método Fusion, utiliza dois modelos para capturar aspectos diferentes do comportamento de um sistema: o modelo de ciclo de vida e o modelo de operações [Coleman et al., 1994].

\section{- Diretrizes para elaboração do Modelo de Ciclo de Vida do Sistema}

O modelo de ciclo de vida mostra as seqüências permissiveis de operações e eventos do sistema fomecendo uma visão global do comportamento do sistema em relaçăo a seu ambiente.

As diretrizes para a elaboração do modelo de ciclo de vida, por envolverem apenas o manuseio da interface do sistema, não diferem daquelas apresentadas no método FUSION-RE/I. A instalação do software, utilização e posterior análise de todas as operações e o efeito gerado por elas é fundamental para captar as seqüências permitidas das operações e a conseqüente construçăo do modelo de ciclo de vida. Deve-se executar tantas vezes quantas forem necessárias o sistema, para verificar 0 comportamento do mesmo, para se produzir a seqüência das operações no modelo de ciclo de vida. O modelo de ciclo de vida será utilizado na construção do modelo de operaçōes.

\section{- Diretrizes para Elaboração do Modelo de Operaçóes do Sistema}

O modelo de operaçöes define a semântica de cada operação do sistema, especificando, através de um gabarito textual, o comportamento de cada operação do sistema, identificada no modelo de ciclo de vida. [Coleman et al., 1994].

O modelo de ciclo de vida elaborado no passo anterior $e$ todas as informaçōes obtidas no passo 1, contidas no banco de dados sobre o sistema, são utilizadas na elaboraçăo do modelo de operações.

As operações identificadas no modelo de ciclo de vida devem ser executadas e através da observação do comportamento do sistema, deve-se completar os campos do gabarito textual do modelo de operações, constituido dos itens: Descrição, Lê, Altera, Envia, Assume, e Resulta, os quais especificam detalhadamente a operaçăo. 
As informações dos itens Descrição e Lê săo obtidas a partir da observação da interface, onde é identificado o conteúdo referente a cada elemento solicitado pela operação (eventos de entrada).

As informações dos itens Altera e Envia são obtidas a partir da observação da interface, da observação da execução da operação, onde é identificado o valor referente a cada elemento acessado e alterado pela operaçäo. Através da observação dos arquivos de trabalho do sistema (identificados no passo 1 do método) é possível identificar se determinada operaçäo cria ou altera arquivos.

As informaçðos do item Assume, são obtidas a partir da observação da interface, da observação dos valores antes e após a execução das operaçōes, do conhecimento adquirido da funcionalidade do sistema, onde săo identificadas as pré-condiçöes necessárias para a execução da operação.

As informações do item Resulta, são obtidas a partir da observaçäo da interface, da observação da execução da operaçäo e do conhecimento da funcionalidade do sistema, onde será verificado o efeito da operação antes e apọ́s a execução da operação.

O preenchimento dos itens Altera, Envia, Assume e Resulta, do modelo de operações do sistema pode ser facilitado através da utilização de ferramentas de visualização de arquivos de dados (tipo Browser). Essas ferramentas permitem, com facilidade, obter visőes do comportamento dos arquivos de dados, através da abertura dos mesmos como se fossem planilhas, possibilitando inclusive que se façam manipulações nos dados armazenados nesses arquivos. A utilização dessas ferramentas permitem major flexibilidade e exatidão nas verificaçöes do comportamento dos arquivos, antes e após a execução das operações. Através do comando do sistema operacional que mostra os arquivos do diretório por ordem de data (DIR/OD), pode-se verificar e guardar as datas da última alteraçäo efetuada em cada arquivo de dados. Após a realização da operação que se está analisando para o preenchimento do gabarito textual, verifica-se novamente a data das alteraçöes efetuadas em cada arquivo e comparando-se com as datas anteriores, identifica-se os arquivos de dados alterados. Essa informação indica quais arquivos devem ser visualizados para se verificar como foram alterados. A modificação no conteúdo dos arquivos pode ser notada utilizando-se uma ferramenta de manipulação de arquivos de dados. O procedimento acima fornece a base para o preenchimento dos gabaritos de cada operação do modelo de operações do sistema. 


\section{- Diretrizes para elaboração do Modelo de Objetos do Sistema}

O objetivo do modelo de objetos do método Fusion é representar a estrutura estática do sistema, através de um diagrama gráfico que mostra as classes existentes no domínio do sistema e os relacionamentos entre elas [Coleman et al., 1994].

Considerando-se que sistemas escritos em Clipper trabalham com bancos de dados baseados no modelo relacional, as tabelas do sistema devem refletir o modelo lógico do banco de dados. Assim, em princípio, o modelo de objetos pode ser criado através da análise dessas tabelas (atributos e conteúdo) identificando-se o modelo entidade-relacionamento que deu origem às mesmas $e$ adicionando-se as demais classes e relacionamentos necessários para complementar o modelo de objetos do sistema. Se houver um documento descrevendo o projeto lógico (modelo entidaderelacionamento) do sistema, o mesmo pode ser usado para auxiliar a interpretação das tabelas; sendo, no entanto, importante que se confira se as tabelas realmente refletem esse modelo.

Durante a análise das tabelas, não sendo possivel identificar o modelo lógico do banco de dados, ou porque o mesmo não existe, ou porque existem muitas tabelas temporárias, que não fazem parte do modelo lógico do banco de dados, e que confundem a interpretação semântica que se deseja obter das tabelas, deve-se elaborar o modelo de objetos do modo descrito a seguir.

O modelo de objetos é construído identificando-se, primeiramente, assuntos com os quais a funcionalidade do sistema se relaciona. Os assuntos identificam diferentes niveis de abstração da funcionalidade do sistema e os possiveis agrupamentos de operações de um mesmo assunto. Os assuntos são denominados temas, segundo a nomenclatura do método FUSION-RE [Penteado, 1996].

Para a identificação dos temas do sistema, sugere-se a utilização de um quadro (quadro 5.1), o qual deverá conter todas as operações identificadas no modelo de ciclo de vida e especificadas no modelo de operaçōes do sistema, produzidos pela engenhana reversa. Deve-se procurar associar essas operaçōes aos diferentes aspectos do dominio do sistema. Esses aspectos, possiveis candidatos a temas, podem ser identificados considerando-se a expressão principal do modelo de ciclo de vida. 
Quadro 5.1 - Operaçǒes e Aspectos do Domínio do Sistema

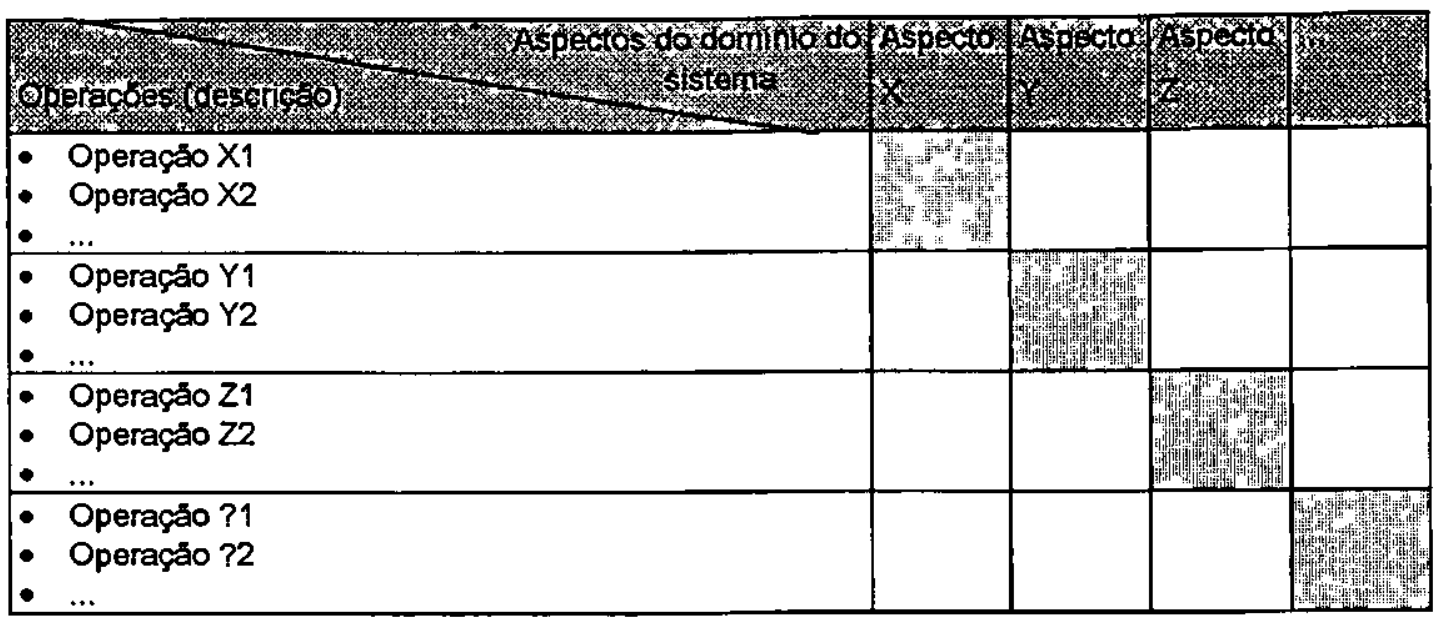

Os aspectos do domínio do problema, juntamente com as operaçöes devem ser analisados para se confirmar ou rejeitar a transformação de um candidato a tema, para um tema propriamente dito. O quadro 5.2, semelhante ao quadro 5.1, deve ser montado para conter os temas finais e respectivas operações identificados.

Quadro 5.2 - Operaçōes e Temas Identificados e Confirmados

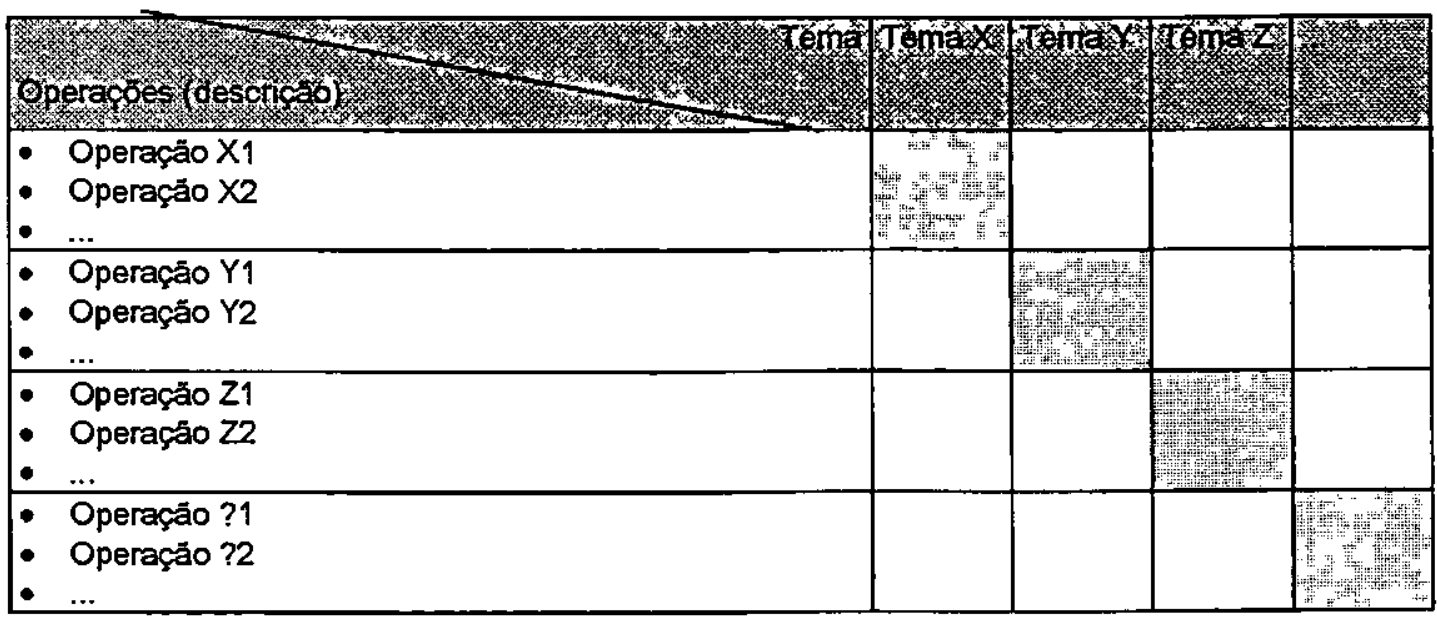

Definidos os temas, a etapa seguinte é a elaboração dos respectivos modelos de objetos. Para a elaboração do modelo de objetos, todas as operaçōes referentes aos temas devem ser novamente analisadas, agora com outro ponto de vista, buscando-se identificar as classes, os relacionamentos, as agregaçōes e as generalizaçōes que constituirão o modelo de objetos [Coleman et al., 1994]. A análise, para cada tema, inicia-se em um alto nivel de abstração, sendo que os detalhes são inseridos somente depois que a estrutura geral for considerada satisfatória. 
Segundo o método FUSION-RE/l [Costa, 1997]:

- Deve-se definir como classe, cada elemento de cada operação que possuir identificação única e os arquivos criados pela execução de uma operação (conforme identificado no modelo de operaçōes).

- Para a definição de relacionamentos, deve-se identificar em cada operação, elementos que sejam associaçóes ou correspondências entre as classes consideradas.

- Para a definição de atributos, de cada classe e de cada relacionamento, devese identificar em cada operação, elementos que sejam valores dessas classes ou valores desses relacionamentos.

- Para a definição de agregação, deve-se identificar uma estrutura de composição entre as classes identificadas.

- Para a definição de generalização, deve-se identificar, entre as classes definidas, aquelas que sejam supertipos, formadas pela fatoração de propriedades comuns de vánas classes subtipos. Para a definição de especialização, deve-se identificar entre as classes subtipos, aquelas que sejam uma versão mais especializada das classes supertipos.

Terminada a elaboração dos modelos de análise do sistema, fica finalizada a etapa de engenharia reversa do processo de reengenharia do sistema. Esses modelos são o ponto de partida para a reconstrução do sistema na etapa de engenharia progressiva.

\subsection{Diretrizes Para o Processo de Engenharia Progressiva}

As diretrizes para 0 processo de engenharia progressiva também foram elaboradas com base na experiência adquinida com a reconstruçăo do sistema SAPES. Embora para a reconstrução do sistema SAPES, tenha sido utilizado a ferramenta FusionCASE, as diretrizes aqui apresentadas são genéricas e direcionadas para 0 processo de engenharia progressiva de qualquer sistema desenvolvido pelo método Fusion de desenvolvimento orientado a objeto. A ferramenta FusionCASE é citada em algumas diretrizes, porém as orientações podem ser seguidas sem a utilização da mesma. 
Antes de se iniciar a etapa de engenharia progressiva, os modelos de análise produzidos pela engenharia reversa devem ser analisados e criticados, pois esses modelos serão o ponto de partida para a reconstrução do sistema na etapa de engenharia progressiva.

\subsubsection{Diretrizes para a Anállse Crítica e Reconstrução dos Modelos de Objetos Produzidos pela Engenharia Reversa}

As diretrizes aqui apresentadas tentam apenas chamar atenção para pontos que devem ser analisados, visto que a análise crítica do modelo de objetos está fortemente relacionada a aspectos específicos da aplicação a qual o sistema se refere.

Partindo-se do princípio que os modelos de análise produzidos pela engenharia reversa e os requisitos exigidos do sistema são bem conhecidos, alguns pontos podem ser citados:

- Deve-se confrontar os modelos obtidos pela engenharia reversa com os requisitos desejáveis do sistema, podendo-se alterar a modelagem de modo a melhor refletir a funcionalidade e demais requisitos exigidos para o sistema.

- Deve-se verificar se a modelagem produzida não tem anomalias em função do estilo de programação empreendido na construção do sistema (por exemplo, tabelas temporárias de processamento).

- Deve-se rever todas as classes, bem como seus atributos e os relacionamentos gerados, procurando-se refazer os modelos de forma a melhor representar a estrutura estática do sistema.

- Classes, atributos e relacionamentos desnecessários devem ser eliminados, ou adequados aos requisitos do sistema (por exemplo: procurar classes que podem ser eliminadas, adicionando-se operações novas).

As alterações efetuadas nos modelos de objetos podem exigir que o modelo de interface seja refeito.

\subsubsection{Diretrizes para a Reconstrução do Modelo de Interface}

Os modelos de ciclo de vida e de operações (os quais compõem a interface do 
sistema) produzidos na fase de engenharia reversa deverão ser refeitos objetivando-se uma melhor adequação aos requisitos do sistema e aos novos modelos de objetos.

O modelo de ciclo de vida, obtido no processo de engenharia reversa, está estruturado de acordo com as operaçōes constantes na interface do sistema e também de acordo com a estrutura de arquivos existente para o sistema em processo de reengenharia (sistema antigo). O novo modelo de ciclo de vida deverá ser baseado na funcionalidade requerida para o sistema, refletindo as seqüências possiveis para as operações do sistema. Para tanto, deve-se refazer o modelo de ciclo de vida, obtido no processo de engenharia reversa, aproveitando-se as partes que estăo em conformidade aos requisitos do sistema e retirando-se ou alterando-se aquelas partes que não estão.

A ferramenta FusionCASE pode proporcionar um rápido auxilio para a criação do novo modelo de ciclo de vida, uma vez que já tem embutida a sintaxe e semântica para a construção das expressões do ciclo de vida. As operaçōes identificadas no modelo de ciclo de vida são armazenadas, automaticamente, em um dicionário de dados para posterior utilização. A ferramenta pode fornecer suporte para o gerenciamento e edição de um dicionário de dados para acondicionar todas as classes, relacionamentos, atributos, operaçōes, métodos e demais componentes do sistema, tanto da fase de análise como da fase de projeto.

Como o modelo de ciclo de vida, o novo modelo de operaçōes do sistema deverá refletir as operaçōes que são necessárias para implementar a funcionalidade do sistema. Cada operação constante no modelo de operações, resultante do processo de engenharia reversa, deverá ser novamente examinada, procurando-se atualizá-las com as novas operações identiflcadas no modelo de ciclo de vida refeito. As operaçöes que foram eliminadas na reconstrução do modelo de ciclo de vida não serão refeitas, porém, os itens do gabarito textual de cada operação deverá ser examinado de forma a ser atualizado (por exemplo: as classes que tiveram atributos alterados, incluídos, ou excluídos, deverão ser atualizadas).

A ferramenta FusionCASE, novamente pode ser útil por prover um ambiente em que os gabarttos de cada operação Identificada e colocada no modelo de ciclo de vida estará automaticamente a disposição, para o preenchimento dos seus itens. preenchimento dos gabaritos é também facilitado pelo suporte sintático e semântico que a ferramenta oferece para a elaboração do modelo de operações. Cada incremento em cada modelo produzido resulta em alteraçōes que são automaticamente feitas pela ferramenta no dicionário de dados e em um arquivo próprio para utilização em etapas 
futuras.

\subsubsection{Diretrizes para a Elaboração dos Modelos de Projeto}

A etapa de projeto do sistema segue o curso normal, como um processo tradicional de desenvolvimento de software baseado no método Fusion, partindo dos novos modelos de análise produzidos.

Na fase de projeto, são gerados modelos mais próximos da implementação (grafos de interação de objetos, grafos de visibilidade e descrição das classes), os quais representam os métodos necessários para a comunicação entre os objjetos, perfazendo uma determinada operação do sistema.

Para cada operação do sistema, identificada no modelo de ciclo de vida $\theta$ especificada no modelo de operaçőes, deverá existir um grafo de interaçăo de objetos, 0 qual fornece uma representação visual para a estrutura dos algoritmos necessários para a implementação da operação. Portanto, déve-se construir grafos de interação de objetos para cada operaçăo que for necessária ao sistema.

A ferramenta FusionCASE possibilita a criação de um grafo de interação de objetos para cada operação, onde são identificadas as classes que participam da operação, bem como os métodos e seus parâmetros, que são ativados para cada operação.

Os grafos de visibilidade deverăo ser elaborados para cada classe do sistema. Esses grafos descrevem as estruturas de referências existentes entre as classes do sistema. Deve-se identificar, nessa fase, os objetos para os quais as instâncias das classes fazem referências e o tipo apropriado de referência para esses objetos.

A ferramenta FusionCASE cria um grafo de visibilidade para cada classe do sistema. Esse grafo é criado a partir das informaçōes constantes dos grafos de interação de objetos. Deve-se então, estabelecer o tipo de visibilidade, mutabilidade, dinâmica da ligação, etc., entre a classe do grafo e as demais classes do sistema.

As descrições das classes são conseqüências naturais de todas as fases até agora descritas. Essas descriçōes são elaboradas a partir de informações vindas do modelo de objetos, dos grafos de interação de objetos, e dos grafos de visibilidade. Cada classe recebe os métodos e atributos estabelecidos nas fases anteriores. A descrição da classe fornece os fundamentos para a implementação. A ferramenta 
FusionCASE, a partir de informações provenientes dos diversos modelos introduzidos na ferramenta, pode gerar automaticamente a descrição de cada classe componente do sistema.

\subsection{DIretrizes para a Implementação do Sistema}

$\mathrm{Na}$ etapa de implementação é utilizada a linguagem Delphi, a qual suporta a orientaçăo a objeto.

Tomando-se como base os modelos produzidos na fase de projeto, a implementação através da linguagem Delphi pode ser efetuada da seguinte maneira:

Das descrições de classes elaboradas, obtém-se o conjunto de classes dos objetos manipulados pelo sistema.

Dos grafos de interaçäo de objetos, obtem-se os passos para a elaboraçäo dos algoritmos. Os dicionánios de dados deverão ser consultados para agilizar o processo de implementação.

Para a elaboração da nova interface do sistema, utiliza-se o modelo de ciclo de vida como guia para a criaçăo do menu.

As classes geradas pela ferramenta FusionCASE são traduzidas quase diretamente para classes utilizadas na linguagem Delphi. A linguagem Delphi tem classes prontas para a manipulação de janelas, entäo a tarefa maior é mapear as classes geradas pela ferramenta FusionCASE para classes Delphi, complementando-as com aquelas classes de manipulação de janelas.

\subsection{Consideraçōes Finais}

Este capítulo apresentou as diretrizes necessánias para um processo de reengenharia de software orientado a função, escrito em linguagem Clipper, para um software orientado a objeto, escrito em linguagem Delphi. Essas diretrizes foram elaboradas com base na experiência adquirida com 0 processo de reengenharia efetuado sobre o sistema SAPES, utilizando-se o método FUSION-RE/l (na etapa de engenharia reversa), o método Fusion e a ferramenta FusionCASE (na etapa de engenharia progressiva). 


\section{Capítulo 6}

CONCLUSÕES

\subsection{Conclusões e Contribuições}

Sistemas legados têm sido causa de freqüentes discussões devido a dois fatores conflitantes: a importância desses sistemas para as organizaçöes e a dificil manutenção dos mesmos. Um recurso que pode ser utilizado para amenizar os problemas relacionados à manutenção de software legado é a reengenharia, através da qual podese aproveitar as boas características do sistema, embutindo-lhes outras que permitirão manter a funcionalidade, melhorando tanto as características que influenciam a facilidade de manutenção, quanto outras características de qualidade.

Este trabalho apresenta diretrizes para auxillar 0 processo de reengenharia. Nessas diretrizes são consideradas as técnicas orientadas a objeto, pois essas mostram ser a melhor perspectiva para o desenvolvimento e manutenção de software e também é considerado o desenvolvimento de sistemas para ambiente Windows, visto ser essa outra tendência verificada atualmente para facilitar o uso $e$, portanto a manutenção de sistemas. 
As diretrizes deste trabalho guiam o processo de reengenharia de sistemas orientados a funçăo, escritos em Clipper, para sistemas orientados a objeto, escritos em Delphi. Essas diretrizes foram obtidas através da execução da reengenharia do sistema SAPES, o qual, apesar de não ser muito antigo, possui diversas características típicas de sistemas legados.

A reengenharia do sistema SAPES consistiu de duas etapas. Na primeira etapa, utilizou-se o método FUSION-RE/l, de engenharia reversa, para a produção dos modelos de análise necessários para a reconstrução do sistema. Com essa experiēncia verificou-se a aplicabilidade do método FUSION-RE/I em um processo de reengenharia de sistemas, diferentemente de seu propósito inicial que era de produzir informaçőes para auxiliar a etapa de manutenção de software.

Para o caso especial, de sistemas escritos em Clipper, percebeu-se, durante a engenharia reversa, que o modelo de objetos poderia ter sido obtido diferentemente do proposto pelo método FUSION-RE/l. O modelo de objetos poderia ser criado através da análise das tabelas Clipper (atributos e conteúdo), identificando-se o modelo entidaderelacionamento que deu origem às mesmas $\theta$ adicionando-se as demais classes $e$ relacionamentos necessários para complementar o modelo de objetos do sistema. Se existir um documento descrevendo o projeto lógico (modelo entidade-relacionamento) do sistema, o mesmo pode ser usado para auxiliar a interpretação das tabelas Clipper.

Outro fato percebido é o de que, possivelmente, não apenas sistemas escritos em Clipper, mas todos os sistemas que são desenvolvidos em linguagem que crie uma base de dados com tabelas relacionais, podem ser reconstruidos, aplicando-se as mesmas diretrizes.

Numa segunda etapa do processo de reengenharia do sistema SAPES, efetuouse a análise crítica dos modelos criados na primeira etapa e utilizando-se a ferramenta FusionCASE, reconstruiu-se esses modelos. Após a reconstrução dos modelos de análise, construiu-se os modelos de projeto, e posteriormente, partiu-se para a implementação do sistema, utilizando-se a linguagem Delphi. Nessa etapa, verificou-se que a ferramenta FusionCASE pode auxiliar as fases de análise e projeto, criando subsidios para a verificação do processo de reconstrução. Por exemplo, a ferramenta FusionCASE, possibilitou, através de suas opções de checagem, a identificação de elementos "perdidos", que foram criados, mas que não foram utilizados ou referenciados na reconstrução. 
As diretrizes apresentadas neste trabalho podem também ser direcionadas ao processo de reengenharia que não utiliza a ferramenta FusionCASE em sua etapa de reconstrução, porém, o resultado pode ser mais demorado e passível de conter erros, os quais a ferramenta FusionCASE pode ajudar a eliminar.

\subsection{Trabalhos Futuros}

Como desdobramento deste trabalho, as diretrizes aqui mencionadas poderiam ser reaplicadas em outros sistemas escritos em Clipper, reconstruindo-os em Delphi. Desse modo, o que aqui é colocado como diretrizes, poderia ser transformado em um método de reengenharia, especifico para essa categoria de sistemas.

Outro trabaiho seria a aplicação das diretrizes em sistemas escritos em outras linguagens, os quais deseja-se reconstruir sob o paradigma de orientação a objeto. Assim, poderia se verificar a aplicabilidade das diretrizes em outras categorias de sistemas.

Um outro campo a ser explorado é o de elaboraçăo de diretrizes para a reengenharia de dados, aplicando-se regras de normalização às tabelas do sistema, de modo a tornar mais fácil a identificação do projeto lógico do banco de dados, a partir do qual o modelo de objetos pode ser desenvolvido. Essas diretrizes poderiam também conter orientações de como transferir os dados para as tabelas normalizadas.

A técnica de aquisição de conhecimento implicito denominada data mining, que permite a extração de conhecimento em base de dados, pode auxiliar a busca de padrões nos dados do banco de dados e facilitar a criação do modelo lógico do mesmo. Outro trabalho a ser desenvolvido poderia ser a aplicação da técnica data mining no processo de reengenharia.

Outras ferramentas CASE, as quais pudessem apoiar e agilizar o processo de reengenharia de software poderiam ser estudadas, levando a diretrizes de como e quando utilizá-las. 


\section{BIBLIOGRAFIA}

\section{Referências}

BENEDUSI, P.; CIMITILE, A.; CARLINI, U. Reverse Engineering Processes, Design Document Production, and Structure Charts. Journal Systems and Software, v.19, pp.225-45, 1992.

BENNETT, K. H. Automated Support of Software Maintenance. Information and Software Technology, v.33, n.1, pp.74-85, 1991.

BENNETT, K. H. Legacy Systems: coping with success. IEEE Software, v.12, n.1, pp.19-23, 1995.

BIGGERSTAFF, T. J. Design Recovery for Maintenance and Reuse. IEEE Computer, V.22, n.7, pp.36-49, 1989.

BOEHM, B. W. A Spiral Model of Software Development and Enhancement. Computer, v.21, n.5, pp.61-72, maio, 1988.

CAINE, S.; GORDON, K. PDL - A Tool for Software Design. In: Proc. National Computer Conference. AFIPS Press, pp.271-276, 1975.

CANFORA, G.; CIMITILE, A.; MUNRO, M. RE': Reverse-engineening and Reuse Reengineering. Journal of Software Maintenance: Research and Practice, v.6, n.2, pp.53-72, 1994.

CHIKOFSKY, E. J. e CROSS II, J. H. Reverse Engineering and Design Recovery: A Taxonomy. IEEE Software, v.7, n.1, pp.13-17, 1990. 
CHIN, D. N.; QUILICl, A. DECODE: A Co-operative Program Understanding Environment. Journal of Software Maintenance: Research and Practice, v.8, n.1, pp.3-33, 1996.

$\mathrm{CHOI}, \mathrm{S}$. C.; SCACCHI, W. Extrating and Restructuring the Design of Large Systems. IEEE Software, v.7, n.1, pp.66-71, 1990.

CLEVELAND, L. A Program Understanding Support Environment. IBM Systems Journal. v.28, n.2, pp.324-344, 1989.

COLEMAN, D. et al. Object-Oriented Development: THE FUSION METHOD. Prentice Hall, Englewood Cliffs, New Jersey, 1994.

COSTA, R. M. Aplicação do Método de Engenhania Reversa FUSION-RE/I na Recuperação da Funcionalidade da Ferramenta de Teste PROTEUM. ICMSC-USP, São Carlos, 1997. Dissertaçăo (mestrado).

CROSS, J. H. Grasp/Ada Uses Control Structure. IEEE Software, v.7, n.3, pp.62, 1990.

DeMARCO, T.; SARSON, C. Structured Analysis and Systems Specification. PrenticeHall, 1979.

GALL, H. e KLOSCH, R. Finding Objects in Procedural Prograrns: An altemative Approach. In: Proceedings of Second Working Conference on Reverse Engineering, Monterey, EUA, pp.208-216, july, 1995.

GANNOD, G. C.; CHENG, B. H. C. Using Informal and Formal Techniques for the Reverse Engineering of $C$ Programs. In: Proceedings of Third Working Conference on Reverse Engineering, Monterey-CA, pp.249-258, nov, 1996.

GT-REG (Georgia Tech's - Reverse Engineering Group). Glossary of Reengineening Terms. Georgia, http://www.cc.gatech.edu/reverse/glossary.html, 1998.

HAMMER, M.; CHAMPY, J. Reengenharia Revolucionando a Empresa. Editora Campus, Rio de Janeiro, 1993

HARANDI, M. T.; NING, J. Q. Knowledge-Based Program Analysis. IEEE Software, v.7, n.1, pp.74-81, 1990.

HARBAND, J. Seela Aids Maintenance with Code-Block Focus. IEEE Software, v.7, n.3, pp.61, 1990.

HATLEY, D. J.; PIRBHAI, I. A. Strategies for Real Time Systems Specifications. Dorset House, 1987.

IEEE CS-TCSE (IEEE Computer Society - Technical Council on Software Engineering). Reengineering \& Reverse Engineering Terminology. Washington, http://www.tcse.org/revengr/taxonomy.htrnl, 1997.

JACOBSON, 1.; LINDSTRÖM, F. Re-egineering of old systems to an object-oriented architeture. SIGPLAN Notices, v.26, n.11, pp.340-350,nov., 1991.

JONES, C. B. Systematic Software Development Using VDM. 2.ed., Prentice-Hall, 1990.

KRÄMER, C.; PRECHELT, L. In: Proceedings of Third Working Conference on Reverse Engineering, Monterey-CA, pp.208-215, nov, 1996.

LAYZELL, P. J.; FREEMAN, M. J.; BENEDUSI, P. Improving Reverse-engineering through the Use of Multiple Knowledge Sources. Journal of Software Maintenance: Research and Practice, v.7, n.4, pp.279-299, 1995.

LEHMAN, M. M. Programs, Life-Cycles, and the Laws of program Evolution. Proc. IEEE pp.1060-1076, 1980. 
LEWIS, B. e McCONNELL, D. J. Reengineering Real-Time Embedded Software onto a Parallel Processing Plataform. In: Proceedings of Third Conference on Reverse Engineering, Monterey, EUA, pp.11-19, nov., 1996.

MACKENZIE, C. L.; HENSHAW, J. Understanding the Legacy. Software Engineering Quality Consultants, Ontario, april, 1994. /TR-74.137/

MITTRA, Sitansu S. A Road Map for Migrating Legacy Systems to Client/Server. Journal of Software Maintenance: Research and Practice, v.8, n.2, pp.117-130, 1995.

MORRIS, P.; FILMAN, R. Mandrake: A Tool for Reverse-Engineering IBM Assembly Code. In: Proceedings of Third Working Conference on Reverse Engineering, Monterey-CA, pp.57-66, nov, 1996.

NEWCOMB, P. e KOTIK G. Reengineering Procedural Into Object-Oriented Systems. In: Proceedings of Second Conference on Reverse Engineering, Toronto, Canada, pp.237-249, jul., 1995.

OMAN, P.W. Maintenance Tools. IEEE Software, v.7, n.3, pp.59-65, 1990.

OXFORD. Dictionary of Computing. Oxford University Press, 1986.

- PENTEADO, R. A. D. Um Método para Engenharia Reversa Orientada a Objetos., IFSC-USP, São Carlos, 1996. Tese (Doutorado)

PREECE, J. et al. Human-Computer Interaction. Wokinghan, Addison-Wesley, 1994.

PREMERLANI, W. J. e BLAHA, M. R. An Approach for Reverse Engineering of Relational Databases. Communications of the ACM, v.37, n.5, pp.42-49, 1994.

PRESSMAN, R. S. Engenharia de Software, Makron Books, 1995.

RAMAMOORTHY, C. V.; TSAl, W. Advances in Software Engineering. IEEE Computer V.29, n.10, pp.47-58, 1996.

REKOFF Jr., M. G. On Reverse Engineering. IEEE Transaction on Systems, Man, and Cybernetics, v.15, n.2, março/abril, 1985.

ROSS, R. G. Entity Modeling: Techniques and Application. Data Research Group, 1988.

ROYCE, W. W. Managing the Development of Large Software Systems: Concepts and Techniques. in Proc. WESCON, pp.1-9, 1970.

RUGABER, S. e WILLS, L. M. Creating a Research Infrastructure for Reengineering. In: Proceedings of Third Working Conference on Reverse Engineering, Monterey-CA, pp.98-102, nov, 1996.

RUGABER, $\mathrm{S}$. et al.. recognizing Design Decision in Programs. IEEE Software, v.7, n.1, pp.46-54, 1990.

SAGE, A.P. Systems Engineering and Systems Management for Reengineering. Joumal Systems and Software, v.30, r.1, pp.03-25, 1995.

SAMUELSON, P. Reverse-Engineering Someone Else's Software: is it Legal? IEEE Software, v.1, n.1, pp.90-96, 1990.

SNEED, H. M. Migration of Procedurally Oriented COBOL Programs in an ObjectOriented Architeture. In: Proceedings of Conference on Software Maintenance, Ortando, EUA, pp.105-116,nov., 1992.

SNEED, H. M. Object-Oriented COBOL Recycling. In: Proceedings of Third Working Conference on Reverse Engineering, Monterey-CA, pp.169-178, nov, 1996. 
SNEED, H. M. e Nyáry, E. Extracting Object-Oriented Specification from Procedurally Oriented Programs. In: Proceedings of Second Conference on Reverse Engineering, Toronto, Canada, pp.217-226,jul., 1995.

SNEED, H. M. Planning the Reengineering of Legacy Systems. IEEE Software, v.12, n.1, pp.24-34, 1995.

SOMMERVILLE, I. Software Engineering (Intemational Computer Science Series). $5^{a}$ Edição. Addison-Wesley Pub Co. 1995.

SPIVEY, J. M. Undestanding Z: A Specification Language and its Formal Semantics. Cambridge University Press, 1988.

STEPHEN, R. M.; LYNN, M. M. Software Migration and Reengineering: A Pilot Project in Reengineering. Journal Systems and Software, v.30, n.1, pp.137-50, 1995.

TANGORRA, F.; CHIAROLLA, D. A methodology for reverse engineering hierarchical databases. Information and Software Technology, v.37, n.4, pp.225-231, nov., 1995.

TONELLA, P. et al. Augmenting Pattem-Based Architetural Recoveny with Flow Analisys: Mosaic - A Case Study. In: Proceedings of Third Working Conference on Reverse Engineering, Monterey-CA, pp.198-208, nov, 1996.

TURINE, M. A. S. Especificação de Requisitos: Uma Introdução. Relatório Técnico do ICMSC $n^{\circ}$ 39. ICMSC-USP. 1996.

ULRICH, W. M. Re-engineering: Defining an integrated migration framework, in Software Reengineering (R. S. Amold, ed.), IEEEE Computer Society Press, LoS Altos, California, pp. 108-118, 1993.

WARD, M. P.; BENNETT, K. H. Formal Methods for Legacy Systems. Joumal of Software Maintenance: Research and Practice, v.7, n.3, pp.203-219, 1995.

WARDEN, R. Re-engineering - A Pratical Methodology With Commercial Applications. in Applied Information Tecnology 12 (Software Reuse and Reverse Engineering in Practice). (P. A. V. Hall, ed.) - Chapman@Hall. 1992.

WATERS, R. C.; CHIKOFSKY, E. J. Reverse Engineering: Progress Along Many Dimensions. Communications of the ACM. v.37, n.5, pp.23-24, 1994.

WONG, K. et al. Structural Redocumentation: A Case Study. IEEE Software, v.12, n.1, pp.46-54, 1995.

YEH, A. S.; HARRIS, D. R. e REUBENSTEIN, H. B. Recovering Abstract Data Types and Object Instances from a Conventional Procedural Language. In: Proceedings of Second Conference on Reverse Engineering, Toronto, Canada, pp.227-236, jul., 1995.

YOURDON, E. Análise Estruturada Modema. Editora Campus, Rio de Janeiro, 1990.

\section{Complementar}

ALBRECHT, A. J. Measuring Application Development Productivity. In: Proc. IBM Application Development Symposium. Monterey, C. A., pp.83-92, 1979.

BENDIFALLAH, S.; SCACCHI, W. Understanding software Maintenance Work. IEEE Transaction on Software Engineering, v.13, n.3, pp.311-23, 1987 
BOLDYREFF, C. Reuse, Software Concepts, Descriptive Methods and the Practitioner Project. ACM Sigsoft Software Engineering Notes, v.14, n.2, pp.25-31, abril, 1989.

BURD, E.; MUNRO, M.; WEZEMAN C. Extracting Reusable Modules from Legacy Code: Considering the Issues of Module Granulanity. in: Proceedings of Third Working Conference on Reverse Engineening, Monterey-CA, pp.189-196, nov, 1996.

CORBI, T.A. Program Understanding: Challeng for the 1990s. IBM Systems Joumal. v.28, n.2, 1989

CURTIS, B. et al. Measuning the Psychological Complexity of Software Maintenance Tasks with the Halsted and McCabe Metrics. IEEE Conference on Software Engineering, v.5, n.2, pp.96-104, 1979

DEKLEVA, S. Delphi Study of Software Maintenance Problems. In: Proc. of 8th Intemational Conference on Software Maintenance, 1992

EDELSTEIN, D.V. Standard for Software Maintenance - Report on the IEEE STD 12191993, Software Engineering Notes, v.18, n.8, pp. 94-5, 1994

FORTE, G. Tools Fair: Out of the lab, onto the shelf - Reverse Engineering and Maintenance. IEEE Software, V.9, N.3, pp.76, 1992

GALLAGER, K.B.; LYLE, J.R. Using Program Slicing in Software Maintenance. IEEE Transactions on Software Engineering, v.17, n.8, pp.751-61, 1991

HALL, P. A. V. Ovenview of reverse engineening and reuse research. Information and Software Technology, v.34, n.4, pp.239-249, abril, 1992.

HOLZNER, Steven. Programando em Visual C++. Berkeley, 1995.

HTTP://www.microsoft.com/visualc/

LIENTZ, B.P.; SWANSON, E.B. Problems in Application Software Maintenance. Comunications of $A C M$, v.24, n.11, pp.31-7, 1981

LIU, C.C. A Look at Software Maintenance. Datamation, nov., pp.51-5, 1976

LIVADAS, P. E.; JOHNSON, T. A New Approach to Finding Objects in Programs, Journal of Software Maintenance: Research and Practice, v.6, n.5, pp.249-260, 1994.

MALAN, R.; LETSINGER, R e COLEMAN, D. Object-Oriented Development at Work Fusion In the Real Word. Prentice Hall. 1996.

MAMONE, S. The IEEE Standard for Software Maintenance. Software Engineering Notes, v.19, n.1,1994

MAYER, R. C. Visual Basic X Delphi: duelo de gigantes?. Byte Brasil, pp.114, 1997.

McCABE, T. Jr.. Battle-Map, ACT Show Code Structura, Complexit. IEEE Software, v.7, n.3, pp.62, 1990.

MISAKA, A. P. S. Modelagem Pelo Método Fusion de um Sistema de Agendamento de Reuniões. Relatórios Técnicos - ICMSC-USP. 1996.

MOORE, M. M. Rule-Based Detection for Reverse Engineering User Interfaces. In: Proceedings of Third Working Conference on Reverse Engineering, Monterey-CA, pp.42-48, nov, 1996.

OGANDO, R. M. et al. An object Finder for Program Structure Understanding in Software Maintenance. Journal of Software Maintenance: Research and Practice, v.6, n.5, pp.261-283, 1994. 
OSBORNE, W.M.; CHIKOFSKY, E.J. Fitting Pieces to the Maintenance Puzzle. IEEE Software, v.7, n.1, pp.10-1, 1990

PENTEADO, R. A. D.; GERMANO, F. S. R.; MASIERO, P. C. An Overall Process Based on Fusion to Reverse Engineer Legacy Code. In: Proceedings of Third Working Conference on Reverse Engineering, Monterey, EUA, pp.170-188, nov, 1996.

PENTEADO, R. A. D.; GERMANO, F. S. R.; MASIERO, P. C. Engenharia Reversa Orientada a Objetos do Ambiente StatSim: método utilizado e resultados obtidos. In: IX Simpósio Brasileiro de Engenharia de Software, Recife, pp.345-360, 1995.

PENTEADO, R. A. D.; GERMANO, F. S. R.; MASIERO, P. C. Melhoria da Manutenibilidade de Software Legado com Base em Engenharia Reversa. In: Anais da Conferencia Internacional de Tecnologia de Software: Qualidade de Software, Curitiba-PR, pp.155-169, jun, 1996.

ROBSON, D. J. et al. Approaches to Program Comprehension. The Joumal of Systems and Software, v.14, n.2, pp.79-84, 1991.

SANCHES, R., A Influência do Software e de seu Processo de Manutenção no Esforço de Manutenção. Universidade de São Paulo, Faculdade de Economia, Administração e Contabilidade, São Paulo, 1993. Tese (Doutorado)

SCHACH, S.R. The Economic Impact of Reuse on Maintenance. Joumal of Software Maintenance: Research and Practice. v.6, n.4, pp.185-96, 1994.

SCHNEIDEWIND, N.F., The State of Software Maintenance. IEEE Transaction on Software Engineening, v.13, n.3, pp. 303-10, 1987.

SILVA, C. R. e SANTOS P. C. F. Delphi X Visual Basic. Byte Brasil, pp.24-28, 1997.

SNEED, H. M.; NYARY, E. Downsizing Large Application Programs. Joumal of Software Maintenance: Research and Practice, v.6, n.5, pp.235-247, 1994.

SOMMERVILLE, I.; SAWYER, P. Requirements Engineening : A Good Practice Guide. John Wiley \& Sons. 1997.

STAPLETON, L. Reverse Engineening Puzzles Out The Past. Open Computing, v.11, n.3, pp.77-82, 1994.

YANG, H. The Supporting Environment for A Reverse Engineening System - The Maintainer's Assistant. In: Proc. IEEE Conference on Software Maintenance, Sorrento, Italy, pp. 13-22, nov., 1991.

YAU, S.S.; CHANG, P.S. Design Stability Measures for Software Maintenance. IEEE Transaction on Software Engineering, v.11, n.9, pp.849-56, 1985.

YOUNGER E. J.; WARD, M. P. Inverse-Engineening a Simple Real-Time Program. Journal of Software Maintenance: Research and Practice, v.6, n.4, pp.197-234, 1994. 


\section{APÊNDICE A}

\section{MOdelo de Ciclo de VIDA do SAPES}

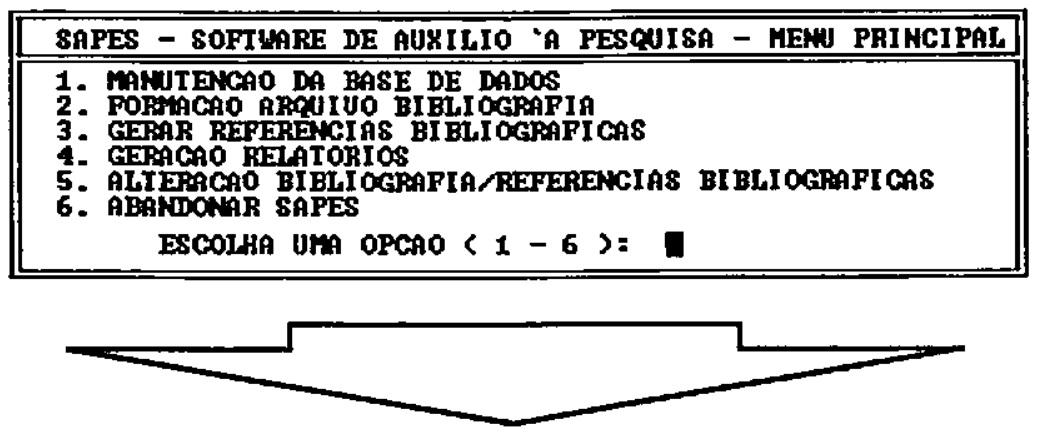

Expressão Geral do ciclo de vida: (Menu Principal do SAPES)

lifecycle SAPES: ((Manut-B_Dados | Formação-Biblio | Geração-Ref_Bib | Geração-Relatórios ] Alteração-Biblio-Ref_Bib)* ( Sair_SAPES)

Manut-B_Dados $=\left(\right.$ Cria-B_Dados $\mid$ (Insere $\mid$ Elimina $\mid$ Consulta $\mid$ Altera $\mid$ Volta_Menu_Princ) ${ }^{*}$

Formação-Biblio = (Padrão | Passo-Autor $\mid$ Passo-Ano | Ano-Autor-Assunto | Ano-Assunto-Autor | Assunto-Autor-Ano | Zerar-Arquivos | Volta_Menu_Princ)*

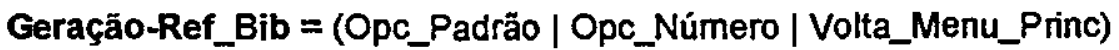




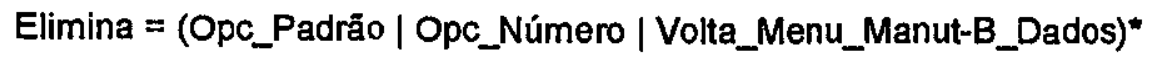

Opc_Padrão = Padrão . (\#Miens_Item_Inex | (\#Mostra_Item . (\#Resumo . (Opc_Eliminar | Volta_Menu_Elimina) | Opc_Eliminar | Volta_Menu_Elimina | Volta_Menu_ManutB_Dados)))

Opc_Número = Número . (\#Mens_Item_Inex $\mid$ (\#Mostra_Item . (\#Resumo. (Opc_Eliminar $\mid$ Volta_Menu_Elimina) | Opc_Eliminar | Volta_Menu_Elimina | Volta_Menu_ManutB_Dados)))

Altera $=($ Opc_Padrão $\mid$ Opc_Número $\mid$ Volta_Menu_Manut-B_Dados)*

Opc_Padrão = Padrão . (\#Mens_Item_Inex $\mid$ (\#Mostra_Item . Altera_Item . ((\#Resumo . Altera_Resumo) (Voltar_Menu_Altera ( Volta_Menu_Manut-B_Dados)))

Opc_Número = Número . (\#Mens_Item_Inex | (\#Mostra_Item . Altera_Item . ((\#Resumo . Altera_Resumo) (Voltar_Menu_Altera ( Volta_Menu_Manut-B_Dados)))

Consulta $=\left(O p c \_\right.$Padrão. $\mid$Opc_Autor $\mid$Opc_Ano $\mid$Opc_Assunto $\mid$Opc_Área $\mid$Opc_Título $\mid$ Opc_Número | Volta_Menu_Manut-B_Dados)*

Opc_Padrão = (Padrão . (\#Mens_Elem_Inex $\mid$ \#Mostra_Item . (Volta_Opc_Padrão $\mid$ \#Resumo | Volta_Menu_Consulta))* | Opc_Mostrar_Padrōes | Voltar_Menu_Consulta)

Opc_Autor $=$ (Autor . (\#Mens_Elem_Inex $\mid$ \#Mostra_Item . (Volta_Opc_Autor $\mid$ \#Resumo $\mid$ Volta_Menu_Consulta))* | Opc_Mostrar_Autores | Voltar_Menu_Consulta)

Opc_Ano $=$ (Ano. (\#Mens_Elem_Inex $\mid$ \#Mostra_Item . (Volta_Opc_Ano $\mid$ \#Resumo $\mid$ Volta_Menu_Consulta))* ${ }^{*}$ Opc_Mostrar_Anos ( Voltar_Menu_Consulta)

Opc_Assunto $=$ (Assunto . (\#Mens_Elem_Inex $\mid$ \#Mostra_Item . (Volta_Opc_Assunto $\mid$ \#Resumo | Volta_Menu_Consulta))* | Opc_Mostrar_Assuntos | Voltar_Menu_Consulta)

Opc_Área = (Área . (\#Mens_Elem_Inex $\mid$ \#Mostra_Item . (Volta_Opc_Área $\mid$ \#Resumo $\mid$ Volta_Menu_Consulta))* (Opc_Mostrar_Áreas ( Voltar_Menu_Consulta) Opc_Título $=($ Título . (\#Mens_Elem_inex $\mid$ \#Mostra_Item . Nolta_Opc_Título $\mid$ \#Resumo $\mid$ Volta_Menu_Consulta))* Opc_Mostrar_Títulos | Voltar_Menu_Consulta) Opc_Número $=$ (Número . (\#Mens_Elem_Inex $\mid$ \#Mostra_Item . Nolta_Opc_Número $\mid$ \#Resumo | Volta_Menu_Consulta))* | Opc_Mostrar_Números | Voltar_Menu_Consulta) 


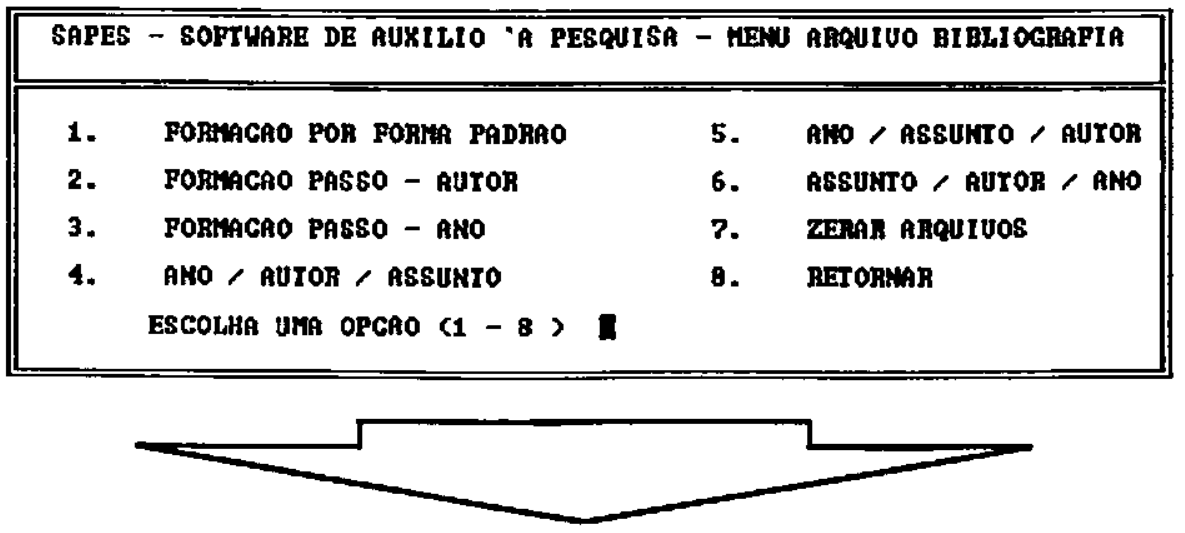

Expressão para: Formação-Biblio (Opçăo 2: Formaçăo Arquivo Bibllografia)
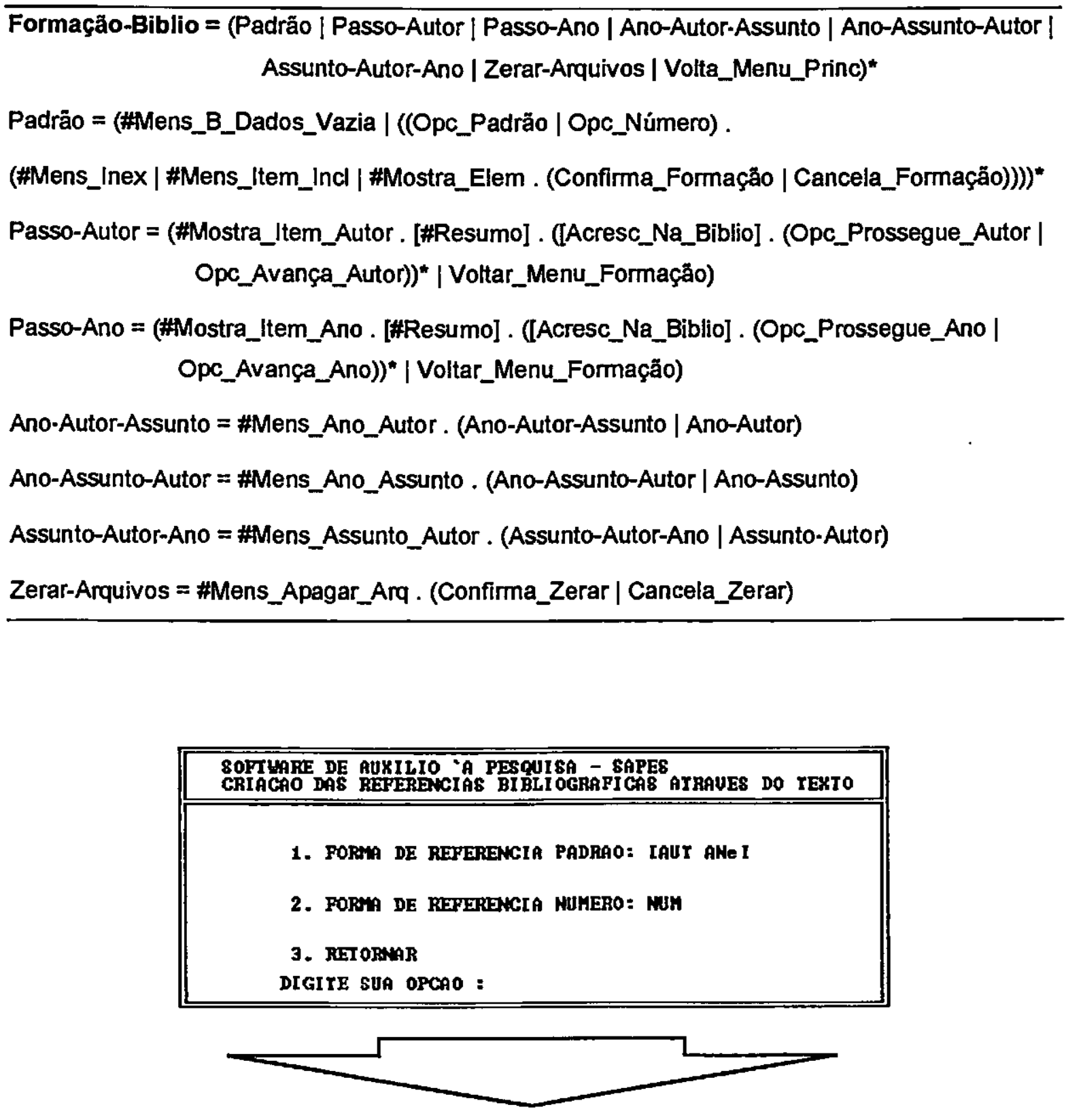

Expressão para: Geração-Ref_Bib (Opção 3: Gerar Referências Bibliográficas) 
Geração-Ref_Bib = (Opc_Padrão | Opc_Número | Volta_Menu_Princ)

Opc_Padrão = \#Mens_Ref_Criadä $\mid$ \#Mens_Ref_Inex

Opc_Número = \#Mens_Ref_Criada | \#Mens_Ref_Inex

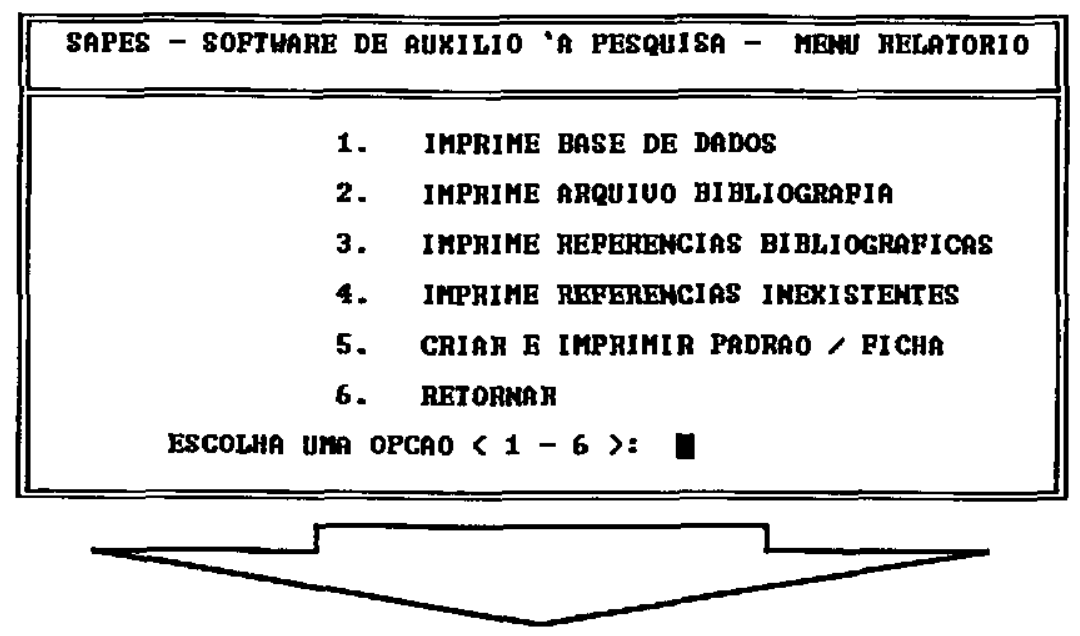

Expressão para: Geração-Relatórios (Opção 4: Geração Relatórios)

Geração-Relatórios $=$ (Imp_B_Dados | Imp_Biblio $\mid$ Imp_Ref_Bib | Imp_Ref_Inex | Ficha | Volta_Menu_Princ)*

Imp_B_Dados $=$ (\#Mens_ABNT . ((Opc_Autor . [Margens] . \#Rel_Autor) $\mid$ (Opc_Número .

[Margens] . \#Rel_Número) | (Opc_Padrão . [Margens] . \#Rel_Padrão))* |

Voltar_Menu_Relatórios)

Imp_Biblio = (\#Mens_ABNT . ((Opc_Autor . [Margens] . \#Rel_Autor) $]$ (Opc_Número . [Margens] .

\#Rel_Número) ] (Opc_Padrão. [Margens]))* | Voltar_Menu_Relatórios)

Imp_Ref_Bib $=$ (\#Mens_ABNT . (Opc_Autor . [Margens] . \#Rel_Autor | Opc_Número . [Margens] .

\#Rel_Número | Opc_Padrão . [Margens] . \#Rel_Padrão)* |

Voltar_Menu_Relatórios)

Imp_Ref_Inex = \#Rel_Ref_Inex

Flcha $=($ Criar_Ficha* $\mid$ Imprimir_Ficha* $\mid$ Voltar_Menu_Relatórios $)$

Criar_Ficha $=($ Padrão $\mid$ Número $) .(\text { \#ens_Op_Bem_Sucedida } \mid \text { \#Mens_Elem_Inex) })^{*}$ Imprimir_Ficha $=(\#|m p r i m i r-F i c h a ~| \# \text { Mens_Ficha_Inex })^{*}$ 


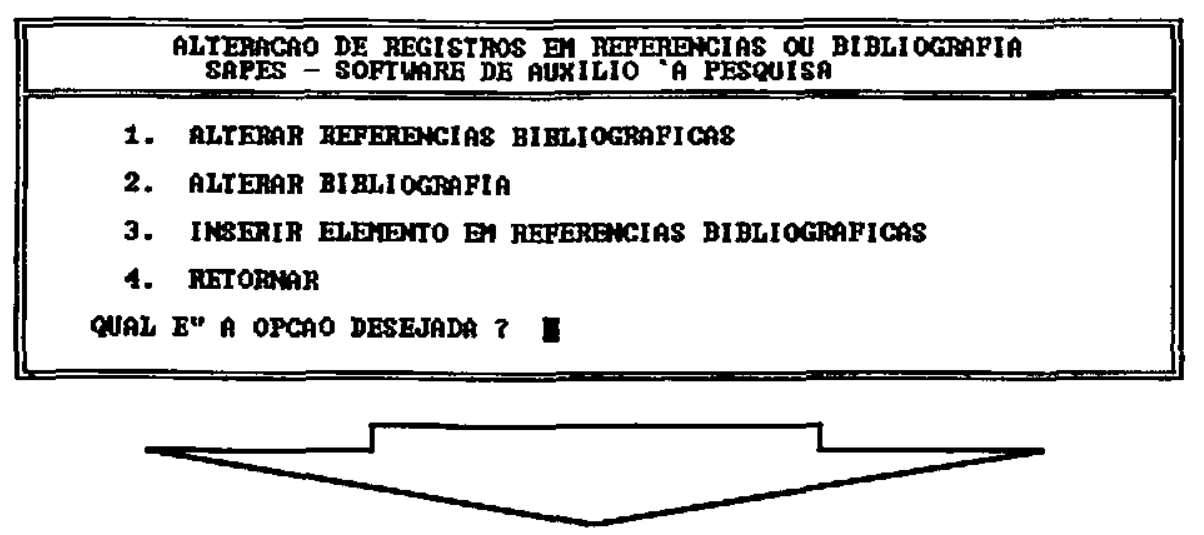

Expressão para: Alteração-Biblio-Ref_Bib (Opçăo 5: Alteraçăo Bibliografia / Referências Bibliográficas)

Alteração-Biblio-Ref_Bib = (Alt_Ref_Bib | Alt_Biblio | Ins_Ref_Bib | Volta_Menu_Princ)*

Alt_Ref_Bib $=(($ Padrão $\mid$ Número $)$. (\#Mens_Item_lnex $\mid$ [Padrão . Número] $\mid$ Voltar_Alt_Bib $\mid$ \#Mens_Arq_Ref_Bib_Vazio)

Alt_Biblio $=(($ Padrão $\mid$ Número $)$. (\#Mens_Item_Inex $\mid$ [Padrão . Número] $) \mid$ Voltar_Alt_Bib $\mid$ \#Mens_Arq_Biblio_Vazio)

Ins_Ref_Bib $=((($ Padrão $\mid$ Número $)$. [\#Mens_Item_inex] $) \mid$ Voltar_Alt_Bib $)$ 


\section{APÊNDICE B \\ MODELO DE OPERAÇÕES DO SAPES \\ Procedimental}

\begin{tabular}{|c|c|}
\hline Operação: & Insere \\
\hline Descriçāo: & Insere um novo item bibliográfico na base de dados \\
\hline \multirow[t]{2}{*}{ Lê: } & $\begin{array}{l}\text { supplied padrão, ano, número, Autor, Área, Título, Assunto, Edição, } \\
\text { Cidade, Estado, País, Tipo de publicação, Número de páginas, Range de } \\
\text { páginas, Artigo, Editora. }\end{array}$ \\
\hline & supplied Linha1, Linha2,..,Linha12 \\
\hline \multirow[t]{3}{*}{ Altera: } & $\begin{array}{l}\text { new registro contendo o item bibliográfico no arquivo BIBGERAL.DBF } \\
\text { (Contém todos os campos identificados em Lê, exceto o Resumo); }\end{array}$ \\
\hline & $\begin{array}{l}\text { new registro contendo o resumo referente ao item bibliográfico inserido no } \\
\text { arquivo OUTR.DBF; }\end{array}$ \\
\hline & $\begin{array}{l}\text { Altera o único registro do arquivo ULTIMO.DBF, o qual contem o último } \\
\text { número usado em um item bibliográfico que foi inserido }\end{array}$ \\
\hline Envia: & agente extemo: $\{$ Mens_Item_Existente $\}$ \\
\hline Assume: & Que item blbliográfico não existe \\
\hline \multirow[t]{2}{*}{ Resulta: } & Um novo item bibliográfico é inserido \\
\hline & O contador de último número usado é incrementado de um \\
\hline
\end{tabular}

FIG. B1 - ESQUEMA PARA OPERAÇÃo INSERE 
Operação: Elimina

Descrição: Elimina um item bibliográfico existente na base de dados

Lê: $\quad$ supplied Padrão, Número

Altera: Deleta um registro contendo o item bibliográfico no arquivo BIBGERAL.DBF;

Deleta o registro do arquivo OUTR.DBF, que contém o resumo referente ao item bibliográfico deletado do arquivo BIBGERAL.DBF

Envia: agente extemo: \{Mens_ltem_inex\}

Assume: Que o item bibliográfico existe para ser deletado

Resulta: Um item bibliográfico é Eliminado

FIG. B2 - ESQUEMA PARA OPERAÇÃo ELIMINA

\section{Operação: Altera}

Descrição: Altera um item bibliográfico existente na base de dados

Lê: $\quad$ supplied Padrão, Número

Altera: $\quad$ Altera os campos de um registro contendo o item bibliográfico no arquivo BIBGERAL.DBF;

Altera os campos de um registro do arquivo OUTR.DBF, que contém o resumo referente ao item bibliográfico alterado no arquivo BIBGERAL.DBF

Envia: agente extemo: \{Mens_item_Inex\}

Assume: Que o item bibliográfico existe para ser alterado

Resulta: Um item bibliográfico é Alterado

Fig. B3 - ESQUEMA PARA OPERAÇÃo ALTERA

\section{Operação: Cria_B_Dados}

Descrição: Apaga todos os itens bibliográficos existentes na base de dados

Lê: $\quad$ supplied Confirma_Cria_B_Dados, Cancela_Cria_B_Dados

Altera: $\quad$ Apaga os registros dos arquivos BIBGERAL.DBF e OUTR.DBF

Envia: $\quad$ agente extemo: $\left\{B \_D a d o s \_V a z i a\right\}$

Assume: Que os Arquivos BIBGERAL.DBF e OUTR.DBF contenham registros

Resulta: Arquivos que compõem a base de dados (BIBGERAL.DBF e OUTR.DBF) são criados novamente

FIG. B4 - Esquema PARA OPERAÇÃo CRIA_B_DADOS

\section{Operação: Consulta}

Descrição: Consulta um item bibliográfico cadastrado na base de dados

Lé: $\quad$ supplied Padrão, Autor, Ano, Assunto, Área, Título, Número; Item bibliográfico na base de dados do arquivo BIBGERAL.DBF

Resumo contido em OUTR.DBF, referente ao item bibliográfico alterado no arquivo BIBGERAL.DBF

Altera:

Envia: $\quad$ agente extemo: (Mens_ltem_Inex\}

Assume: Que o item bibliográfico exista para ser consultado

Resulta: $\quad \mathrm{O}$ item bibliográfico é consultado 
Operação: Formação_Biblio

Descrição: Inclui item bibliográfico na Bibliografia

Lê: $\quad$ supplied Padrão, Autor, Ano, Ano-Autor-Assunto, Ano-Assunto-Autor, Assunto-Autor-Ano, Confirma_Zerar, Cancela_Zerar,

Item bibliográfico na base de dados do arquivo BIBGERAL.DBF

Altera: new registro no arquivo BIBLIOG.DBF

Envia: agente extemo: $\{$ Mens_Inex\};

agente extemo: \{Mens_ltem_Incl\};

agente extemo: \{Mens_B_Dados_Vazia\}

Assume: Que a base de dados BIBGERAL.DBF não esteja vazia e que o item esteja cadastrado;

Que o item ainda não tenha sido incluido no arquivo de bibliografia BIBLIOG.DBF

Resulta: Inclui um item bibliográfico no arquivo de bibliografias

FIG. B6 - ESQUEMA PARA OPERAÇÃo FormaÇÃo_BIBLIO

Operação: Zerar-Arquivos

Descrição: Apaga (Zera) todos os itens blbliográficos da Bibliografia

Lê: $\quad$ supplied Confirma_Zerar, Cancela_Zerar

Altera: Apaga todos os registros do arquivo BIBLIOG.DBF

Envia: $\quad$ agente extemo: $\{$ Mens_Apagar_Arq\}

Assume: Que exista bibliografias incluidas no arquivo de bibliografias

Resulta: $O$ arquivo de bibliografias BIBLIOG.DBF é zerado

FIg. B7 - ESQUEMA PARA OPERAÇĀo ZERAR-ARQUIVOS

Operação: Geração-Ref_Bib

Descriçăo: Geraçāo do arquivo de referências bibliográficas REFBIB.DBF e do arquivo de referências inexistentes INEX.DBF

Lê: $\quad$ supplied Opc_Padrão, Opc_Número;

Referências no arquivo texto ENTRADA.TXT;

Base de dados no arquivo BIBGERAL.DBF

Altera: new Registros em REFBIB.DBF contendo as referências encontradas no texto e existentes na base de dados;

new Registros em INEX.DBF contendo as referências encontradas no texto, porém inexistentes na base de dados

Envia: $\quad$ agente extemo: $\{$ Mens_Ref_Criada\};

agente extemo: \{Mens_Ref_Inex\}

Assume: Que os itens referenciados no texto ENTRADA.DAT estejam cadastrados na base de dados

Resulta: $\quad O$ arquivo de referēncias bibliográficas $R E F B I B . D B F$ é atualizado com as bibijografias lidas no arquivo texto e encontradas na base de dados;

$O$ arquivo de referências bibliográficas INEX.DBF é atualizado com as bibliografias lidas no arquivo texto e não encontradas na base de dados

FIG. B8 - Esquema PARA OPERAÇÃo GeraÇĀO-REF_BiB 


\begin{tabular}{|c|c|}
\hline Operaçăo: & Imp_B_Dados \\
\hline Descrição: & $\begin{array}{l}\text { Imprime os iteris bibliográficos existentes na base de dados ordenada por } \\
\text { autor ou por número, ou por padräo }\end{array}$ \\
\hline \multirow[t]{2}{*}{ Lê: } & supplied Opc_Autor, Opc_Número, Opc_Padrão; \\
\hline & Base de dados no arquivo BIBGERAL.DBF \\
\hline Altera: & $\begin{array}{l}\text { new recria os arquivos BATR.DBF, NATR.DBF; FORR.DBF, os quais } \\
\text { passarão a conter o conteúdo de BIBGERAL, ordenados respectivarnente } \\
\text { por Autor, Número e Forma. }\end{array}$ \\
\hline Envia: & agente extemo: $\{$ Mens_ABNT $\}$; \\
\hline & agente externo: $\{$ Rel__Autor $\}$; \\
\hline & agente externo: \{Rel_Número\}; \\
\hline & agente externo: \{Rel_Padrão\} \\
\hline Assume: & Assume que existam registros na base de dados \\
\hline Resulta: & Relatório da base de dados ordenada, na tela ou impressora \\
\hline
\end{tabular}

FIG. B9 - ESQUEMA PARA OPERAÇĀO IMP_B_DADOS

\section{Operação: Imp_Biblio}

Descrição: Imprime os itens bibliográficos do arquivo de bibllografias ordenado por autor, número ou por padrão

Lê: $\quad$ supplied Opc_Autor, Opc_Número, Opc_Padrão;

Bibliografias no arquivo BIBLIOG.DBF

Altera: new recria os arquivos BATR.DBF, NATR.DBF; FORR.DBF, os quais passaräo a conter o conteúdo de BIBLIOG, ordenados respectivamente por Autor, Número e Forma.

Envia: $\quad$ agente externo: $\{$ Mens_ABNT $\}$;

agente externo: $\{$ Rel_Autor $\}$;

agente externo: \{Rel_Número\};

agente externo: \{Rel_Padräo\}

Assume: Assume que existam registros no arquivo de bibliografias

Resulta: Relatónio das bibliografias ordenado, na tela ou impressora

FIG: B10 - ESQUEMA PARA OPERAÇÃo IMP_BIBLIO

\section{Operação: Imp_Ref_Inex}

Descriçăo: Imprime 0 arquivo de referências inexistentes

Lê: referências inexistentes do arquivo INEX.DBF

Altera:

Envia: agente externo: \{Rel_Ref_Inex\}

Assume: Que as referências inexistentes existam e tenham sido geradas

Resulta: Relatório de referências inexistentes geradas

FIG. B1 1 - ESQUEMA PARA OPERAÇÃo IMP_REF_INEX 


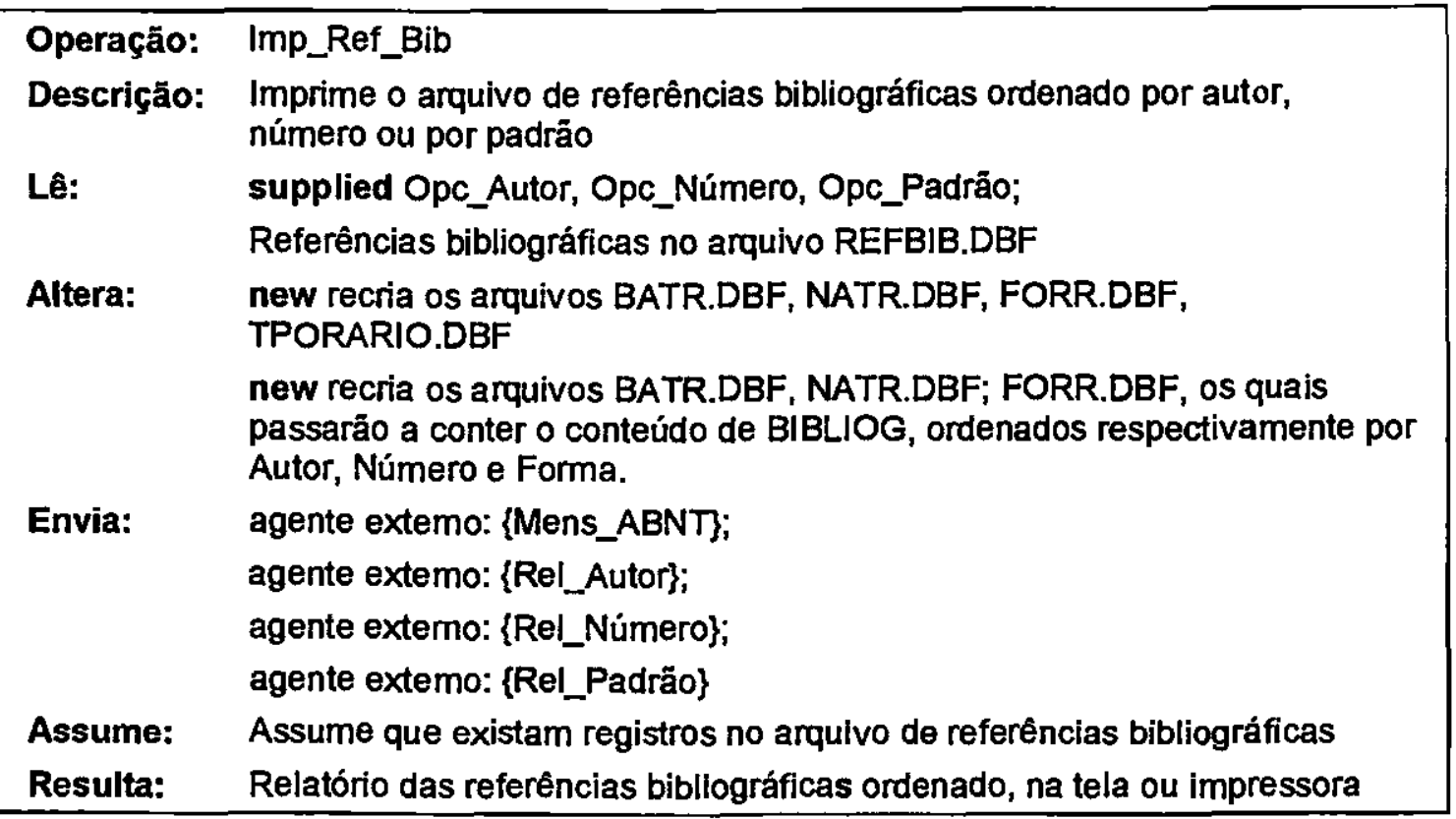

FIG. B12 - ESQUEMA PARA OPERAÇÃo IMP_REF_BIB

\section{Operação: Criar_Ficha}

Descrição: Cria a ficha técnica para um item bibliográfico existente na B.Dados

Lé: $\quad$ supplied Padrão, Número;

Item bibliográfico na base de dados do arquivo BIBGERAL.DBF

Altera: new recria 0 arquivo PADRAO.DBF contendo 0 item bibliográfico

Envia: $\quad$ agente extemo: $\{$ Mens_Op_Bem_Sucedida\};

agente extemo: \{Mens_Elem_Inex\}

Assume: Que o item bibliográfico existe para a ficha ser criada

Resulta: Uma ficha técrica é criada

FIg. B13 - Esquema PARA_OPERAÇÃo CRIAR_Ficha

Operação: Imprimir_Ficha

Descrição: Imprime a ficha técnica criada para um item bibliográfico

Lê: $\quad F i c h a$ técnica no arquivo PADRAO.DBF

Altera:

Envia: $\quad$ agente extemo: $\{$ Ficha_impressa\};

agente extemo: \{Mens_Ficha_Inex\}

Assume: Que a ficha tenha sido criada

Resulta: Uma ficha técrica é impressa 


\section{Operaçāo: Alt_Ref_Bib}

Descriçăo: Altera uma referência bibliográfica criada

Lê: $\quad$ supplied Padrão, Número

Altera: Referência bibliográfica no arquivo REFBIB.DBF

Envia: agente externo: \{Mens_ltem_Inex\};

agente externo: \{Mens_Arq_Ref_Bib_Vazio\}

Assume: Que a referência bibliográfica exista

Resulta: Referência bibliográfica alterada

FIo. B15 - EsQUEMA PARA OPERAÇÃo ALT_REF_BIB

Operaçåo: Alt_Biblio

Descrição: Altera uma bibliografia criada

Lê: $\quad$ supplied Padrão, Número

Altera: Bibliografia no arquivo BIBLIOG.DBF

Envia: agente externo: \{Mens_Itern_Inex\};

agente extemo: \{Mens_Arq_Biblio_Vazio\}

Assume: Que a bibliografia exista

Resulta: Bibliografia alterada

Fig. B16 - ESquema Para OPERAÇÃo Alt_BIBLIo

\section{Operação: Ins_Ref_Bib}

Descrição: Insere um item bibliográfico existente na base de dados, diretamente no arquivo de referências bibligráficas

Lê: $\quad$ supplied Padrão, Número;

Item bibliográfico na base de dados do arquivo BIBGERAL.DBF

Altera: new registro contendo o item bibliográfico no arquivo REFBIB.DBF

Envia: agente extemo: \{Mens_ltem_Inex\}

Assume: Que o item bibliográfico exista na base de dados para ser inserido no arquivo de referências bibliográficas

Resulta: item bibliográfico inserido no arquivo de referências bibliográficas

FIG. B17 - ESQUEMA PARA OPERAÇĀoINS_REF_BIB 


\section{APÊNDICE C}

\section{MOdELOS DO SAPES PROdUZIDOS COM APOIO DA}

FERRAMENTA FUSIONCASE

\section{1 - MODELOS DE ANÁLISE}

\section{1 - Diagrama de Contexto do Sistema}

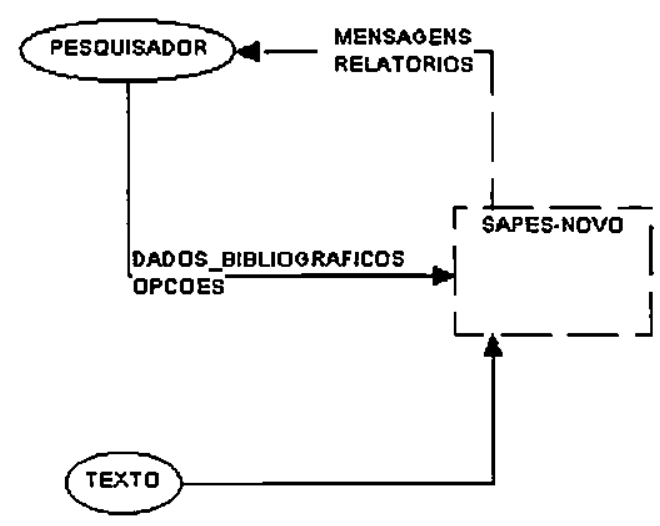




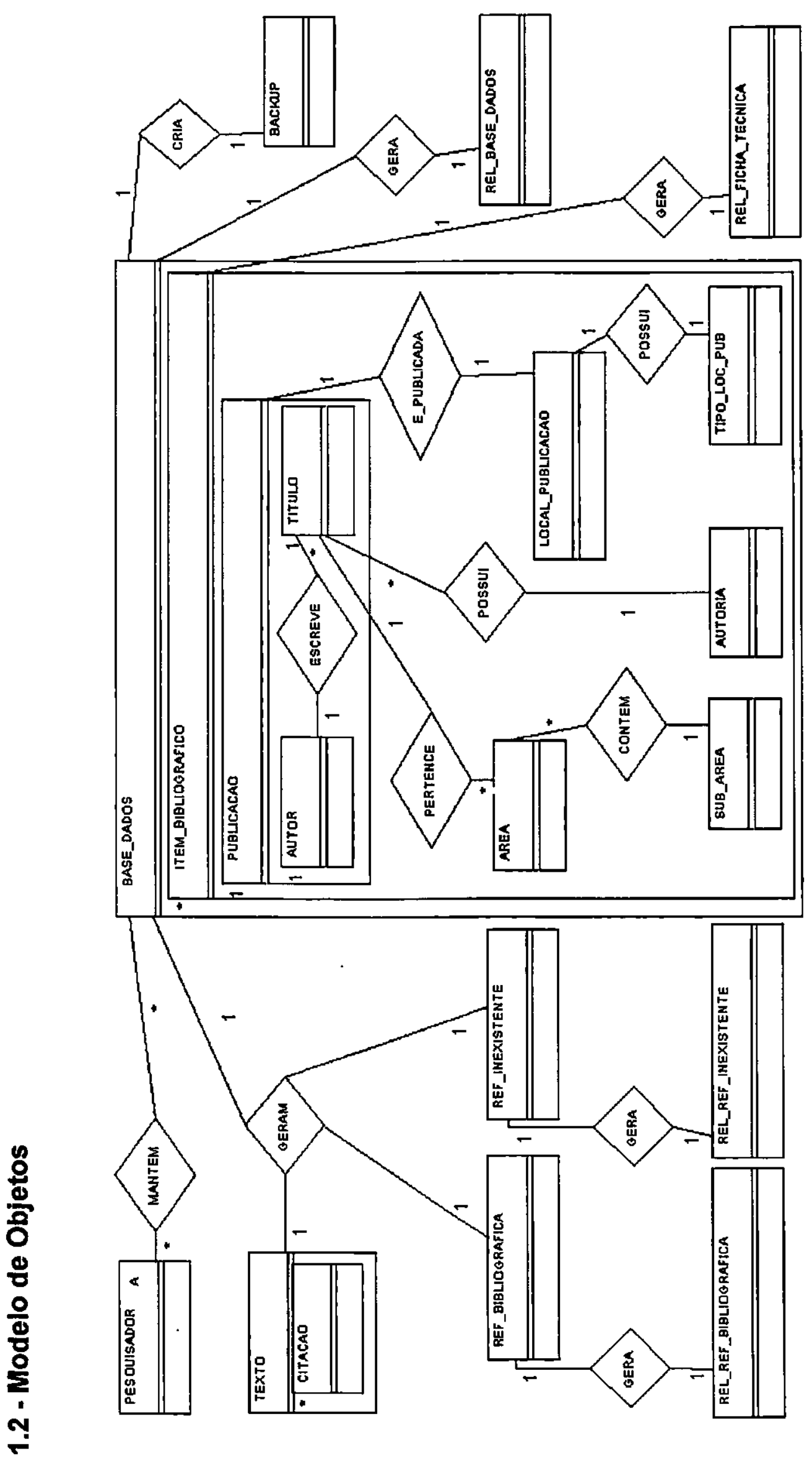




\section{3 - Modelo de Clclo de VIda}

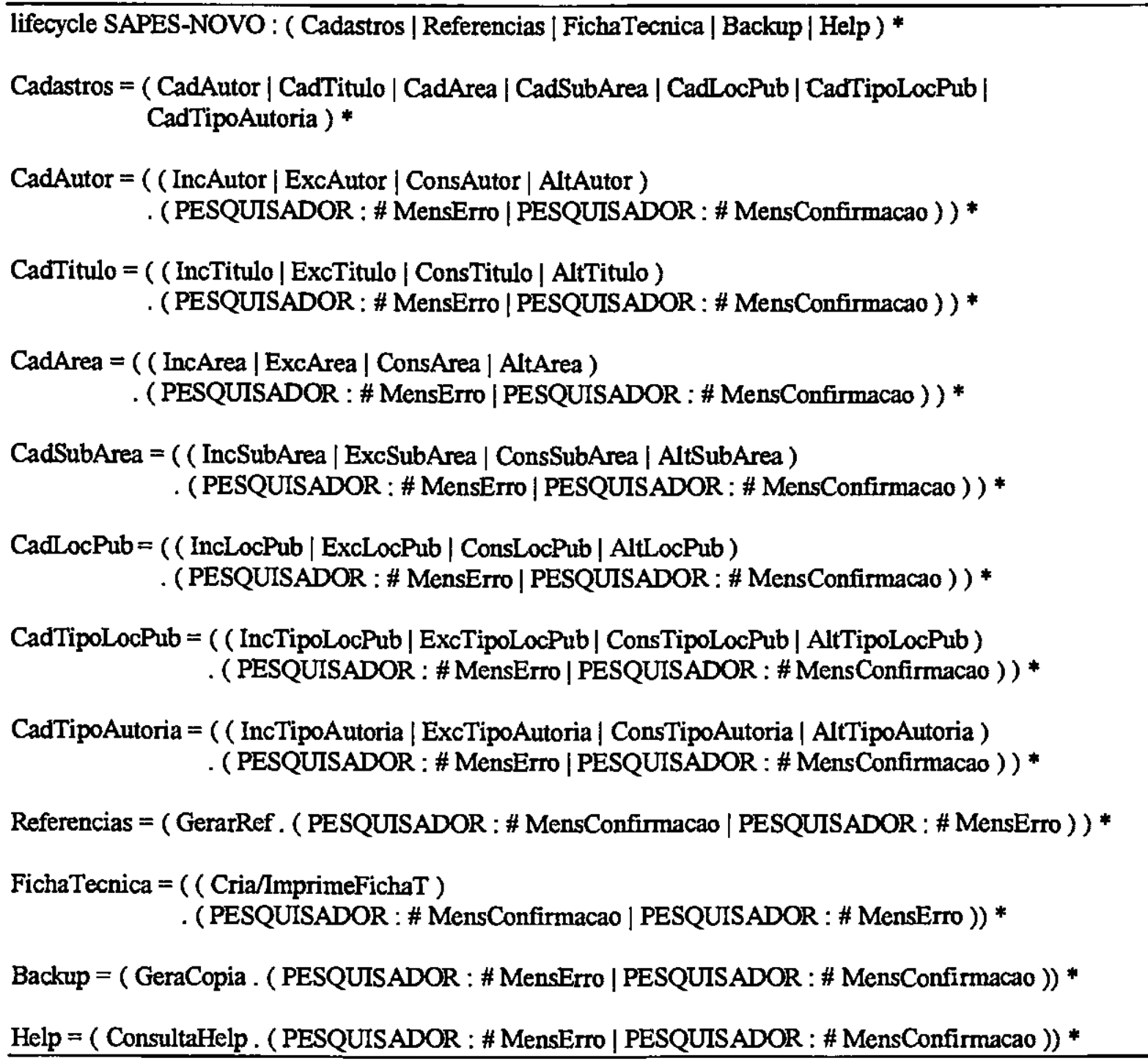

\section{4 - Modelo de Operaçōes do Sistema}

Alterar Ärea

Operation : AltArea

Supplied : aREA : AREA

Description : "Altera a denominacao de uma area."

Reads : aREA : AREA

Changes : area : AREA

Sends : PESQUISADOR \{ MensConfirmacao, MensErro \}

Assumes : " Que a area exista para ser alterada. "

Result : " a denominacao de uma area eh alterada. " 


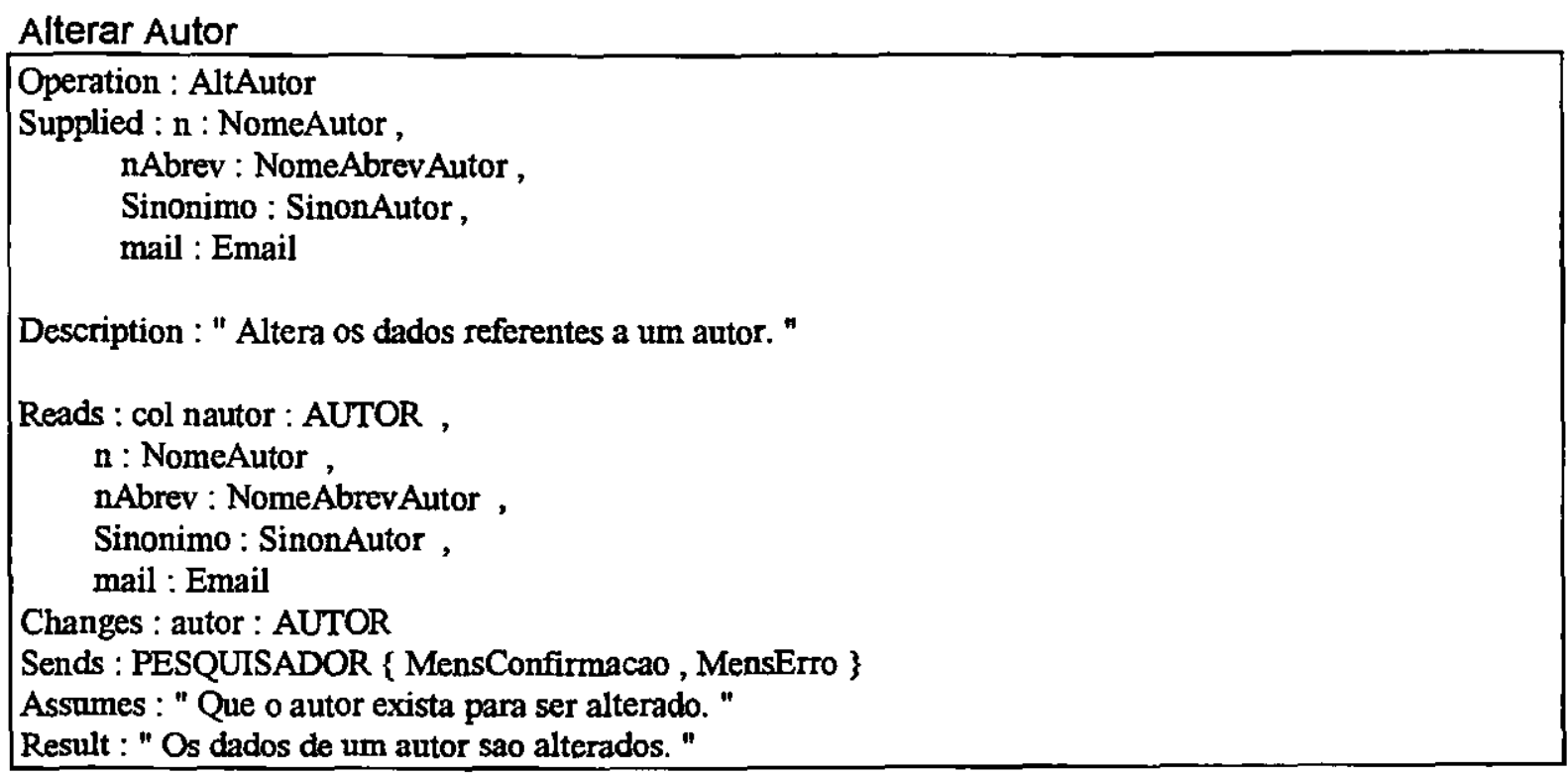

\section{Alterar Local de Publicação}

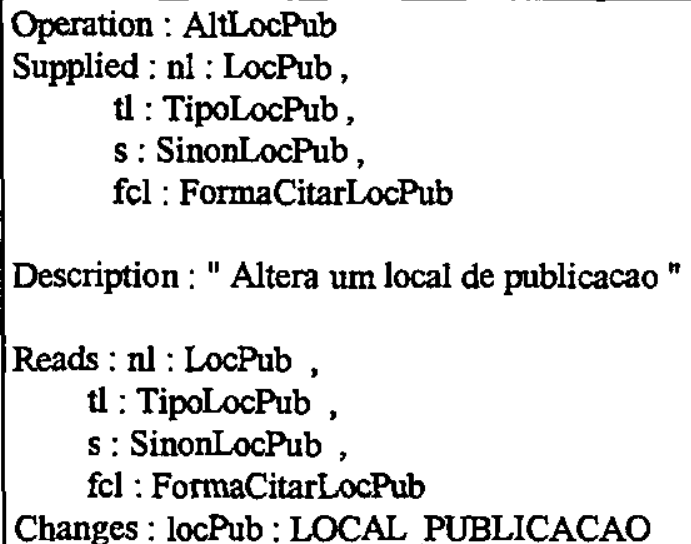

Sends : PESQUISADOR \{ MensConfirmacao, MensErro \}

Assumes : "Que o local de publicacao exista para poder ser alterado. "

Result : "Um local de publicacao eh alterado. "

Alterar Sub-Área

Operation : AltSubArea

Supplied : a : Area, sa : SubArea

Description : " Altera uma subarea, para uma dada area."

Reads : a : Area,

sa : SubArea

Changes : subArea : SUB_AREA

Sends : PESQUISADOR \{ MensConfirmacao, MensErro \}

Assumes : "Que exista a subarea a ser alterada para uma dada area. "

Result : " Uma subarea eh alterada para uma dada area. " 
Alterar Tipo de Autoria

Operation : AltTipoAutoria

Supplied : ta : TipoAutoria

Description : " Altera um tipo de autoria. "

Reads : ta : TipoAutoria

Changes : tipoAut : AUTORIA

Sends : PESQUISADOR \{ MensConfirmacao, MensErro \}

Assumes : "Que exista o tipo de autoria a ser alterado."

Result : " Um tipo de autoria eh alterado. "

Alterar Título

Operation : Alt Titulo

Supplied : $\mathbf{n}$ : NomeAutor,

tit : Titulo,

locPub : LocPub,

area : Area,

subArea : SubArea,

anoPub : AnoPub,

numPag: NumPag,

palChl : PalChave,

palCh2 : PalChave,

palCh3 : PalChave,

tipoAut: TipoAutoria,

formaRef : FormaReferencia,

locFis : LocFisica,

infCompl : InformComplem

Description : " Altera os dados de um titulo, para um determinado autor. "

Reads : $\mathbf{n}:$ NomeAutor,

tit : Titulo ,

locPub : LocPub,

area : Area ,

subArea : SubArea,

anoPub : AnoPub ,

numPag: NumPag ,

palChl : PalChave,

palCh2 : PalChave,

palCh3 : PalChave,

tipoAut : TipoAutoria ,

formaRef : FormaReferencia ,

locFis : LocFisica ,

infCompl : InformComplem

Changes : titulo : TITULO

Sends : PESQUISADOR \{ MensConfirmacao, MensErro \}

Assumes : "Que o titulo exista para o dado autor. "

Result : "Os dados de um titulo de um dado autor sao alterados. " 
Alterar Tipo de Local de Publicação

Operation : AltTipoLocPub

Supplied : tlp : TipoLocPub

Description : " Altera um tipo de local de publicacao. "

Reads : tlp : TipoLocPub

Changes : tipoLocPub : TIPO_LOC_PUB

Sends : PESQUISADOR \{ MensConfirmacao, MensErro \}

Assumes : "Que exista o tipo de local de publicacao para ser alterado. "

Result : " Um tipo de local de publicacao eh alterado. "

\section{Consultar Área}

Operation : ConsArea

Supplied : a : Area

Description : "Consulta uma dada area."

Reads : a : Area

Sends : PESQUISADOR \{ MensConfirmacao, MensErro \}

Assumes : "Que exista o objeto area na classe AREA, para consulta. "

Result : "Um objeto area eh consultado. "

\section{Consultar Autor}

Operation : ConsAutor

Supplied : $\mathbf{n}:$ NomeAutor

Description : "Consulta um autor."

Reads : $\mathrm{n}$ : NomeAutor

Sends : PESQUISADOR \{ MensConfirmacao, MensErro \}

Assumes : " Que o objeto autor exista para a classe autor. "

Result : " Um autor eh consultado. "

Consultar Local de Publicação

Operation : ConsLocPub

Supplied : nl : LocPub

Description : " Consulta um local de publicacao. "

Reads : nl : LocPub

Sends : PESQUISADOR \{ MensConfirmacao, MensErro \}

Assumes: "Que o local de publicacao exista. "

Result : " Um local de publicacao eh consultado. " 


\section{Consultar Sub-Área}

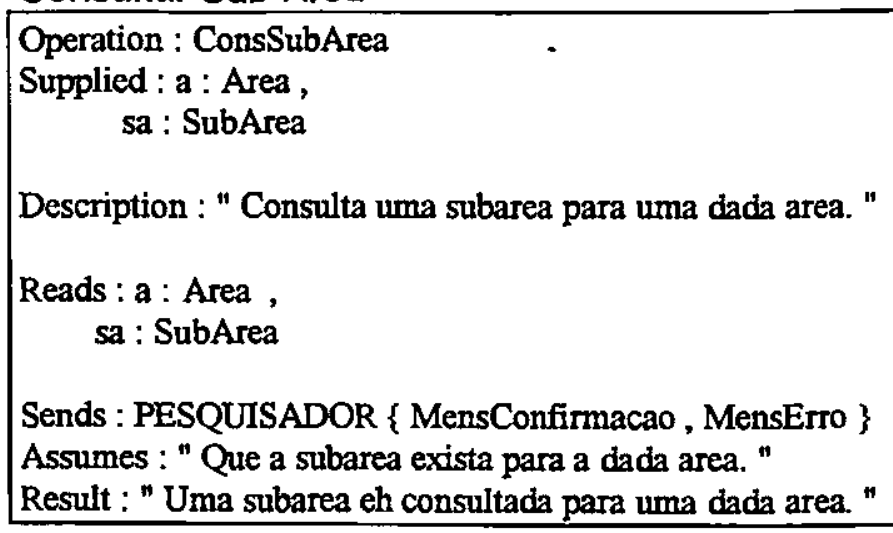

\section{Consultar Tipo de Autoria}

Operation : ConsTipoAutoria

Supplied : ta : TipoAutoria

Description : " Consulta um tipo de autoria. "

Reads : ta : TipoAutoria

Sends : PESQUISADOR \{ MensConfirmacao, MensErro \}

Assumes: "Que exista o tipo de autoria."

Result : "Um tipo de autoria eh consultado. "

Consultar Tipo de Local de Publicação

Operation : ConsTipoLocPub

Supplied : tlp : TipoLocPub

Description : " Consulta um tipo de local de publicacao. "

Reads : tlp : TipoLocPub

Sends : PESQUISADOR \{ MensConfirmacao, MensErro \}

Assumes : " Que exista um tipo de local de publicacao para ser consultado.

"

Result : " Um tipo de local de publicacao eh consultado. "

Consultar Título

Operation : ConsTitulo

Supplied : $\mathbf{n}:$ NomeAutor, tit : Titulo

Description : " Consulta um titulo para um dado autor. "

Reads : $\mathbf{n}:$ NomeAutor, tit : Titulo

Sends : PESQUISADOR \{ MensConfirmacao, MensErro \}

Assumes: " Que o titulo exista para um dado autor."

Result : " Consulta um titulo para um dado autor. " 


\section{Criar/lmprimir Ficha Técnica}

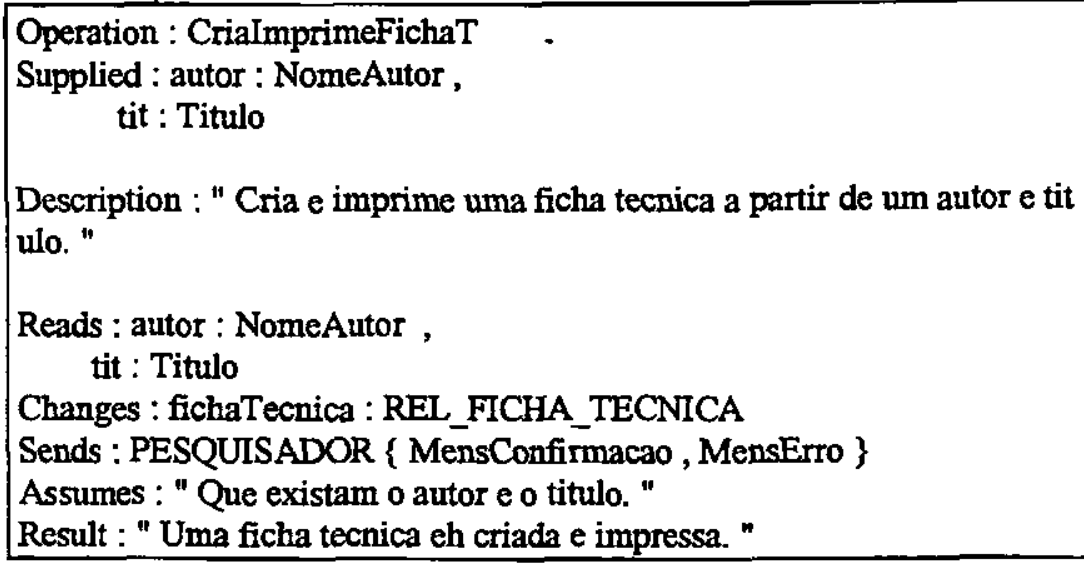

Excluir Área

Operation : ExcArea

Supplied : a : Area

Description : " Exclui uma area existente. "

Reads : a : Area

Changes : area : AREA

Sends : PESQUISADOR \{ MensConfirmacao, MensErro \}

Assumes : " Que exista o objeto area na classe AREA, para ser excluido. "

Result : " Um objeto area eh excluido da classe AREA. "

\section{Excluir Autor}

Operation : ExcAutor

Supplied : $\mathbf{n}:$ NomeAutor

Description : " Exclui um autor existente. "

Reads : $\mathbf{n}:$ NomeAutor

Changes : autor: AUTOR

Sends : PESQUISADOR \{ MensErro, MensConfirmacao \}

Assumes : "Que o objeto autor exista na classe Autor. "

Result : " Um objeto autor eh deletado da classe Autor. "

\section{Excluir Local de Publicação}

Operation : ExcLocPub

Supplied : $\mathbf{n l}:$ LocPub

Description : " Exclui um dado local de publicacao."

Reads : $\mathbf{n l}:$ LocPub

Changes : locPub : LOCAL_PUBLICACAO

Sends : PESQUISADOR \{ MensConfirmacao, MensErro \}

Assumes: "Que o local de publicacao exista para ser excluido."

Result : "Um local de publicacao eh excluido." 
Excluir Sub-Área

Operation : ExcSubArea
Supplied : a : Area,
sa : SubArea
Description : " Exclui uma subarea para uma dada area. "
Reads : a : Area ,
sa : SubArea
Changes : subArea : SUB_AREA
Sends : PESQUISADOR \{ MensConfirmacao, MensErro \}
Assumes : "Que exista a subarea a ser excluida para uma dada area. "
Result : "Uma subarea eh excluida para uma dada area. "

\section{Excluir Tipo de Autoria}

Operation : ExcTipoAutoria

Supplied : ta : TipoAutoria

Description : " Exclui um tipo de autoria existente. "

Reads : ta : TipoAutoria

Changes : tipoAut : AUTORIA

Sends : PESQUISADOR \{ MensConfirmacao, MensErro \}

Assumes : " Que exista o tipo de autoria a ser excluido."

Result : " Um tipo de autoria eh excluido. "

Excluir Tipo de Local de Publicação

Operation : ExcTipoLocPub

Supplied : tlp : TipoLocPub

Description : "Exclui um tipo de local de publicacao."

Reads : tlp : TipoLocPub

Changes: tipoLocPub : TIPO_LOC_PUB

Sends : PESQUISADOR \{ MensConfirmacao, MensErro \}

Assumes: " Que exista o tipo de local de publicacao para ser excluido."

Result : "Um tipo de local de publicacao eh excluido."

\section{ExcluirTítulo}

\section{Operation : ExcTitulo}

Supplied : $\mathbf{n}:$ NomeAutor , tit : Titulo

Description : " Dado um autor, exclui um titulo."

Reads : $\mathbf{n}$ : NomeAutor, tit : Titulo

Changes : titulo : TITULO

Sends : PESQUISADOR \{ MensConfirmacao, MensErro \}

Assumes: " Que o titulo exista para um determinado autor. "

Result : "Um titulo eh excluido para um determinado autor. " 


\section{Gerar Cópia}

Operation : GeraCopia

Supplied : nomeArq : NomeArqBack

Description : " Gera uma copia de seguranca, da base de dados. "

Reads : nomeArq : NomeArqBack

Changes : new bACKUP : BACKUP

Sends : PESQUISADOR \{ MensConfirmacao, MensErro \}

Assumes : " Que exista a base de dados."

Result : " Uma copia de seguranca eh gerada. "

\section{Gerar Referências}

Operation : GerarRef

Supplied : arqTexto : NomeArqTexto, arqRefExiste : NomeArqRefExiste , arqRefInexiste : NomeArqReflnexiste

Description : "Gera as referencias bibliograficas existentes e inexistente

s, a partir da base de dados e do arquivo texto. "

Reads : arqTexto : NomeArqTexto , arqRefExiste : NomeArqRefExiste , arqRefInexiste : NomeArqReflnexiste

Changes : : REF_BIBLIOGRAFICA, : REF_INEXISTENTE

Sends : PESQUUISADOR \{ MensConfirmacao, MensErro \}

Assumes : "Que o arquivo de texto, contendo as citacoes exista. "

Result : " Sao gerados dois arquivos, um contendo as referencias existentes , outro contendo as referencias inexistentes. "

Incluir Área

Operation : IncArea

Supplied : a : Area

Description : " Inclui uma nova area. "

Reads : a : Area

Changes : new area : AREA

Sends : PESQUISADOR \{ MensConfirmacao, MensErro \}

Assumes: "Que esse objeto area da classe AREA nao exista."

Result : "Um novo objeto area da eh incluido na classe AREA. " 
Incluir Autor

Operation : IncAutor

Supplied : $\mathbf{n}$ : NomeAutor, nAbrev : NomeAbrevAutor, Sinonimo : SinonAutor, mail : Email

Description : " -Insere um novo autor.- "

Reads : $\mathbf{n}$ : NomeAutor, nAbrev : NomeAbrevAutor, Sinonimo : SinonAutor , mail : Email

Changes : new autor: AUTOR

Sends : PESQUISADOR \{MensConfirmacao, MensErro \}

Assumes : " Que este objeto autor da Classe Autor nao exista. "

Result : " Um novo objeto autor eh incluido na classe Autor. "

Incluir Local de Publicação

Operation : IncLocPub

Supplied : nl : LocPub,

tl : TipoLocPub,

$s$ : sinonLocPub,

fcl : FormaCitarLocPub

Description : " Inclui um novo local de publicacao. "

Reads : nl : LocPub,

tl : TipoLocPub,

s: sinonLocPub,

fcl : FormaCitarLocPub

Changes : new locPub : LOCAL_PUBLICACAO

Sends : PESQUISADOR \{ MensConfirmacao , MensErro \}

Assumes: "Que o local de publicacao nao exista. "

Result : "Um novo local de publicacao eb inserido. "

Incluir Sub-Área

Operation : IncSubArea

Supplied : a : Area,

sa : SubArea

Description : " Inclui uma nova subarea para uma determinada area. "

Reads : a : Area,

sa: SubArea

Changes : new subArea : SUB_AREA

Sends : PESQUISADOR \{ MensConfirmacao, MensErro \}

Assumes : "Que a subarea nao exista para a dada area."

Result : "Uma nova subarea eb incluida, para uma dada area. " 
Incluir Tipo de Autoria

Operation : IncTipoAutoria

Supplied : ta : TipoAutoria

Description : " Inclui um novo tipo de autoria. "

Reads : ta : TipoAutoria

Changes : new tipoAut : AUTORIA

Sends : PESQUISADOR \{ MensConfirmacao, MensErro \}

Assumes : " Que o tipo de autoria nao tenha sido incluido."

Result : "Um novo tipo de autoria eh incluido."

Incluir Tipo de Local de Publicação

Operation : IncTipoLocPub

Supplied : tlp : TipoLocPub

Description : " Inclui um novo tipo de local de publicacao. "

Reads : tlp : TipoLocPub

Changes : new tipoLocPub : TIPO_LOC_PUB

Sends : PESQUISADOR \{ MensConfirmacao, MensErro \}

Assumes: "Que nao existe esse tipo de local de publicacao. "

Result : "Um novo tipo de local de publicacao eh inserido. "

Incluir Título

Operation : IncTitulo

Supplied : $\mathbf{n}:$ NomeAutor,

tit : Titulo,

locPub : LocPub,

area : Area ,

anoPub : AnoPub,

numPag : NumPag,

palChl : PalChave,

palch2 : PalChave,

palCh3 : PalChave, tipoAut: TipoAutoria,

formaRef : FormaReferencia,

infCompl : InformComplem

Description : " Dado um autor, inclui um novo titulo. "

Reads : $\mathbf{n}$ : NomeAutor,

tit : Titulo,

locPub : LocPub,

area : Area ,

anoPub : AnoPub,

numPag : NumPag ,

palCh1: PalChave,

tipoAut : TipoAutoria ,

formaRef : FormaReferencia ,

infCompl : InformComplem

Changes : new titulo: TITULO

Sends : PESQUISADOR \{ MensConfirmacao, MensErro \}

Assumes : "Que o titulo nao exista para um determinado autor selecionado. "

Result : " Um titulo eh inserido para um determinado autor selecionado. " 


\section{2 - MODELOS DE PROJETO}

\section{1 - Grafos de Interação de Objetos}
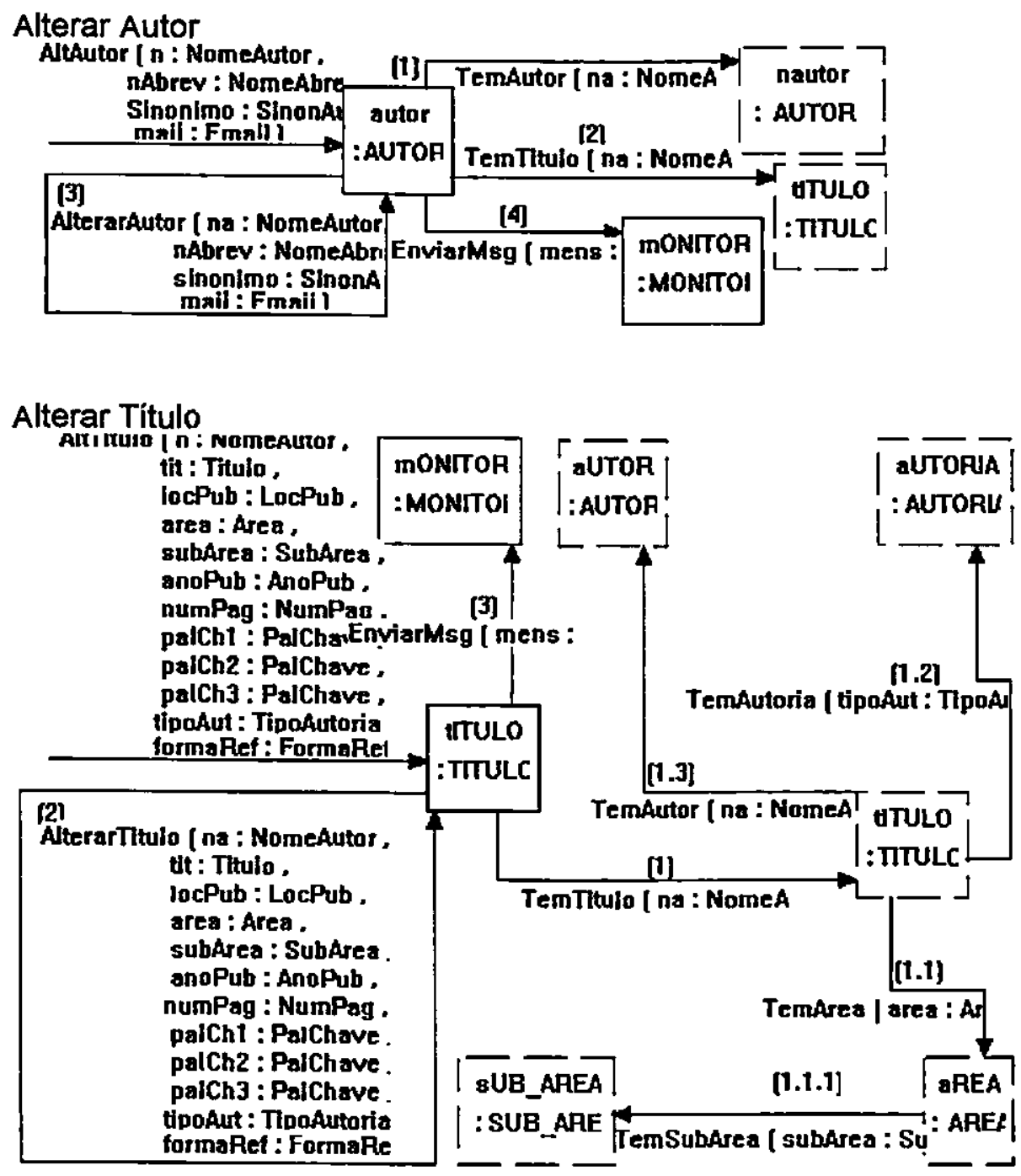

Consultar Autor

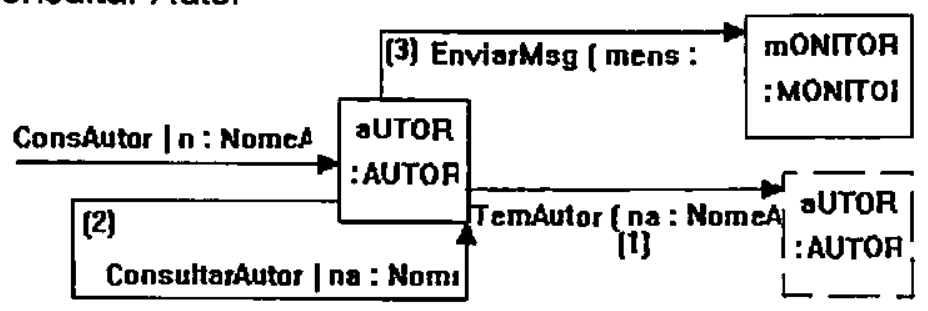


Consultar Título
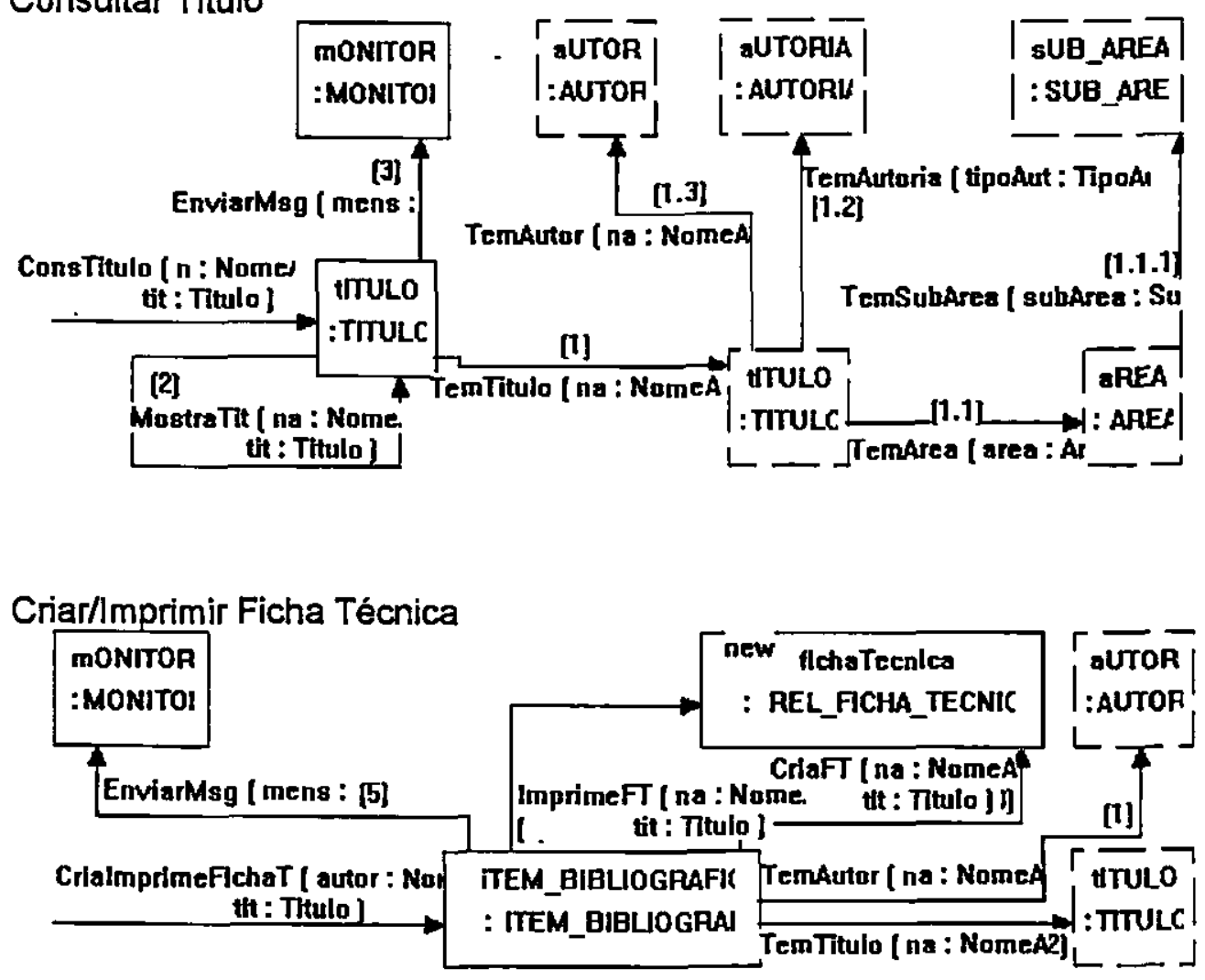

Excluir Autor

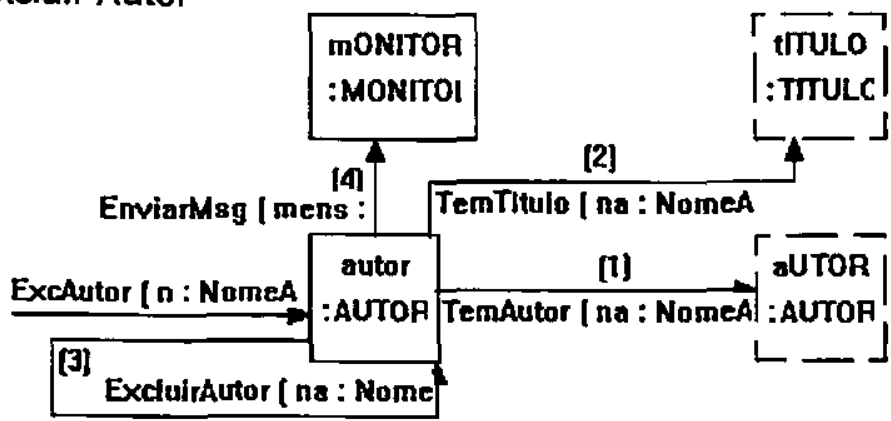

ExcluirTítulo

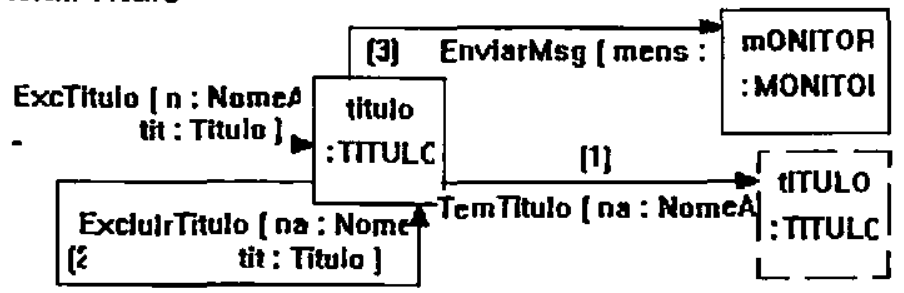


Gerar Cópia

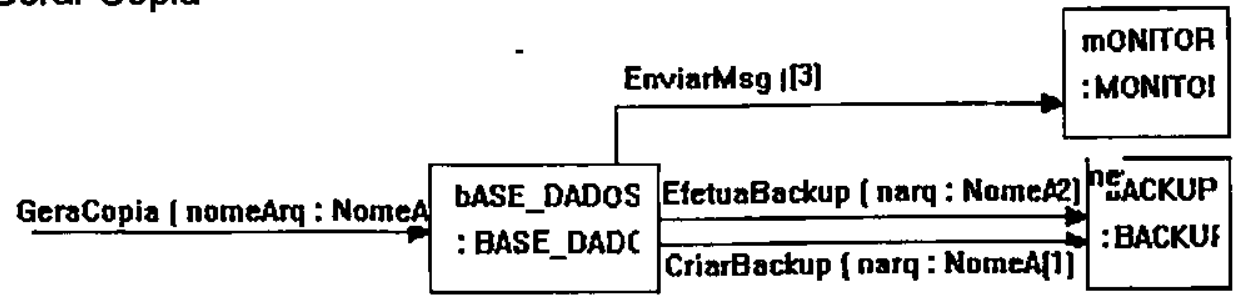

Gerar Referências

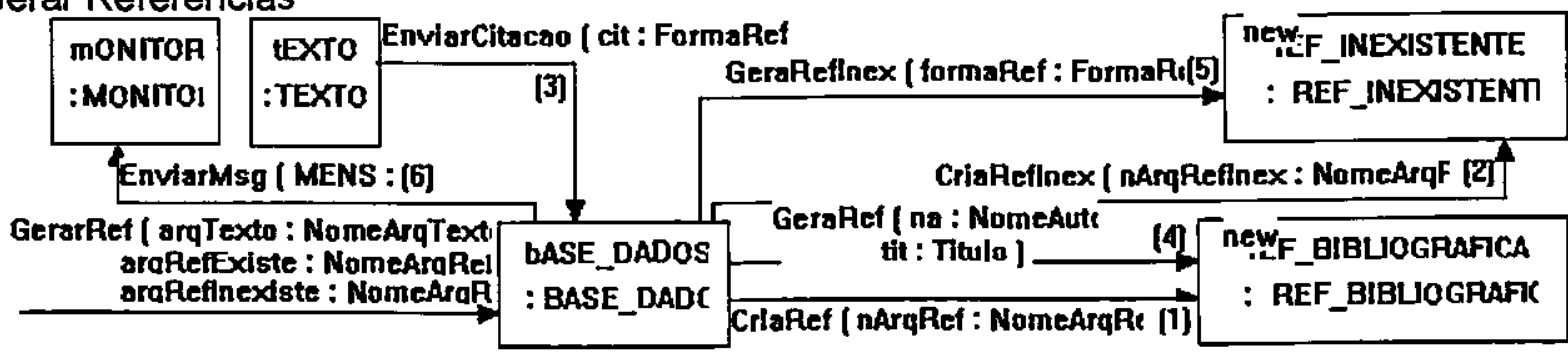

Incluir Autor

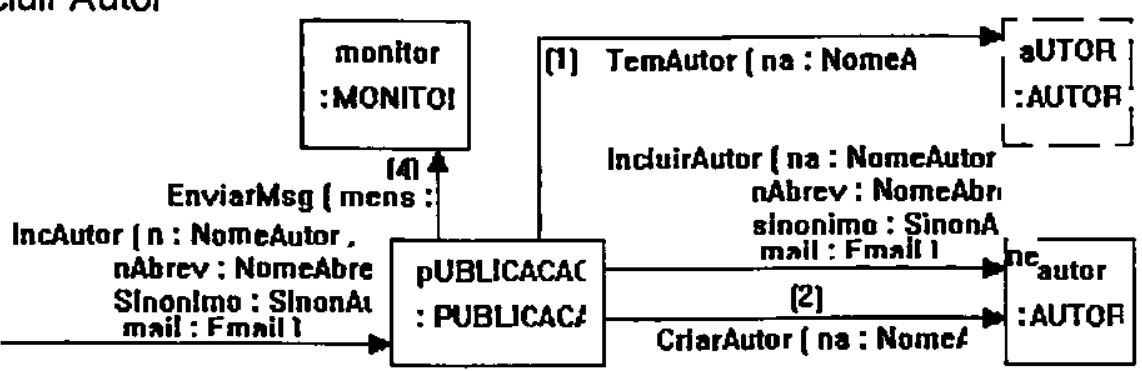

Incluir Título

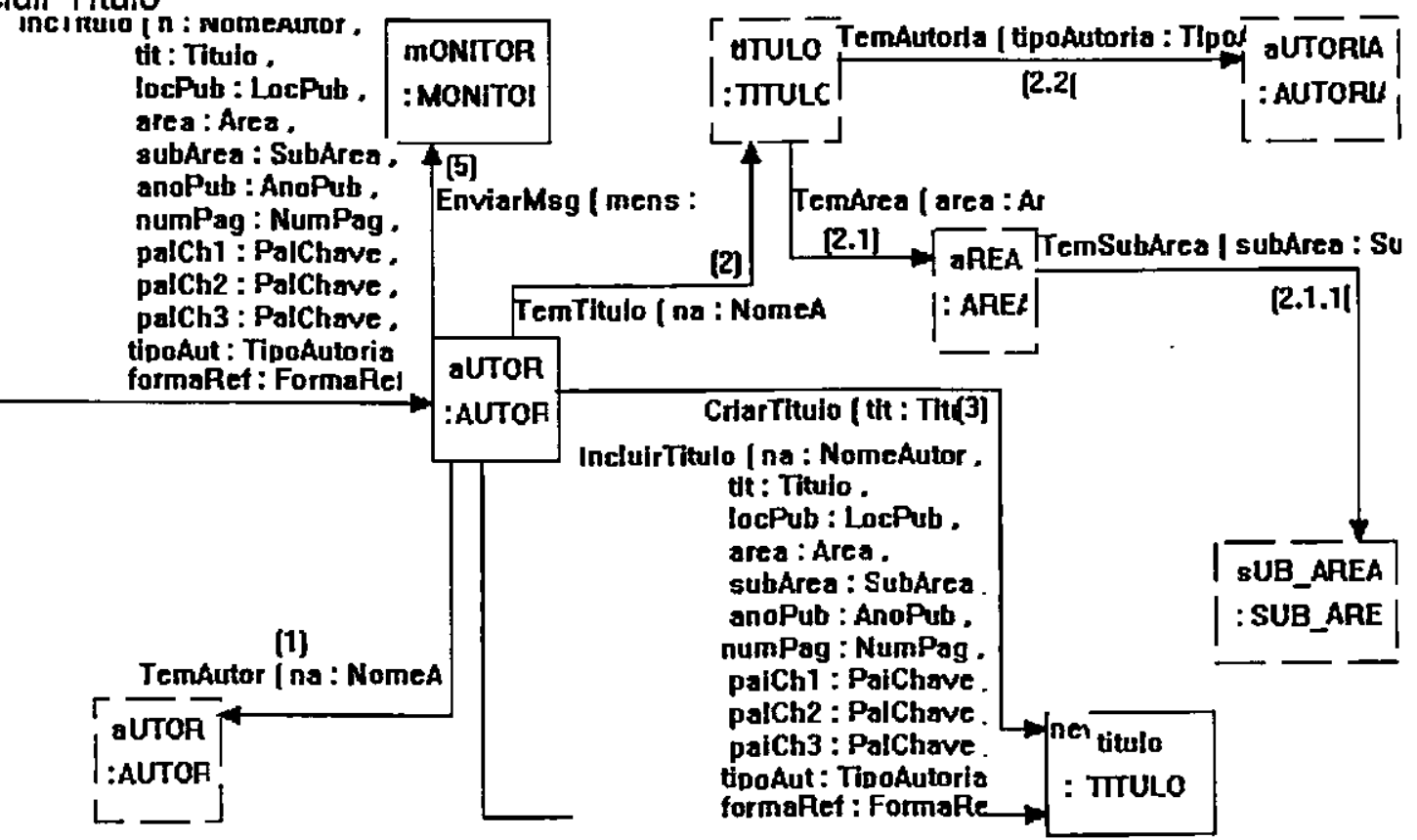




\section{2 - Grafos de Visibilidade}
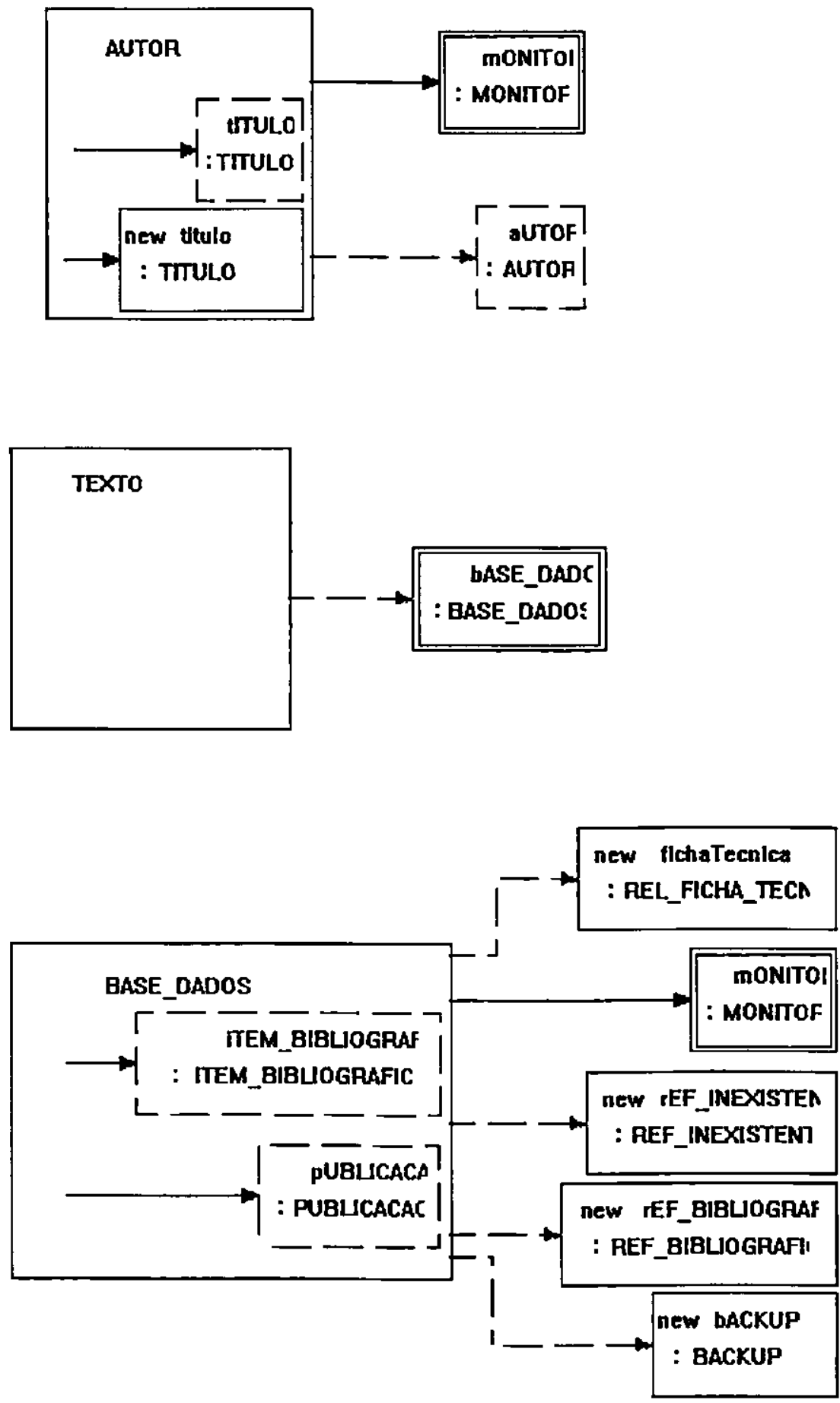


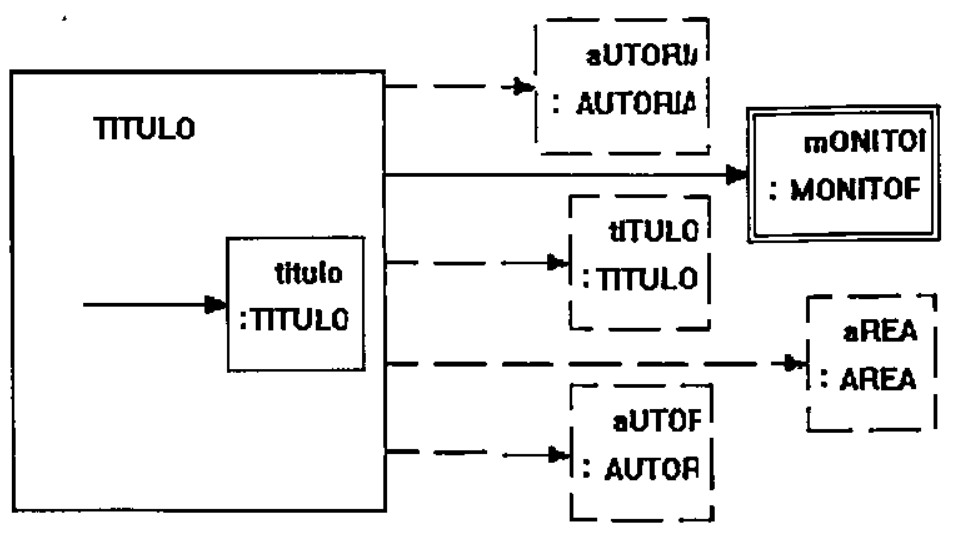

\title{
2.3 - Descrição de Classes
}

\author{
class AUTOR isa \\ attribute variable Codigo : \\ attribute variable Nome : \\ attribute variable NomeAbreviado : \\ attribute variable FormaReferencia : \\ attribute variable E-mail : \\ attribute variable Sinonimo : \\ method IncluirAutor ( $\mathrm{na}$ : NomeAutor, \\ nAbrev : NomeAbrevAutor, \\ sinonimo : SinonAutor, \\ mail : Email ) \\ method IncTitulo ( $\mathrm{n}:$ NomeAutor, \\ tit : Titulo, \\ locPub : LocPub, \\ area : Area, \\ subArea : SubArea, \\ anoPub : AnoPub, \\ numPag : NumPag, \\ palChl : PalChave, \\ palCh2 : PalChave, \\ palCh3 : PalChave, \\ tipoAut : TipoAutoria, \\ formaRef : FormaReferencia , \\ locFis : LocFisica , \\ infCompl : InformComplem ) \\ method AltAutor ( $\mathbf{n}$ : NomeAutor, \\ nAbrev : NomeAbrevAutor, \\ Sinonimo : SinonAutor, \\ mail : Email ) \\ method AlterarAutor ( na : NomeAutor, \\ nAbrev: NomeAbrevAutor, \\ sinonimo : SinonAutor,
}


mail : Email)

method ConsAutor ( $n:$ NomeAutor)

method ExcAutor ( $n$ : NomeAutor)

method TemAutor ( na : NomeAutor)

attribute variable tITULO : exclusive unbound col TITULO

method CriarAutor ( na : NomeAutor )

method ExcluirAutor ( na : NomeAutor)

method ConsultarAutor ( na : NomeAutor)

attribute variable mONITOR : exclusive unbound MONITOR

attribute variable tITULO : shared bound col TITULO

attribute variable titulo : shared bound TITULO

endclass.

class BACKUP isa

method CriarBackup ( narq : NomeArqBack)

method EfetuaBackup ( narq : NomeArqBack )

endclass_

class BASE DADOS isa

method CriaImprimeFichaT ( autor: NomeAutor, tit : Titulo )

method GerarRef ( arqTexto : NomeArqTexto, arqRefExiste : NomeArqRefExiste , arqReflnexiste : NomeArqRefinexiste )

method EnviarCitacao ( cit : FormaReferencia)

method GeraCopia ( nomeArq : NomeArqBack)

attribute variable iTEM_BIBLIOGRAFICO : shared bound col ITEM_BIBLIOGRAFICO

attribute variable pUBLICACAO : shared bound col PUBLICACAO

attribute variable mONITOR : shared unbound MONITOR

endclass_

class MONITOR isa

method EnviarMsg ( mens : char )

endiclass_

class REF_BIBLIOGRAFICA isa

method GeraRef ( na : NomeAutor, tit : Titulo )

method CriaRef ( nArqRef : NomeArqRefExiste)

endclass

class REF_INEXISTENTE isa

method GeraReflnex ( formaRef : FormaReferencia)

method CriaRefInex ( nArqRefInex : NomeArqRefInexiste)

endclass_ 


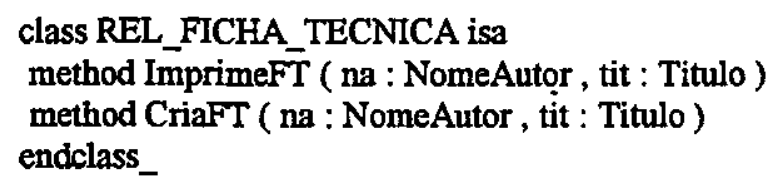

method Cons'Titulo ( $\mathrm{n}:$ NomeAutor, tit : Titulo )

method Tem'Titulo (na : NomeAutor) 
method ExcTitulo ( $\mathrm{n}:$ NomeAutor , tit : Titulo )

method IncTipoAutoria ( ta : TipoAutoria)

method MostraTit ( $\mathrm{n}:$ NomeAutor, tit : Titulo )

attribute variable tITULO : shared bound col TITULO

method CriarTitulo ( tit : Titulo )

method ExcluirTitulo ( na : NomeAutor, tit : Titulo )

attribute variable titulo : shared bound TITULO

attribute variable mONITOR : exclusive unbound MONITOR

endclass. 